Universidad de Lima

Facultad de Ciencias Empresariales y Económicas

Carrera de Economía

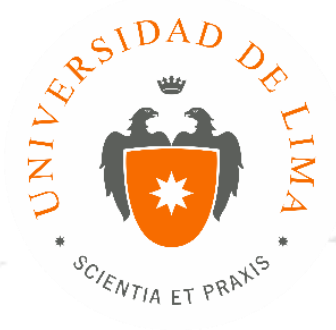

\title{
RELACIÓN ENTRE EDUCACIÓN E INGRESO: LOS RETORNOS A LA EDUCACIÓN EN EL PERÚ ESTIMADOS PARA EL AÑO 2013
}

Trabajo de investigación para optar el Título Profesional de Economista

\section{Manuel Sadot Torres Zambrano \\ Código 20052206}

\section{Asesor}

Napoleón Ambrocio Barrios

\author{
Lima - Perú
}

Junio del 2018 


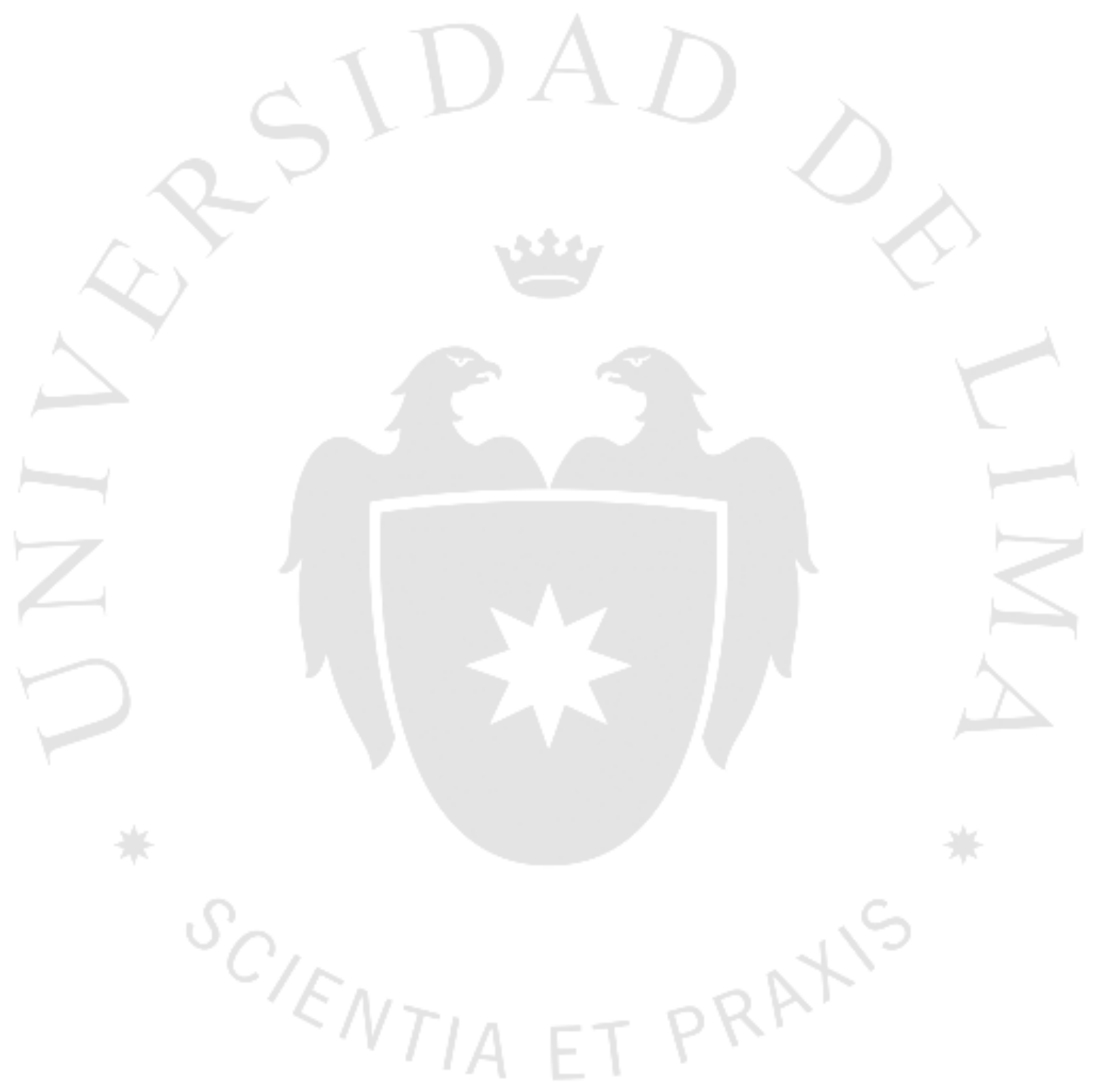




\section{RELACIÓN ENTRE EDUCACIÓN E INGRESO: LOS RETORNOS A LA EDUCACIÓN EN EL PERÚ ESTIMADOS PARA EL AÑO 2013}




\section{TABLA DE CONTENIDO}

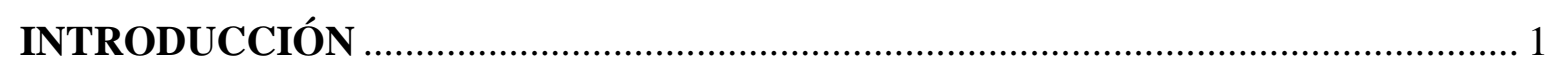

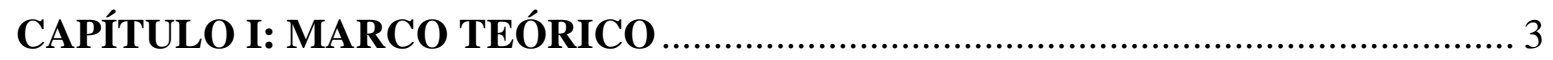

1.1. Evolución del Capital Humano ........................................................................ 4

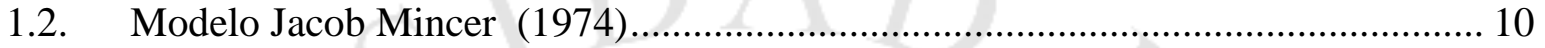

1.3. Estudios del Capital Humano ................................................................. 15

1.3.1. Estudios aplicativos en el Perú ...................................................................... 16

1.3.2. Estudios aplicativos en el exterior ............................................................ 18

1.4. Críticas al Capital Humano ............................................................................. 19

CAPÍTULO II: ANÁLISIS DEL INGRESO, EDUCACION Y OTRAS

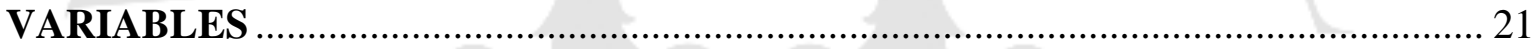

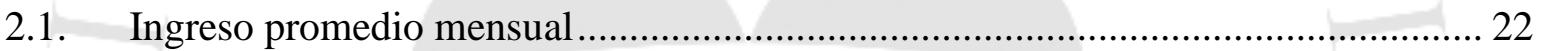

2.2. Evolución de la población por grupos de edades ............................................... 24

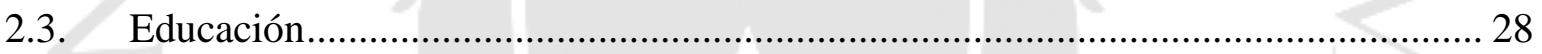

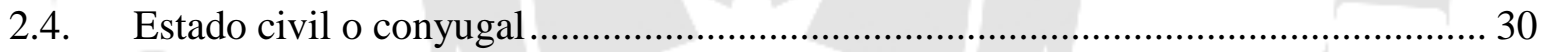

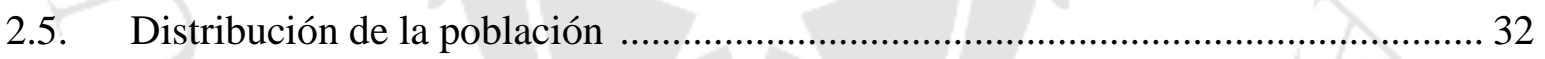

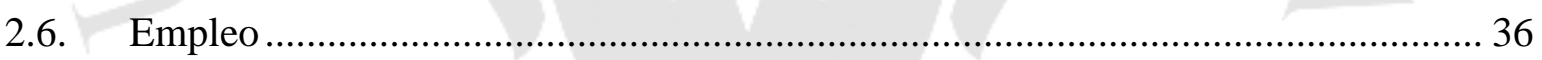

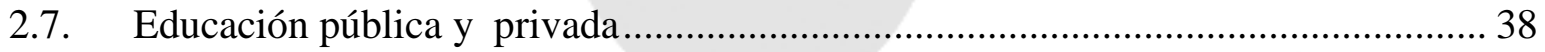

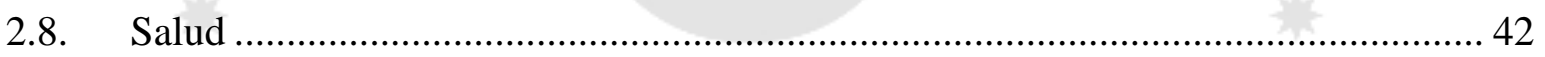

CAPÍTULO III: CONTRASTACIÓN DE HIPÓTESIS .......................................... 44

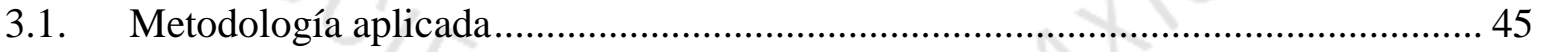

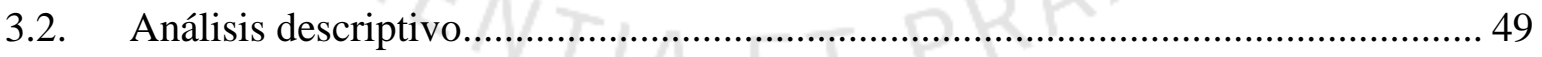

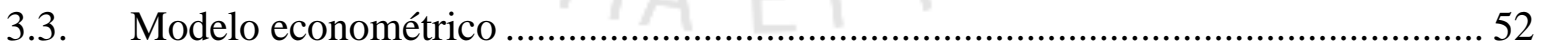

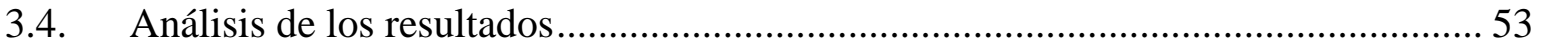

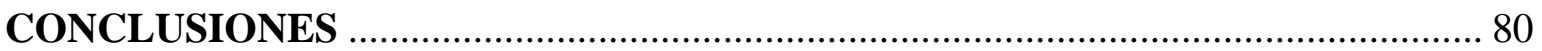

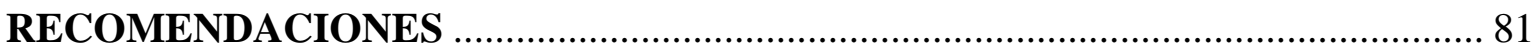

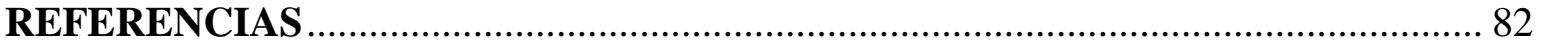

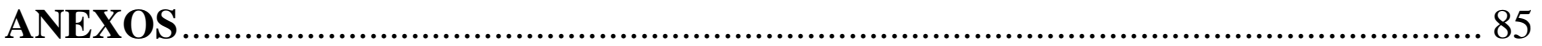




\section{INDICE DE TABLAS}

Tabla 1.1 Aportes a la teoría del Capital Humano............................................................. 5

Tabla 1.2 Evolución de la sociedad industrial a la sociedad del conocimiento.................. 10

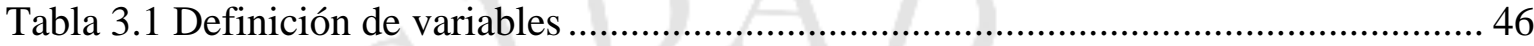

Tabla 3.2 Resumen estadístico de las 32148 observaciones........................................ 50

Tabla 3.3 Distribución del nivel educativo de las 32148 observaciones ......................... 51

Tabla 3.4 Primer modelo econométrico................................................................ 54

Tabla 3.5 Segundo modelo econométrico planteado.................................................... 56

Tabla 3.6 Segundo modelo econométrico.................................................................... 57

Tabla 3.7 Primer modelo modificado, reemplazando la variable EDUC por PRIM_I,

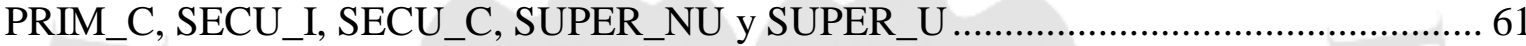

Tabla 3.8 Segundo modelo modificado, reemplazando la variable EDUC por PRIM_I,

PRIM_C, SECU_I, SECU_C, SUPE_NU_I, SUPE_NU_C, SUPE_U_I y SUPE_U_C .... 65

Tabla 3.9 Segundo modelo modificado, agregando variable AGRA ............................... 69

Tabla 3.10 Tabla resumen sector Agricultura.............................................................. 70

Tabla 3.11 Segundo modelo modificado, agregando variable COME ............................. 71

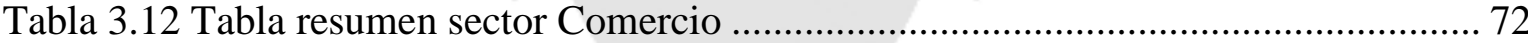

Tabla 3.13 Segundo modelo modificado, agregando variable CONS ............................. 73

Tabla 3.14 Tabla resumen sector Construcción ............................................................... 74

Tabla 3.15 Segundo modelo modificado, agregando variable MANU ............................. 75

Tabla 3.16 Tabla resumen sector Manufactura.............................................................. 76

Tabla 3.17 Segundo modelo modificado, agregando variable MINE …........................... 77

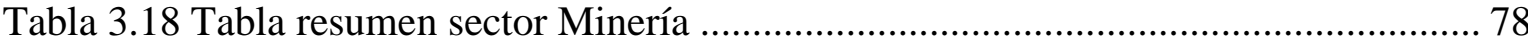




\section{INDICE DE FIGURAS}

Figura 1.1 Relaciones del Capital Humano, innato y adquirido ...................................... 8

Figura 1.2 Evolución de las tendencias en el ingreso laboral según el nivel educativo ...... 18

Figura 2.1 Evolución del ingreso promedio mensual, según ámbito geográfico, del año

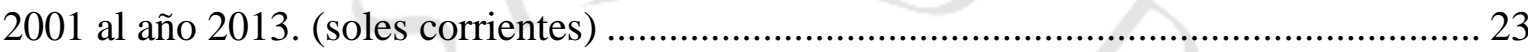

Figura 2.2 Evolución del ingreso promedio mensual, según área geográfica, del año 2001 al

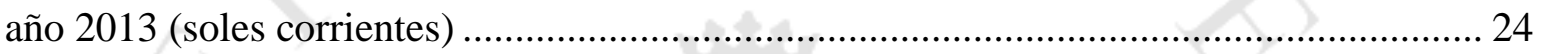

Figura 2.3 Población entre 15 años a 65 años, según grupo de edad, del año 2000 al año

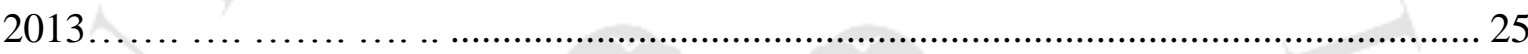

Figura 2.4 PEA ocupada según grupo de edades del año 2004 al año 2013 (en miles de

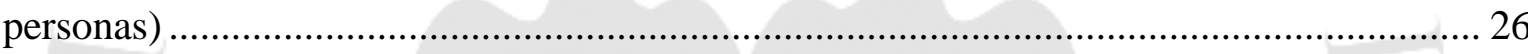

Figura 2.5 Distribución de la PEA ocupada según niveles de educación del año 2001 al

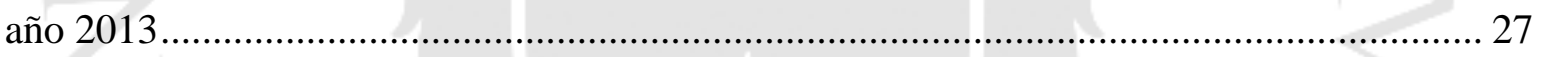

Figura 2.6 Promedio de años de educación de la población de 15 años a más, por grupos de

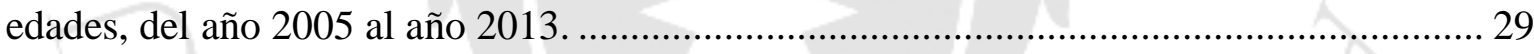

Figura 2.7 Promedio de años de educación alcanzado por la población de 15 años a más,

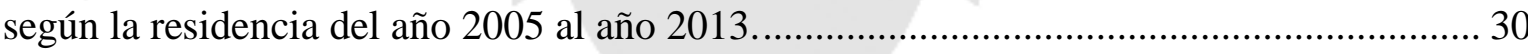

Figura 2.8 Distribución de la población según el estado civil o conyugal, del año 1993, el

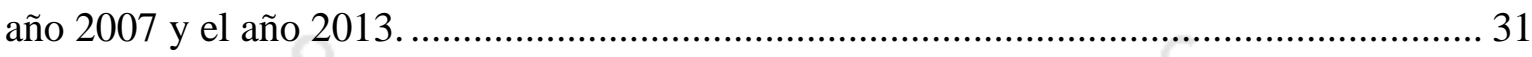

Figura 2.9 Población total, según sexo del año 2000 al año 2013 .................................. 32

Figura 2.10 Población de hombres según grupo de edades del año 2000 al año 2013....... 33

Figura 2.11 Población de mujeres según grupo de edades del año 2000 al año 2013 ........ 34

Figura 2.12 Nivel de educación alcanzado por hombres de 25 años a más, en porcentajes,

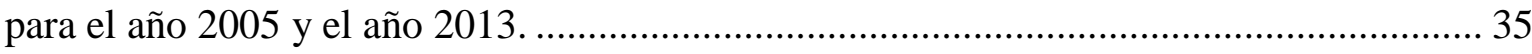

Figura 2.13 Nivel de educación alcanzado por mujeres de 25 años a más, en porcentajes, para el año 2005 y el año 2013. 36 
Figura 2.14 Evolución de la PEA ocupada según categoría de ocupación del año 2004 al

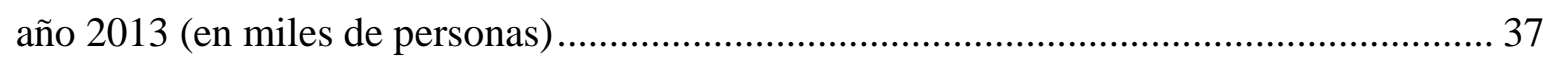

Figura 2.15 Evolución de las matriculas en educación primaria, del año 2004 al año 2013 (en miles de personas) 38

Figura 2.16 Evolución de las matriculas en educación secundaria, del año 2004 al año 2013 (en miles de personas)

Figura 2.17 Evolución de las matriculas en educación no universitaria, del año 2004 al año 2013 (en miles de personas). 40

Figura 2.18 Evolución de las matriculas en educación universitaria, del año 2004 al año 2013 (en miles de personas)

Figura 2.19 Numero de graduados en el nivel superior universitario, del año 2004 al año 2013

Figura 2.20 Porcentaje de la población que presentó algún problema de salud crónico, del año 2005 al año 2013

Figura 3.1 Tendencia de los retornos, según el nivel educativo, desde el año 1985 al año 2004

Figura 3.2 Tendencia de los retornos, según el nivel educativo, desde el año 1985 al año 2013 


\section{INDICE DE ANEXOS}

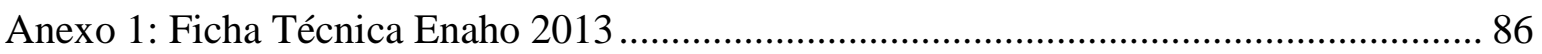

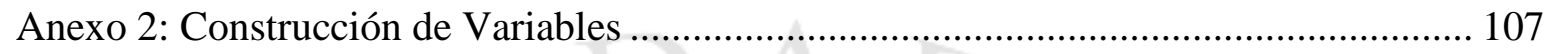

Anexo 3: Plan de Recodificaciones ................................................................... 108

Anexo 4: Ecuación Mincer - Yamada 2004 (total urbano) ........................................... 115

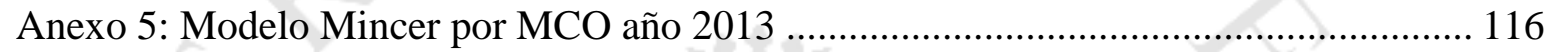




\section{INTRODUCCIÓN}

Un estado debe impulsar políticas enfocadas a la educación y la mejora de la experiencia laboral con el fin de que la persona sea más productiva, en pro de lograr generar un círculo virtuoso en el que se beneficia tanto la persona con un mayor ingreso y beneficios relacionados, como el estado con un crecimiento y desarrollo económico sostenido.

En el presente trabajo de investigación se realiza una estimación de las tasas de retorno a la educación en el Perú según los niveles educativos para el año 2013, con énfasis en la educación superior universitaria y no universitaria.

El objetivo general de esta investigación es estimar los retornos a la educación para cada nivel educativo en el año 2013, en base al modelo de Mincer e incorporando otras variables explicativas. Mediante el análisis se mostró las diferentes tasas de retorno a la educación en los niveles superior, secundario y primario, especialmente entre el nivel superior universitario y no universitario.

Los objetivos específicos de la presente investigación buscan establecer en base al análisis del año 2013 las diferencias entre las tasas del retorno a la educación, y evaluar las tasas de retorno a la educación en un modelo de ingreso.

El primer objetivo específico es estimar los retornos a la educación en el Perú para el año 2013 desagregando la variable educación, con énfasis en la educación superior.

El segundo objetivo específico es estimar loa tasa de retorno a la educación en el Perú de las personas con nivel superior universitario completo y del nivel superior no universitario completo; así como de las personas con estudios superiores universitarios incompletos y personas con estudios superiores no universitarios incompletos para cada sector.

La hipótesis general es que son las variables: años de educación, años de experiencia, el estado civil, el sexo de las personas, el lugar de residencia, el ser trabajador dependiente, el haber recibido una educación privada, la salud, el fenotipo y el sector económico; las que explican el ingreso de una persona en la estimación para el año 2013 
En cuanto a las hipótesis específicas guardan relación con los objetivos descritos anteriormente:

La primera hipótesis específica es demostrar que las tasas de retorno a la educación en el Perú estimados para el año 2013 del nivel educativo superior, tanto universitario como no universitario, han sido mayores respecto a los retornos estimados para los años previos.

La segunda hipótesis específica es evaluar si las tasas de retorno a la educación de las personas con nivel superior completo son mayores a las personas con educación superior incompleta para cada sector económico: agricultura, comercio, construcción, manufactura y minero 


\section{CAPÍTULO I: MARCO TEÓRICO}

En este capítulo se desarrolla el marco teórico de la teoría del Capital Humano en el siglo $\mathrm{XX}$, desde las primeras aproximaciones en la historia del pensamiento económico hasta la teoría definida como tal por parte de Schultz, Becker y Mincer.

Seguidamente, se explica el modelo de "Schooling, experience and earnings" formulado por Mincer y utilizado para la estimación de los retornos a la educación, el retorno a la educación es el ingreso adicional que una persona recibe por cada año o nivel adicional de educación que invirtió (Yamada, 2007, p.8).

Asimismo, se mencionan las principales investigaciones y estimaciones realizadas tanto en el Perú como en el exterior. Finalmente, se expone las principales críticas a la teoría del Capital Humano.
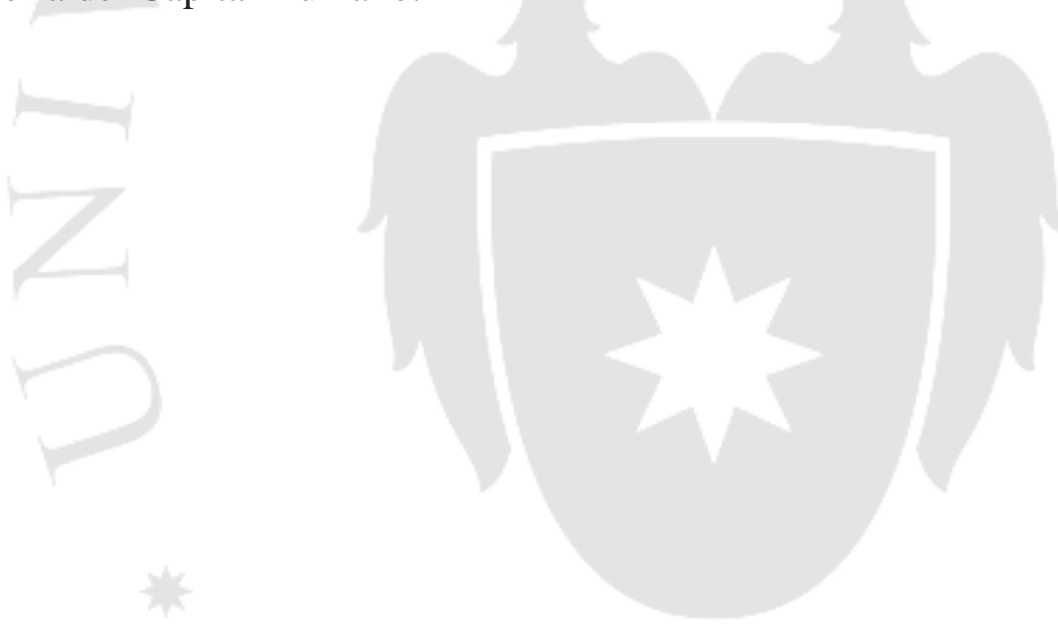


\subsection{Evolución del Capital Humano}

La relación entre el capital humano y el crecimiento económico integra tanto a la persona como un individuo dentro de la sociedad, como a la sociedad en su estructura social funcional. La relevancia del capital humano en la sociedad se relaciona con las necesidades de los individuos para interaccionar (una de ellas: la educación), que le permitan ampliar las capacidades y aptitudes personales en un contexto social y económico, que tiene sus primeros análisis o aproximaciones conceptuales desde mediados del siglo XVII.

En el siglo XVIII, Adam Smith se refería que las sociedades dependen del conocimiento y de las destrezas de su población para el logro de sus objetivos; las cuales estaban expresadas en las facultades productivas, adquiridas y útiles, de todos los habitantes de un país. Smith se refería a lo anterior realizando una comparación de un hombre educado y una máquina muy costosa, comparables por el tiempo y trabajo invertido.

Marshall, en su obra Principios de Economía, introduce el término "capital social" desde la perspectiva de la productividad definida como un medio para la adquisición o como un balance de los requisitos de producción; asimismo precisa la definición con lo siguiente “... consiste en aquellas cosas que ayudan o apoyan el trabajo de la producción o,..., consiste en aquellas cosas sin las cuales la producción no podría llevarse adelante con la misma eficacia, pero que no son gratuitos regalos de la naturaleza." (Marshall, 1920, p. 788).

El concepto de capital humano es el resultado de los aportes de diversos autores en la historia del pensamiento económico, basados en el análisis de la sociedad y el crecimiento económico; en la siguiente tabla se resumen los principales autores y sus obras en las cuales se refieren y forman parte de la base de la teoría del capital humano. 
Tabla 1.1

Aportes a la teoría del Capital Humano

\begin{tabular}{|c|c|c|}
\hline AUTOR & PERIODO & OBRA \\
\hline William Petty & $(1623-1687)$ & Escritos sobre Economía \\
\hline Richard Cantilon & $(1680-1734)$ & $\begin{array}{c}\text { Ensayo sobre la naturaleza del } \\
\text { comercio }\end{array}$ \\
\hline Adam Smith & $(1723-1790)$ & La Riqueza de las Naciones \\
\hline John Stuart Mill & $(1806-1873)$ & Principios de Economía Política \\
\hline Alfred Marshall & $(1842-1924)$ & Principios de Economía \\
\hline Irving Fisher & $(1867-1947)$ & $\begin{array}{c}\text { La naturaleza del Capital y la } \\
\text { Renta }\end{array}$ \\
\hline
\end{tabular}

Fuente: Oroval, E. y Escardivul, J. (1998).

A mediados del siglo pasado, tras la segunda guerra mundial, se desarrolla la teoría neoclásica, Solow y Swan consideran que el crecimiento económico de un país se encuentra explicado por la acumulación de capital y trabajo (factores) y el progreso tecnológico; que a su vez dependen de la tasa de ahorro y el crecimiento de la población. Asimismo determinan que los factores (capital y trabajo) tienen rendimientos decrecientes, y la acumulación de capital a largo plazo está determinada por el crecimiento tecnológico exógeno. Sin embargo, no son definidos los agentes que favorecen al progreso tecnológico para el crecimiento en el largo plazo. (Sala-i-Martin, X., 2000)

Schultz realizó investigaciones sobre los recursos humanos en la actividad agrícola y elaboró una teoría específica de las calificaciones en el desempeño laboral y el crecimiento económico. Define el concepto de la siguiente manera:

Aunque es obvio que las personas adquieren las habilidades y conocimiento útiles, no es obvio que estas habilidades y conocimiento son una forma de capital,... este capital...., que ha crecido en las sociedades occidentales a un ritmo más rápido que el capital convencional (no humano), y que su crecimiento puede ser la característica más distintiva del sistema económico. ... los incrementos de la producción nacional han sido relacionados en gran manera con aumentos de la tierra, horas hombre, y el capital físico reproducible. La inversión en capital humano es probablemente la principal explicación de esta diferencia (Schultz, 1961, p. i). 
Schultz (1962), describe a la acumulación del capital humano como un proceso de inversión. La persona decide realizar una inversión en sí misma y que difiere del concepto de consumo, la persona para adaptarse a las necesidades del mercado laboral dependerá de las habilidades adquiridas; el capital humano determina la capacidad que una persona tiene para realizar su actividad laboral.

Mincer (1974) y Becker (1975), desarrollan el concepto de capital humano desde un análisis de las personas, ellas deciden el nivel óptimo de educación comparando el valor presente de las ganancias esperadas posteriores a los años de educación adicionales frente a los costos relacionados a cursar cada año educativo adicional.

Becker (1975), considera el valor del capital humano como un factor económico primario en su estudio sobre el conocimiento, el mayor tesoro de una sociedad es el capital humano que se posee, diferenciando entre las habilidades y las destrezas que las personas van adquiriendo a lo largo de su vida. Asimismo, hace diferencia en la manera de adquirir el conocimiento, ya sea por medio de estudios formales (las escuelas) o por medios informales (la experiencia).

En ese sentido, una persona para mejorar la productividad en su actividad dentro del mercado laboral demanda de la educación, buscando obtener mayores ganancias futuras. La obtención de un beneficio compensatorio futuro de las actividades educativas mediante un análisis de flujos de ganancias y de costos a lo largo del ciclo de vida de la persona permite determinar la tasa de rentabilidad de la educación; si el resultado es positivo y se tiene una mayor tasa que otro tipo de inversión, el resultado será que las familias invertirán en educación. ${ }^{1}$

El principal beneficio de la educación es monetario, con un mejor salario o ingreso; aunque también existen otros beneficios no monetarios: una mejor salud, una mayor eficiencia en la producción de bienes y servicios en el hogar, realizar trabajos menos peligrosos, una mayor estabilidad laboral. Asimismo, los costos son: directos (pago de matrícula y cursos) e indirectos (transporte, libros, alimentación). Además, hay factores que pueden condicionar el comportamiento de personas, tales como el nivel de ingreso, el

\footnotetext{
${ }^{1}$ Becker (1975) desarrolla un análisis detallado.
} 
sexo, el lugar de residencia (Yamada, 2007), restricciones crediticias (Castro, 2010), la habilidad innata, etc.

A mediados de los ochenta surge la teoría neo keynesiana del crecimiento endógeno que rechaza el supuesto neoclásico del progreso tecnológico exógeno, se centran en las personas y su aporte al crecimiento económico, el capital humano tiene una alta valoración.

El progreso tecnológico y el crecimiento económico se explican desde la inversión en capital humano; la innovación y el conocimiento. Además se centra en las externalidades positivas y efectos secundarios de una economía basada en el conocimiento que soporta al desarrollo económico; siendo los factores endógenos determinantes del crecimiento de largo plazo.

Romer (1990) complementa lo anterior, añadiendo el capital humano como insumo. La implicancia más importante del modelo es que la economía con más grande stock de capital humano experimentará un crecimiento más rápido, lo cual explica las tasas de crecimiento per cápita de los países desarrollados en el siglo XX.

En la teoría de crecimiento endógeno, la investigación e inversión en educación y capital humano, conduce a la adquisición de habilidades y a su vez aumenta la intensidad y eficiencia con la que se utilizan las tecnologías existentes, con lo que se promueve el avance tecnológico generando un círculo virtuoso.

Los países que crecen rápidamente comparten rasgos en común, a pesar de diferir en sus caminos, estos requieren un mayor capital humano, recursos naturales y capital físico; a estos factores es necesario incorporar el progreso técnico que permita incrementar la productividad de los factores existentes. En el largo plazo, sólo se puede crecer sostenidamente a altas tasas a través de aumentos en la productividad de los factores (Samuelson, 2005).

Giménez (2005) diferencia al capital humano, uno de origen innato y el otro adquirido. El innato comprende actitudes físicas e intelectuales, que puede verse alterado por las condiciones de alimentación y salud. En tanto el adquirido se irá formando a lo largo de la vida de los sujetos a través de la educación formal e informal recibida 
(formación general) y por la experiencia laboral acumulada (formación específica), estos tres tipos de formación adquirida van a condicionar la instrucción laboral y el sistema de valores de los sujetos, que determinará su rendimiento en el trabajo junto a las aptitudes innatas.

Figura 1.1

Relaciones del Capital Humano, innato y adquirido

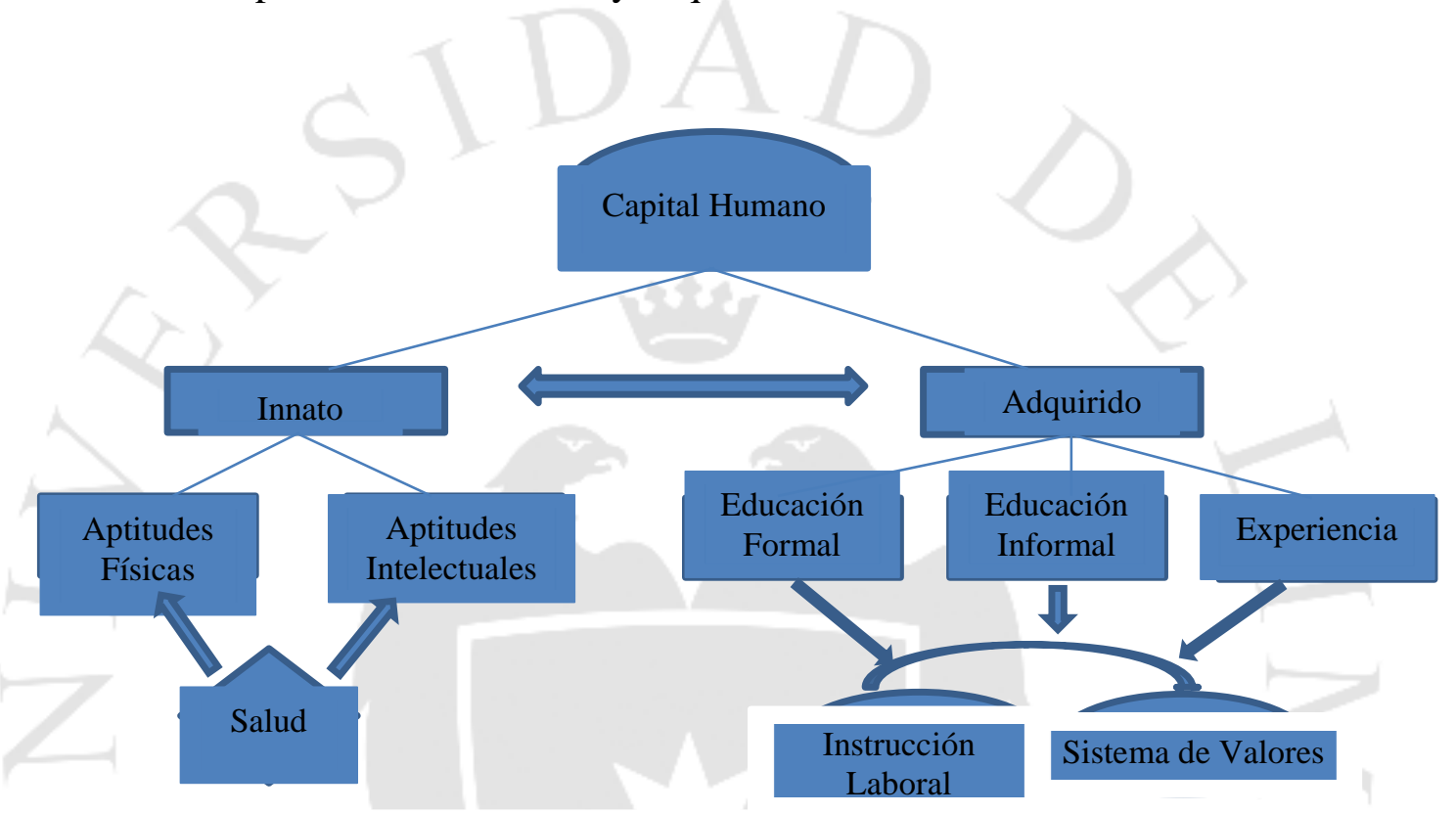

Fuente: Giménez (2005).

Con el desarrollo del concepto de capital humano se reconoce que la mano de obra es diferente de una persona a otra y la calidad del capital humano influye en la producción final de la economía; no obstante, la calidad de la mano de obra se puede mejorar mediante la inversión en capital humano. Por tanto, la educación, la experiencia y las habilidades de un trabajador, tienen un valor económico tanto para los personas como para la economía en su conjunto.

La sociedad contemporánea depende del conocimiento y de su capital humano. Para las personas la inversión en sus capacidades productivas representa incrementar también sus ingresos personales y nivel de vida. En tanto, para la sociedad representa una fuente de bienestar social y el motor del crecimiento económico. 
Actualmente la calidad del capital humano y de las actividades de formación es una preocupación continua por parte del empleador. Asimismo el trabajador para insertarse o mantenerse dentro del mercado laboral debe mejorar su productividad y competitividad; la educación (conocimiento) y la experiencia dentro del puesto de trabajo son importantes en el ámbito laboral. La productividad es inseparable del capital humano, al aumentar la productividad mejoran las posibilidades del crecimiento; las destrezas adquiridas son productivas si se cuentan con equipos de alta tecnología y la adaptación a tecnologías avanzadas (Brunner y Elacqua, 2003).

El nuevo enfoque de formación concibe que el aprendizaje se da a lo largo de toda la vida y se plantea como propósito no sólo de adquirir conocimientos, sino también valores fundamentales como disciplina, trabajo, respeto, puntualidad y autoestima, etc.; competencias básicas para la comunicación; el manejo numérico y la solución de problemas; estrategias meta cognitivas que los lleven a "aprender a aprender" y a "aprender a pensar"; y conocimientos pertinentes, coherentes y flexibles ante las demandas. Así mismo, reconoce que el aprendizaje tiene lugar en muchas condiciones, tanto formales como informales (Mtpe, 2000).

El Capital Humano y el concepto de la sociedad del conocimiento están relacionados, a mayor nivel de educación permite utilizar eficientemente la información y aumentar la demanda de productos tecnológicos sofisticados; asimismo, hacer más fácil la innovación y adopción tecnológica en los procesos productivos. El cocimiento adquirido por medio de la educación debe utilizarse en la producción de bienes y servicios, de otra forma no se estaría en presencia de una economía del conocimiento. 
Tabla 1.2

Evolución de la sociedad industrial a la sociedad del conocimiento

\begin{tabular}{|c|c|c|c|c|c|}
\hline Individual & $\begin{array}{c}\text { Dominio } \\
\text { previo }\end{array}$ & $\begin{array}{c}\text { Medición } \\
\text { previa }\end{array}$ & $\begin{array}{c}\text { Elemento } \\
\text { incorporado }\end{array}$ & $\begin{array}{c}\text { Nuevo } \\
\text { dominio }\end{array}$ & $\begin{array}{c}\text { Nueva } \\
\text { medición }\end{array}$ \\
\hline $\begin{array}{c}\text { Onganicia } \\
\text { cional }\end{array}$ & $\begin{array}{c}\text { Coeficiente } \\
\text { intelectual }\end{array}$ & $\begin{array}{c}\text { Inteligencia } \\
\text { emocional }\end{array}$ & $\begin{array}{c}\text { Personalidad } \\
\text { integral }\end{array}$ & $\begin{array}{c}\text { Perfil de } \\
\text { madurez } \\
\text { CH y CI }\end{array}$ \\
\hline Social & $\begin{array}{c}\text { Desarrollo } \\
\text { económico }\end{array}$ & $\begin{array}{c}\text { Estados } \\
\text { financieros }\end{array}$ & $\begin{array}{c}\text { Capital } \\
\text { intelectual }\end{array}$ & $\begin{array}{c}\text { Organización } \\
\text { integral }\end{array}$ & $\begin{array}{c}\text { Reporte } \\
\text { integral } \\
\text { de valor }\end{array}$ \\
\hline \hline
\end{tabular}

Fuente: Madrigal Torres, B. (2009)

\subsection{Modelo Jacob Mincer (1974)}

A continuación se explica el modelo "Schooling, experience and earnings" mediante la formulación del modelo, con el cual se estimaran los retornos a la educación.

El modelo parte de las siguientes consideraciones:

$\mathrm{n}=$ la duración de la vida laboral más la duración de la escolaridad

$\mathrm{Y}_{\mathrm{s}}=$ las ganancias anuales de un individuo con "s" años de escolaridad

$\mathrm{V}_{\mathrm{s}}=$ valor presente de los ingresos de toda la vida de un individuo al inicio de la enseñanza

$\mathrm{r} \quad=$ tasa de descuento

$\mathrm{t}=0,1,2, \ldots, \mathrm{n}$; tiempo en años

$\mathrm{d}=$ diferencia en la cantidad de años la educación

e $\quad=$ base de los logaritmos naturales

De ahí plantea la siguiente expresión:

$$
V_{S=} y_{s} \sum_{t=s+1}^{n}\left(\frac{1}{1+r}\right)^{t}
$$


Con el proceso de descuento discreto. Y más convenientemente, cuando el proceso es continúo está representado en la siguiente expresión:

$$
V_{s}=Y_{s} \int_{s}^{n} e^{-r t} d t=\frac{Y_{s}\left(e^{-r s}-e^{-r n}\right)}{r}
$$

Del mismo modo, el valor presente de los ingresos de un individuo, ajustado en base a "s - d" años de escolaridad es:

$$
V_{s-d}=\frac{Y_{s-d}}{r}\left(e^{-r(s-d)}-e^{-r n}\right)
$$

El ratio $\mathrm{K}_{\mathrm{s} \text {, s-d }}$ de ganancia anual después de "s" años de ingresos, y después de "s - d" años de escolaridad, se halla mediante $V_{s}=V_{s-d}$.

$$
K_{s, s-d}=\frac{Y_{S}}{Y_{s-d}}=\frac{e^{-r(s-d)}-e^{-r n}}{e^{-r s}-e^{-r n}}=\frac{e^{r(n+d-s)}-1}{e^{r(n-s)}-1}
$$

Se ve de $\mathrm{K}_{\mathrm{s}, \mathrm{s}-\mathrm{d}}$ que:

1. Personas con más escolaridad poseen una remuneración más alta anual.

2. La diferencia entre los ingresos de las personas se debe a la diferencia en la inversión de "d" años de escolaridad; es mayor cuanto mayor es la tasa de retorno de la escolaridad.

3. La diferencia es mayor cuanto más corto es el lapso de la vida laboral, ya que los costos de escolaridad deben ser recuperados en un período relativamente corto. 
La conclusión de que "k" como constante se mantiene cuándo se asumen ingresos fijos en el tiempo, independientemente de la escolaridad. Redefiniendo " $\mathrm{n}$ " con ingresos fijos en el tiempo.

$$
\begin{gathered}
V_{s}=Y_{s} \int_{s}^{n+s} e^{-r t} d t=\frac{Y_{s}}{r} e^{-r s}\left(1-e^{-r n}\right) ; \\
V_{s-d}=Y_{s-d} \int_{s-d}^{n+s-d} e^{-r t} d t=\frac{Y_{s-d}}{r} e^{-r s}\left(1-e^{-r n}\right) e^{-r(s-d)} ;
\end{gathered}
$$

Resolviendo $\mathrm{K}_{\mathrm{s}, \mathrm{s}-\mathrm{d} \text {; }}$ de la ecuación de valor presente se obtiene:

$$
K_{s, S-d}=\frac{Y_{S}}{Y_{S-d}}=\frac{e^{-r(s-d)}}{e^{-r s}}=e^{r d}
$$

Aquí, a diferencia de la ecuación (1.1) el ratio de ganancia de los ingresos (k) que difieren de los años de escolarización (d), no dependen del nivel de escolarización (s) ni de la duración de la vida laboral (n), cuando el tiempo es finito, a pesar de ser corto.

Ahora se define.

$$
\begin{gathered}
K_{s, 0}=\frac{Y_{s}}{Y_{0}}=K_{s} ; \operatorname{de}(1.2) \\
K_{s}=e^{r s} ;
\end{gathered}
$$

En logaritmos la fórmula es:

$$
\ln Y_{S}=\ln Y_{0}+r s .
$$

De la formula anterior después de los análisis aplicativos realizados para Estados Unidos, observa que las ganancias anuales son casi el doble después de dos a tres décadas de experiencia en cada grupo escolar, tras lo cual incluye la experiencia al modelo. 
En una función de ingresos en el que las ganancias son logarítmicas, los años de experiencia de trabajo deben introducirse de forma aditiva y en forma aritmética; ya que el término experiencia no es lineal, sino cóncavo:

$$
\ln E_{t}=\ln E_{s}+\beta_{1} \mathrm{t}-\beta_{2} \mathrm{t}^{2} .
$$

Con " $\mathrm{t}$ " como años de experiencia y " $\mathrm{E}_{\mathrm{s}}$ " es la capacidad de ganancias después de escolarización, se obtiene el modelo final (1.5):

$$
\begin{gathered}
\ln E_{s}=\ln E_{0}+r s \\
\ln E_{t}=\ln E_{0}+r s+\beta_{1} \mathrm{t}-\beta_{2} \mathrm{t}^{2}
\end{gathered}
$$

Mincer (1974) en su obra "Schooling, experience and earnings", explica el ingreso salarial en función de años de educación formal (escolarización), obtenida por las personas por medio de la inversión; en un primer momento solo utiliza el número de años empleados en la formación educativa formal.

El modelo está centrado en la dinámica de los ciclos de vida de los ingresos, explorando la relación entre los ingresos observados, los potenciales, y la inversión en educación; en un principio solo de la educación formal y posteriormente incluye la experiencia laboral.

Un supuesto básico es que el individuo decide invertir en su formación hasta hacer máximo el valor actual de la totalidad de ingresos futuros esperados. Una persona decide seguir estudiando, en lugar de incorporarse al mercado laboral, porque espera obtener mayores ingresos económicos el futuro.

Mincer introduce el concepto de la experiencia laboral, en la relación entre el salario y la educación formal (años de escolaridad). Al no contar con información directa sobre los años de experiencia laboral emplea el concepto de experiencia potencial; definida como: la edad menos los años de escolaridad menos los años previos a la 
educación primaria ${ }^{2}$; se considera el término elevado al cuadrático para capturar el efecto decreciente de la experiencia.

La versión más generalizada de esta ecuación propone que los ingresos (logaritmo natural del ingreso por hora) están en función de los años de educación y los años de experiencia potencial. Representados en la suma de una función lineal de los años de educación y una cuadrática de los de experiencia potencial, tal como se muestra en la siguiente ecuación:

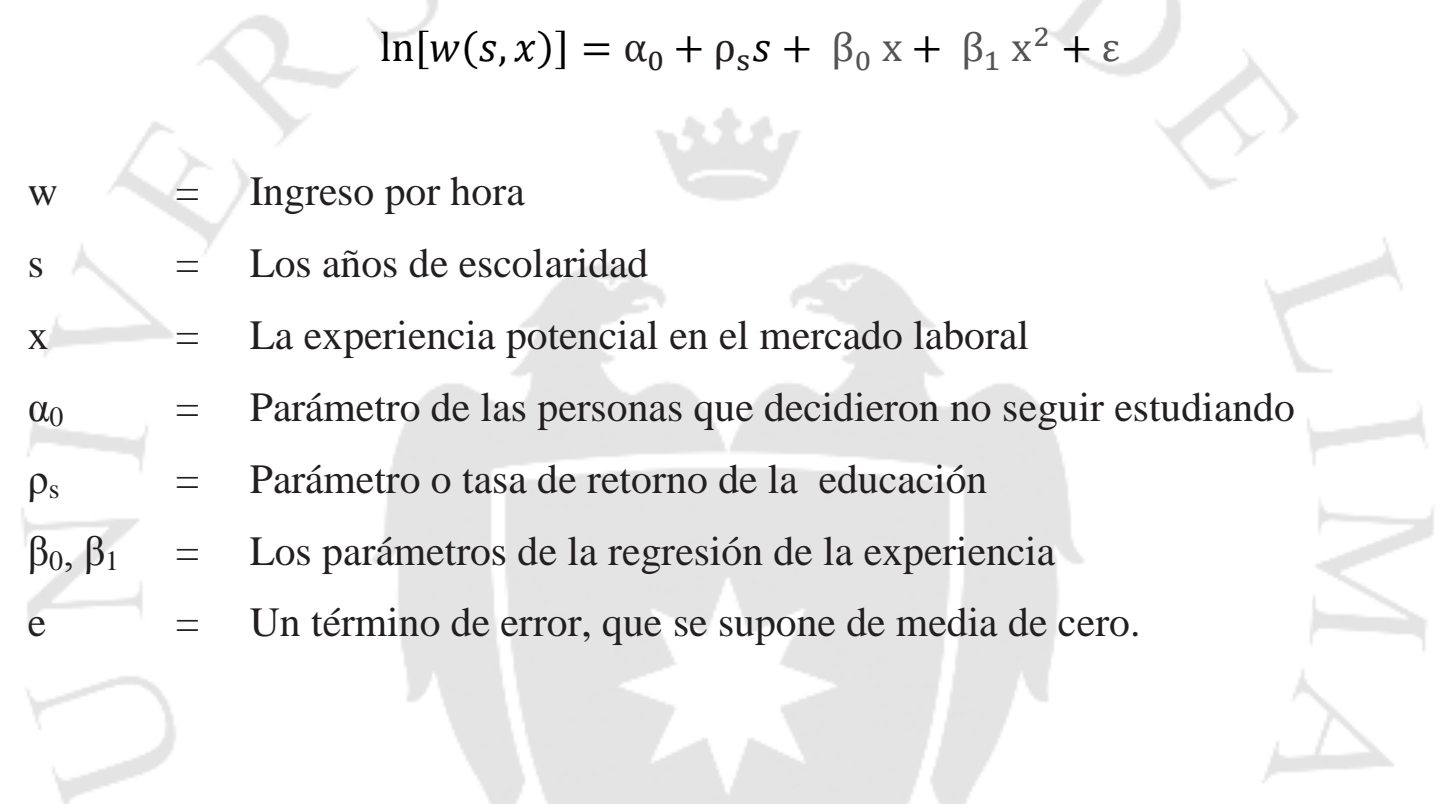

Existen un conjunto de tasas diferentes de rentabilidad para grupos con distintos niveles de educación (años), siendo los perfiles de experiencia e ingreso relativamente paralelos para grupos de educación diferentes (Galassi, 2011).

Al utilizar la experiencia potencial, envés de la edad, se captura la forma del perfil edad e ingreso y las diferencias en las pendientes de grupos con diferente nivel de educación, obteniéndose tasas de retorno a la educación en el mercado laboral a cada nivel educativo.

El modelo de ingreso determinado por la inversión del individuo se centra en la oferta de su capital humano, no considerando en el análisis los efectos de la demanda existente en el mercado laboral. Si bien los ingresos se explican por el capital humano

\footnotetext{
${ }^{2}$ Mincer lo determina en seis años por convención, que es la edad de ingreso a la educación básica.
} 
acumulado, este a su vez se relaciona y es explicado por las capacidades y oportunidades determinadas, lo cual es una limitación en el modelo.

Son con las investigaciones de, Heckman, Lochner y Todd en el 2001 estimando la relación de los ingresos con la escolaridad por medio de mínimos cuadrados ordinarios y técnicas de variables instrumentales para la variable educación que se ha logrado demostrar lo acertado de las especificaciones desarrolladas aplicadas a diferentes economías (Destinobles, 2006).

Determinando que el aumento del ingreso por hora relacionado al rendimiento adicional de un año de educación formal, se cumple en tanto se verifiquen dos condiciones: primero que la productividad marginal y el ingreso real sean proporcionales, y segundo que el incremento de la productividad debido a un año más de educación formal se derive necesariamente del sistema educativo.

La primera condición se satisface en modelos competitivos del mercado de trabajo, en el modelo de negociación bilateral y el modelo de monopsonio, a condición de que es el poder de mercado ejercido por los trabajadores o los empresarios casi uniformemente sobre la escala de los salarios; en tanto para la segunda condición, consideran que es menos evidente que se dé, dado que por lo menos la educación cumple dos funciones: una función de trasmisión de los conocimientos y una función de señal; según Philippe Aghion y de Elie Cohen (como se citó en Destinobles, 2006, p. 22).

Finalmente lo principal del modelo de Mincer, desde la formulación y posterior análisis aplicativo, es que no depende de supuestos explícitos acerca del contexto económico; por tanto, posibilita la comparación en el tiempo. Sumado a los aportes metodológicos de Chiswick y Heckman que posibilitan un análisis con mayor profundidad.

\subsection{Estudios del Capital Humano}

La evidencia econométrica proporcionada por Barro para los años 1991, 1997 y 2001, así como Benhabib y Spiegel para el año 1994 y varios otros investigadores sugieren que el nivel de escolaridad, especialmente el nivel primario, es un importante determinante de 
crecimiento económico del PIB per cápita real. Asimismo, el gasto público en educación como porcentaje del PIB tiene un impacto positivo en el crecimiento económico (INE, 2011).

Barro, en el año 1991, analiza a 98 países en el periodo de 1960-1985 mediante una estimación en corte transversal de la tasa de crecimiento del ingreso per cápita y la tasa de escolarización primaria y secundaria iniciales encontrando una relación positiva; el capital humano se definió con la tasa de escolarización primaria y secundaria iniciales.

De Gregorio, en el año 1992, realizo un estudio para 12 países latinoamericanos en el periodo de 1950-1985 encontrando que el capital humano medido por la tasa de alfabetización, tiene un efecto positivo.

Barro, en el año 2001, utilizó como fuente de datos un panel de alrededor de 100 países observados desde 1965 a 1995, y mediante un análisis de en cortes transversales de 10 años utilizando las calificaciones de pruebas en ciencias, matemáticas y lectura -comparables internacionalmente como una medida de calidad de educación-, obtuvo que son los puntajes en ciencias lo que están relacionados de manera fuerte y positiva con el crecimiento económico. Asimismo, dada una determinada calidad en la educación, la cantidad en años de educación continua se reflejan en un efecto positivo en el crecimiento económico.

\subsubsection{Estudios aplicativos en el Perú}

Rodríguez, en el año 1993, estima las tasas internas de retorno de la educación utilizando la metodología de análisis de costo beneficio a través de los flujos de ingreso calculados usando la ecuación de Mincer, obtuvo que diferenciándose por niveles educativos es la educación primaria la que tiene mayores tasas de retorno, y la educación de los hombres muestra mayor rentabilidad que la de las mujeres. La inversión en educación para el Perú tiene alta rentabilidad social y privada (Calónico y Ñopo, 2007).

Saavedra y Maruyama, en el año 1999, realizan un análisis de ingresos entre el año 1985 y el año 1997; centrados en la interacción entre retornos a la educación y la experiencia. La investigación concluye que los trabajadores que asistieron a una escuela 
privada en todos los niveles educativos, obtienen una mayor prima de salario. En tanto para los retornos, encontraron que los retornos cayeron de $10 \%$ en el año 1985 a $7 \%$ en el año 1991 pero luego crecieron en el año 1994 a $9 \%$ y luego pasaron a $10 \%$ en el año 1997 , explicado por un patrón pro cíclico. (Yamada, 2007).

Yamada (2007) estima retornos a la educación al año 2004, con especial énfasis sobre la educación superior. Los retornos a la educación primaria incompleta se ubican en $5,6 \%$ para la primaria completa en 3,8 \% . En tanto, el retorno a la educación secundaria se sitúa en 5,1\%, para la secundaria incompleta en 6,3\%. El retorno a la educación superior no universitaria se ubica en 10,8 \%, mientras que el retorno a la educación universitaria se sitúa en $17,3 \%$. Encontrado evidencia de no linealidad en los retornos a la educación.

La inversión en educación es importante para cada nivel educativo; se evidencia que a diferencia del acceso a la educación primaria y secundaria, el acceso a la educación superior es un mecanismo seguro para salir de la pobreza en nuestro país.

Calónico y Ñopo (2007) estiman los retornos en el Mercado laboral Peruano para 1997 y 2000, estimando los retornos en base a los logros en lugar de años de educación, enfocados sobre las diferencias entre graduados de instituciones Públicas y Privadas. (p. 8) Los resultados indican que la mayor diferencia en los retornos se da en los niveles primario y secundario. La educación superior funciona como un mecanismo que tienen las personas para igualar oportunidades.

Díaz (2008) realiza un estudio sobre las tendencias de la educación superior en el Perú al año 2005, tomando como base el estudio de Saavedra y Maruyama sobre el análisis de la evolución de los diferenciales de ingresos según niveles educativos, mostrando que el diferencial de ingresos para quienes adquirieron educación secundaria completa respecto de aquellos con primaria o secundaria incompleta se ha reducido, y el diferencial de aquellos con educación universitaria respecto de aquellos con secundaria completa ha aumentado.

En la siguiente figura se observa la diferencia porcentual en los ingresos en tendencia del ingreso laboral, según el nivel superior universitario y superior no universitario sobre el nivel secundaria completa. 
Figura 1.2

Evolución de las tendencias en el ingreso laboral según el nivel educativo

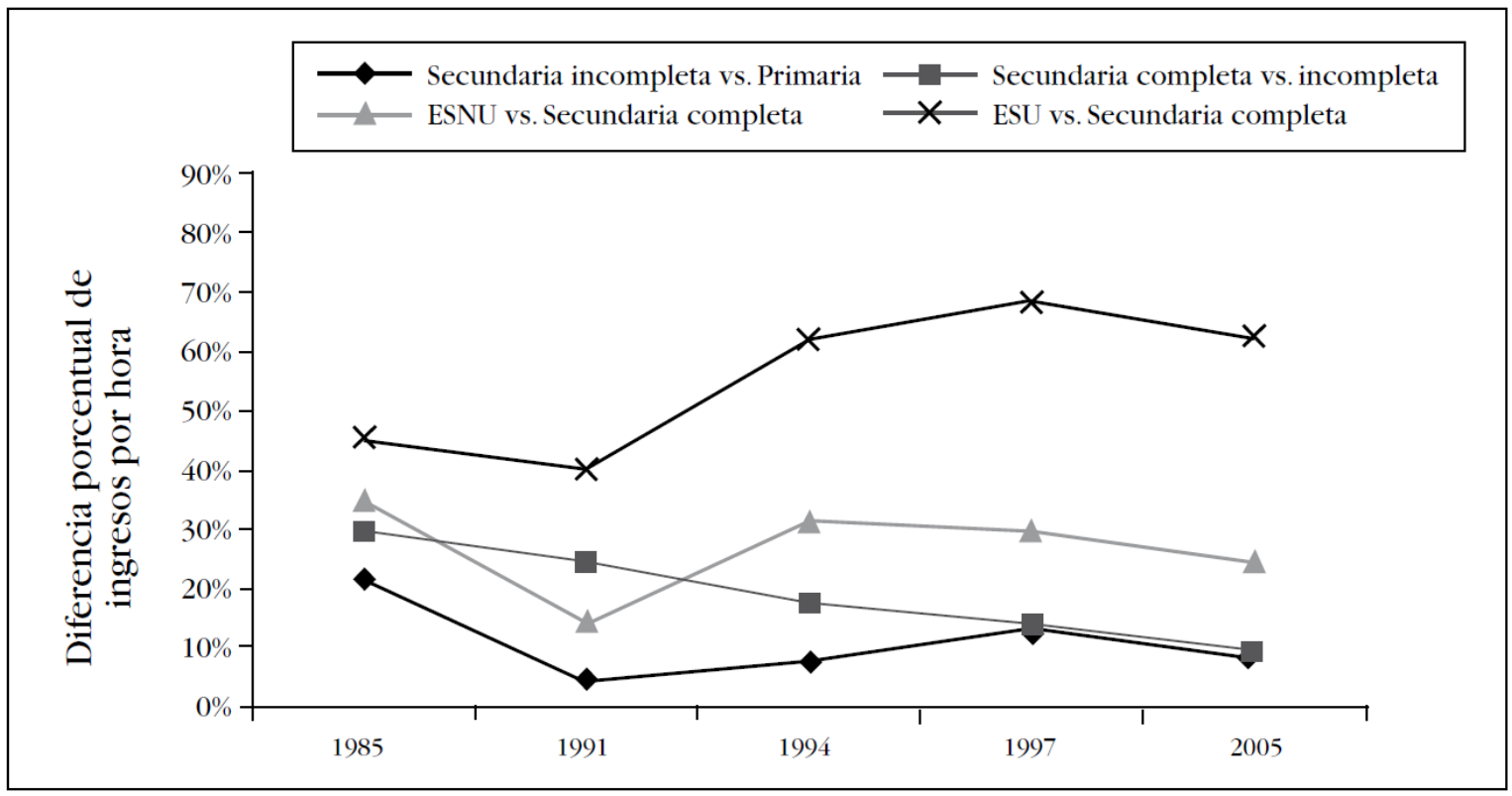

Fuente: Díaz (2008).

\subsubsection{Estudios aplicativos en el exterior}

Sapelli (2009) desarrolla un resumen de los análisis realizados en la región Latinoamericana y Mundial, presentados a continuación:

Savantini, para el año 2005 en Argentina, encuentra un aumento del retorno a la educación secundaria con respecto a la primaria, con un retorno a la educación primaria de $4,9 \%$ y un retorno a la educación secundaria promedio de alrededor del $9 \%$.

Crespo y Cortez, para el año 2005 en Brasil, no encuentra una diferencia significativa entre los retornos a los años de educación secundaria y los retornos a los años de educación primaria. Los retornos a la educación primaria son muy similares dentro de Latinoamérica, con retornos entre $4,9 \%$ y $7,2 \%$.

Oliver, para el año 1998, encuentra para España que los retornos son relativamente constantes para todo el sistema de educación español; 11,2 \% para educación primaria, 9,7\% para educación secundaria y $11 \%$ para educación superior. 
Jaeger y Page, para el año 1996, en Estados Unidos, encuentran que los retornos son constantes para todos los niveles educativos $(7,6 \%)$, con un único cambio para el último año de educación superior, que tiene un retorno del $19 \%$.

Sapelli (2009), los retornos encontrados para Chile, en la educación primaria, es en promedio de 5,6 \%. Los retornos de educación secundaria, tienen un promedio de 14,3\% para la Media Técnica y para la Media Humanista de $11,7 \%$. Argentina muestra tasas alrededor de 9,5\%, México cercanas al $5 \%$. Mora, en Colombia, encuentra que las tasas de retornos de la educación secundaria están alrededor de 10,5\%.

Sapelli (2009) menciona los retornos a la educación superior alcanzan niveles relativamente similares en todos los países latinoamericanos (Argentina, Chile, Brasil, Colombia y México) con retornos entre el $16 \%$ y el $25 \%$.

\subsection{Críticas al Capital Humano}

Son tres las principales críticas al capital humano, con diferentes enfoques, señalados a continuación:

Arrow, Stiglitz y Spence proponen la hipótesis del filtro apoyada en la teoría de la información, se considera que la educación facilita la identificación de las capacidades de la persona con el fin de poder filtrarlas; no buscando aumentar la productividad de la persona, tal como lo supone la teoría del capital humano, sino que la finalidad del sistema educativo se resume en filtrar a los individuos más aptos y en brindar esta información a los empleadores acerca de las cualidades de sus futuros trabajadores. Los empleadores se basan en la señalización, el nivel educativo facilita el proceso de selección (Lassibille y Navarro, 2012).

En este sentido, el recibir educación formal dentro del sistema de educación no tiene un efecto desde la persona, sino que es un mecanismo para la clasificación según sus capacidades presentes obtenidas de la educación recibida; el empleador valora a la educación y se refleja, circunstancialmente, con un mayor nivel de ingreso para el individuo. 
Schaafsma, Gullason y Kodde plantean que la demanda de educación podría estar motivada por el simplemente deseo de adquirir el conocimiento, lograr satisfacer una necesidad. De este punto, la adquisición de educación no es más que un simple acto de consumo. (González, 2011).

La noción de que la educación formal es solo un acto de consumo para la satisfacción de una necesidad esta centrada en el carácter subjetivo del individuo, mas no lo coloca en la perspectiva de obtener un beneficio económico reflejado en un mayor ingreso (inversión); no obstante, si con el consumo en educación se lograse obtener un mayor ingreso personal, la educación sería una inversión al fin y al cabo.

Doeringer y Piore, y Ashton y Green, plantean la perspectiva institucional, poniendo énfasis en la demanda de trabajo. La educación influye en el crecimiento bajo el cumplimiento de requisitos institucionales como la existencia de relaciones laborales cooperativas, un sistema de formación institucionalizado, colaboración entre empresarios, trabajadores y el gobierno, etc. (González, 2011).

Si la educación está integrada a las instituciones del sistema social surgirán los beneficios; por tanto, la educación formal tendrá efectos positivos en el crecimiento económico. 


\section{CAPÍTULO II: ANÁLISIS DEL INGRESO, EDUCACIÓN Y OTRAS VARIABLES}

En este capítulo se realiza un análisis de la evolución de las variables relacionadas con el ingreso. Las variables a analizar son: el ingreso promedio mensual, los años de educación en promedio, el estado civil o conyugal, la distribución de la población por género, la residencia de las personas, la dependencia del trabajador a un salario, la demanda entre educación privada y pública, y la salud referida a enfermedades crónicas.

Se utiliza la base de datos del Instituto Nacional de Estadística e Informática (INEI) del año 2000 al año 2013, el Censo 2007 y la Encuesta Nacional de Hogares (Enaho); considerando las restricciones en la base de datos para analizar la evolución anual de algunas variables previas a la Enaho 2004.

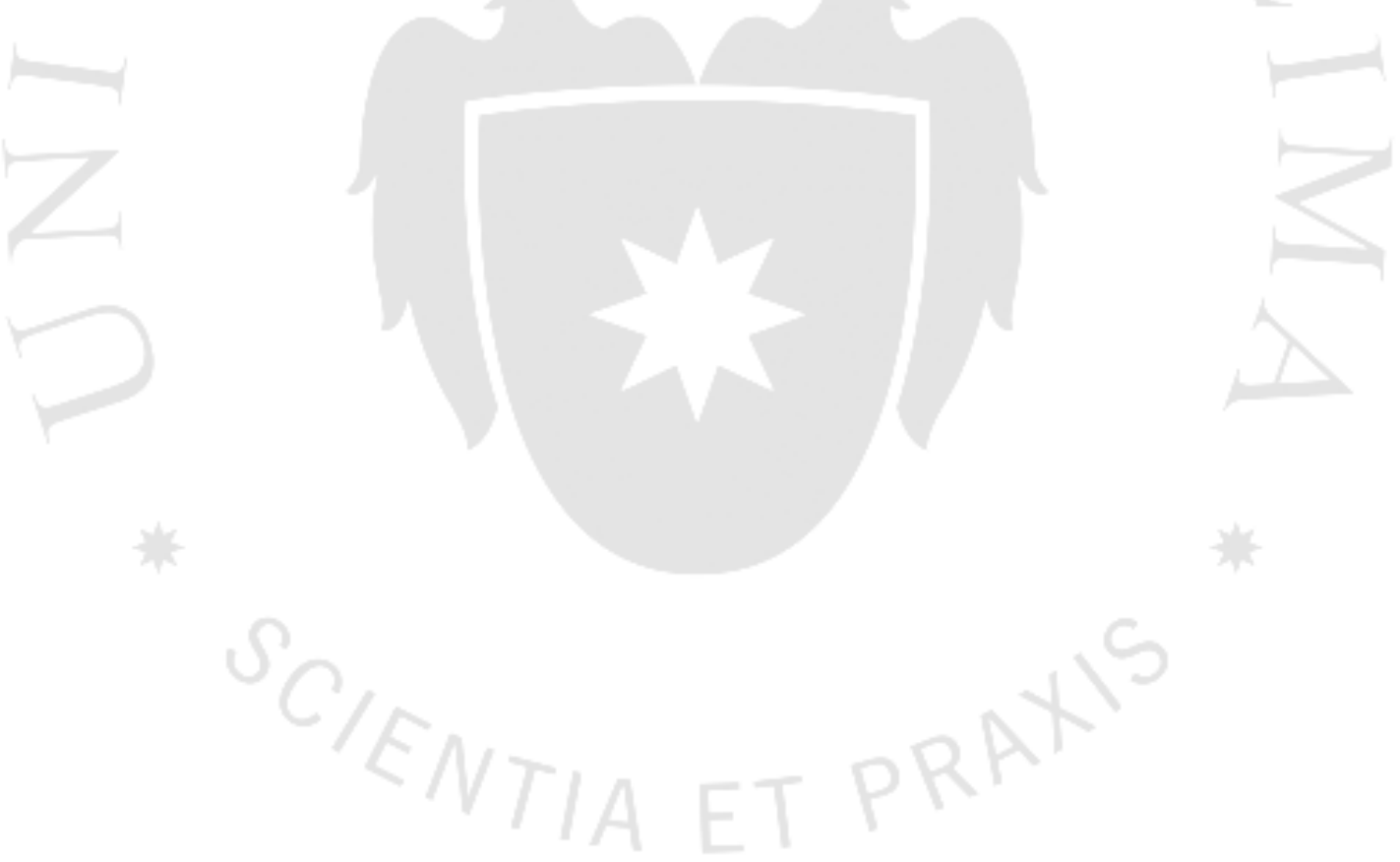




\subsection{Ingreso promedio mensual}

El ingreso promedio mensual se ha incrementado, en Lima Metropolitana, en 61,8 \% del año 2001 al año 2013, pasando de S/ 960,40 a S/ 1 554,05. El incremento puede ser explicado por el crecimiento económico sostenido reflejado en el PBI que ha venido creciendo a importantes tasas, 5,8 \% para el año 2013. Sumado al crecimiento económico, también se ha dado una evolución positiva de la productividad en los últimos años. No obstante, sin perjuicio de los avances registrados, existe todavía un amplio margen de acción para sostener en el largo plazo el crecimiento económico del Perú, la productividad para la competitividad y el crecimiento (Vera Tudela, 2013).

Mejorar el Capital Humano, mediante la educación (conocimiento), se refleja generalmente en un mayor nivel de ingreso personal, que a su vez es un medio para alcanzar el bienestar y lograr el desarrollo.

En el Informe sobre Desarrollo Humano del año 1996, se analizó las vinculaciones entre el crecimiento económico y el desarrollo humano, explicando las relaciones importantes en ambas direcciones (circulo virtuoso), influenciadas por el comportamiento de las familias y por políticas de gobierno. En principio, se parte del crecimiento económico que permite generar los recursos para incrementar el desarrollo humano, en tanto que el desarrollo humano, al mejorar el capital humano, incrementa la productividad y las posibilidades del crecimiento económico sostenido (Vásquez, 2012).

En la siguiente figura se muestra la evolución del incremento del ingreso promedio mensual del año 2001 al año 2013, diferenciados para el total de la población, para Lima Metropolitana y para el resto del país. 
Figura 2.1

Evolución del ingreso promedio mensual, según ámbito geográfico, del año 2001 al año 2013 (soles corrientes)

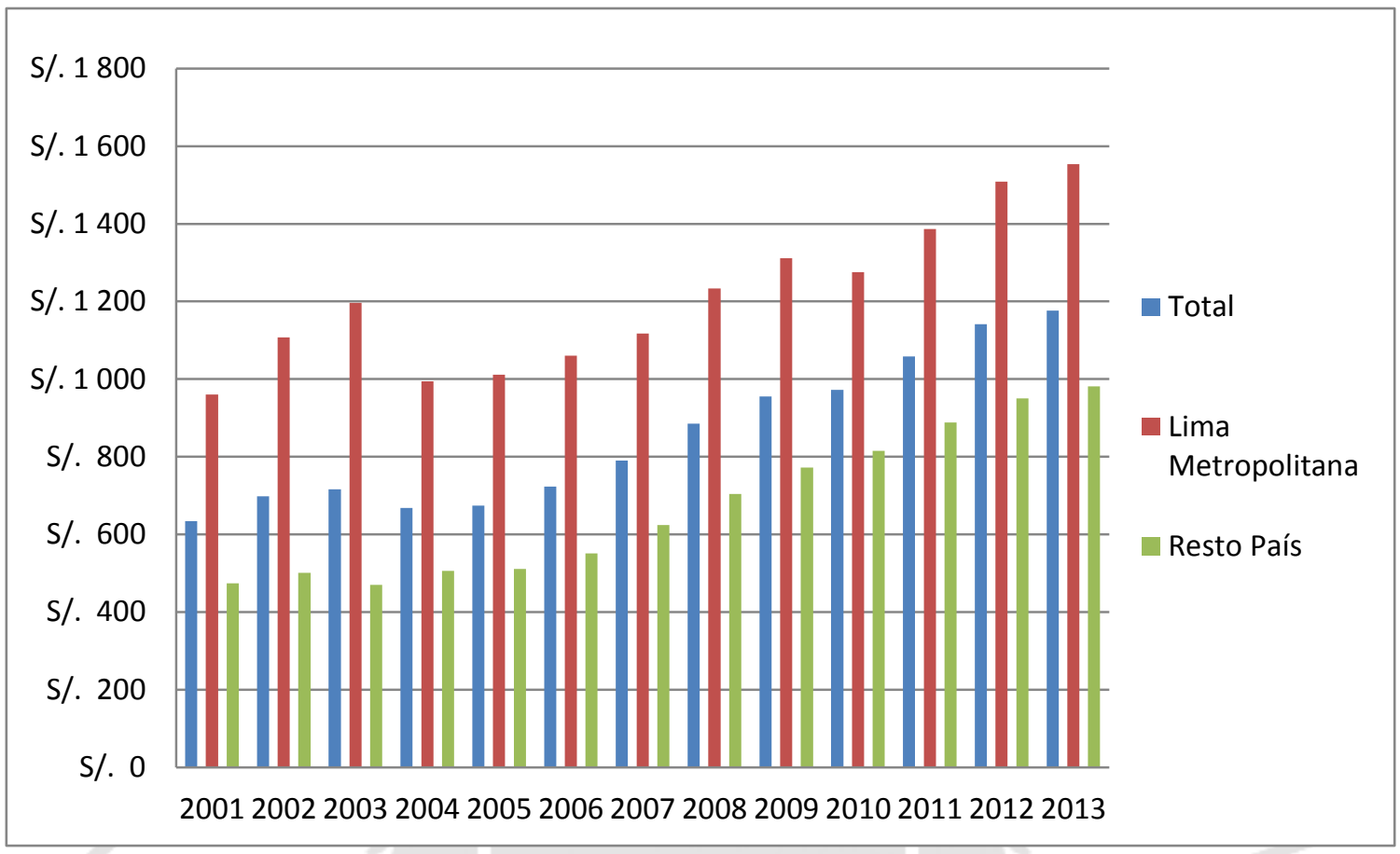

Fuente: Instituto Nacional de Estadística e Informática - Encuesta Nacional de Hogares Elaboración propia

En tanto el ingreso promedio mensual del área urbana para el año 2001 al año 2013, se ha incrementado en 72,9 \%, aumentando de S/ 761,60 a S/ 1 317,15. Asimismo, el ingreso promedio mensual del área rural para el mismo periodo, se ha incrementado en $117,1 \%$ de S/ 287,10 a S/ 623,30.

El mayor incremento de los ingresos promedios en el área urbana se deben a los efectos propios del crecimiento económico registrado en el Perú. En el área urbana, se refleja en mayor medida el crecimiento económico, el aumento de la productividad de factores también explica esta diferencia entre áreas, así como la distribución poblacional.

En la siguiente figura se muestra la evolución del incremento en el ingreso promedio mensual para el área urbana y rural. 
Figura 2.2

Evolución del ingreso promedio mensual, según área geográfica, del año 2001 al año 2013 (soles corrientes)

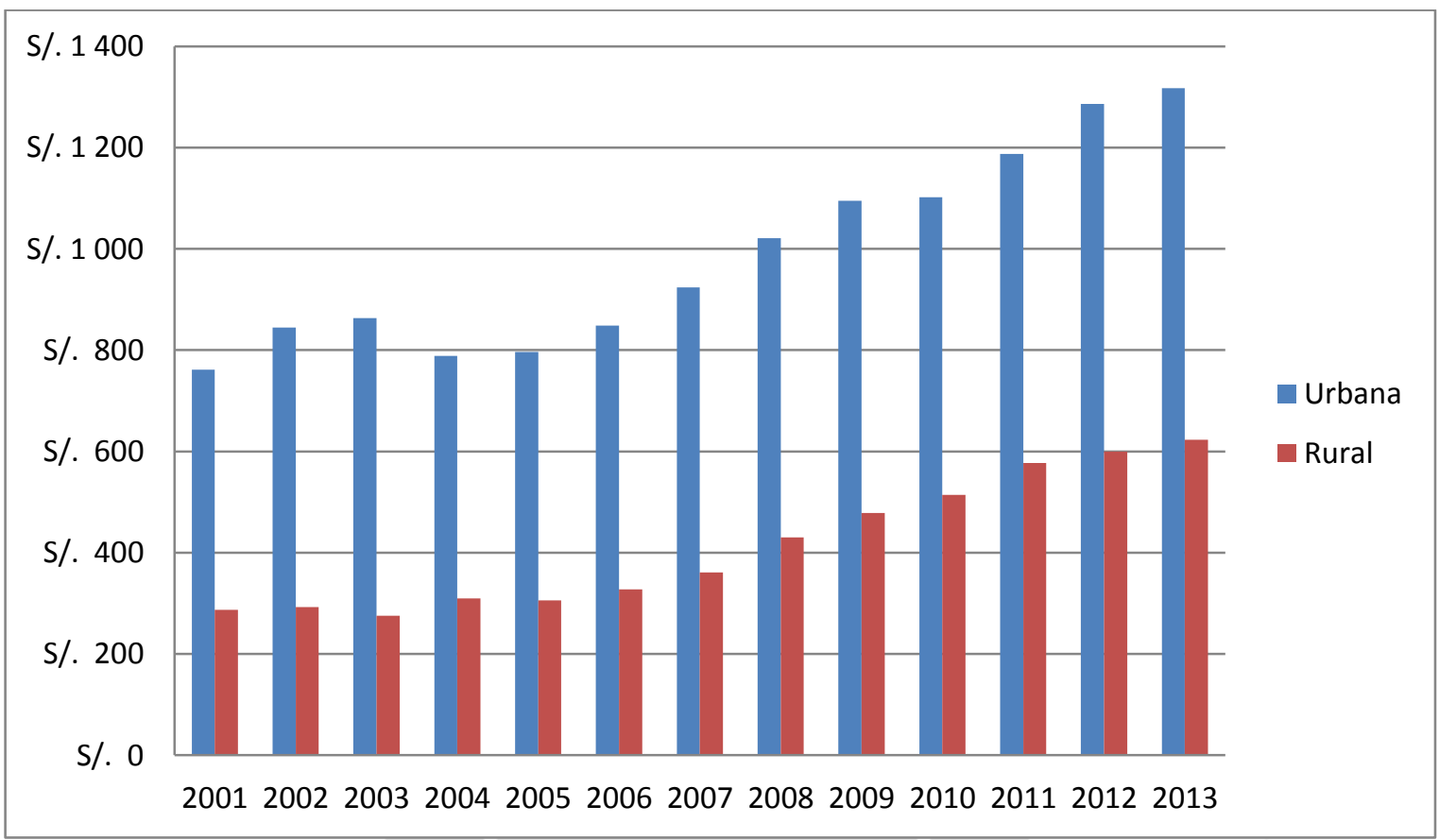

Fuente: Instituto Nacional de Estadística e Informática - Encuesta Nacional de Hogares Elaboración propia

\subsection{Evolución de la población por grupos de edades}

Del año 2001 al año 2013, se muestra una tendencia clara de la evolución de los grupos de edades en la población total, siendo la mayor parte de la población la comprendida entre las edades de 15 años a 40 años.

Al año 2013, se registra una población menor a 15 años de 8754763 personas, entre 15 años a 40 años se registran 12836058 personas, entre 40 años a 65 años son 6976769 personas.

En la siguiente figura se muestra la distribución poblacional por grupos de edades de 15 años a 65 años, comprendido desde el año 2000 al año 2013. 
Figura 2.3

Población entre 15 años a 65 años, según grupo de edad, del año 2000 al año 2013

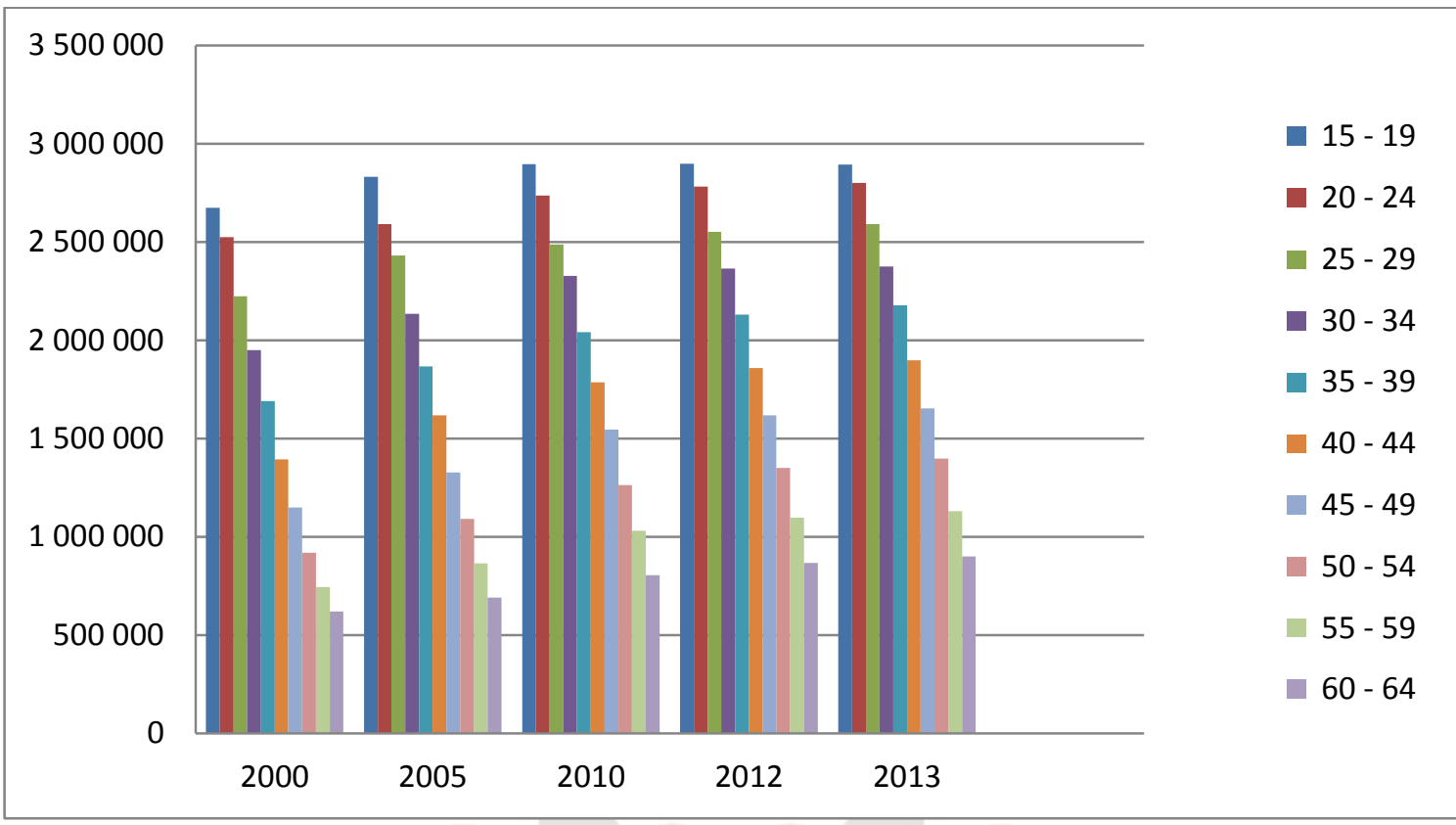

Fuente: Instituto Nacional de Estadística e Informática - Encuesta Nacional de Hogares Elaboración Propia

Por otro Lado, La evolución de la Población Económicamente Activa (PEA) por grupos de edades, desde el año 2001 al año 2013, es la siguiente: de 14 años a 24 años presenta una variación de 1,4\%, pasando de 2771907 personas a 3156875 personas; de 25 años a 44 años presenta una variación de 18,5\%, pasando de 5965819 personas a 7566312 personas; y de 45 años a 65 años presenta una variación de $40 \%$, pasando de 2590867 personas a 4128481 personas.

La mayor variación se da en el tercer grupo de edad, lo cual en base a la figura anterior se observa que el aumento está comprendido entre los grupos de edades de 25 años a 50 años. A continuación se presenta la evolución de la PEA por grupos de edades. 
Figura 2.4

PEA ocupada según grupo de edades del año 2004 al año 2013 (en miles de personas)

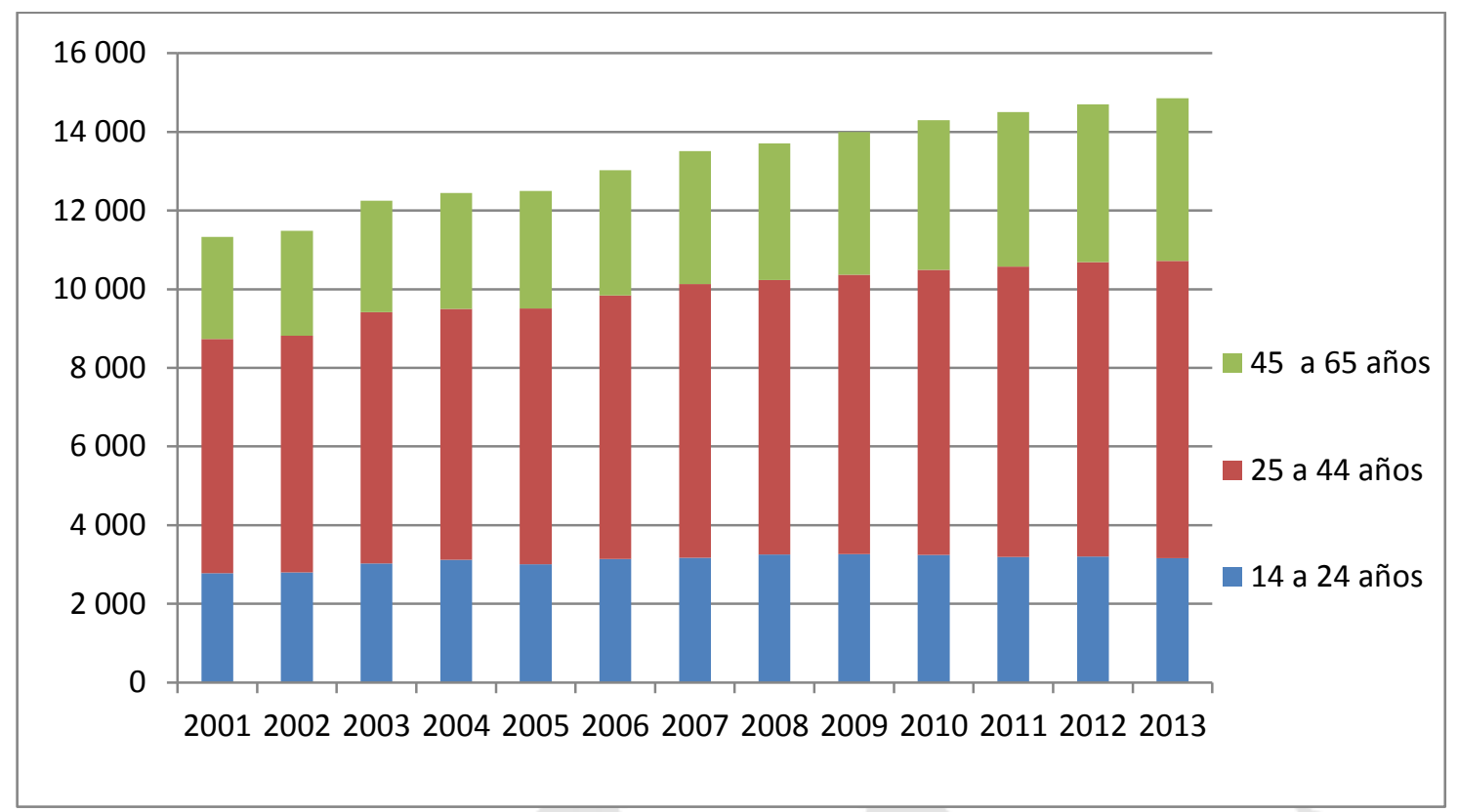

Fuente: Instituto Nacional de Estadística e Informática - Encuesta Nacional de Hogares Elaboración Propia

La evolución de la PEA, según nivel de educación, es importante para mostrar las variaciones en cada nivel de educación en el tiempo; para lo cual se analiza el porcentaje que representa cada nivel educativo respecto al total del año 2001 y del año 2013.

El porcentaje del nivel de educación respecto al total de personas para el año 2001 es: con nivel primario ${ }^{3}$ representa el 39,03\%, con nivel secundario representa el 40,02 \%, con nivel superior no universitario representa el 10,51\% y con nivel superior universitario representa el 10,45 \%. En tanto, para el año 2013 la distribución es la siguiente: con nivel primario representa el 26,86\%, con nivel secundario representa el 42,24\%, con nivel superior no universitario representa el $14,67 \%$ y con nivel superior universitario representa el $16,25 \%$.

La mayor variación de la distribución es en el nivel superior no universitario y el nivel superior universitario. En el año 2001, habían 1246020 personas con nivel superior no universitario y 1238707 con nivel superior universitario. Para el año 2013, habían

\footnotetext{
${ }^{3}$ El INEI incluye tanto al nivel primario como al inferior.
} 
2299303 personas con nivel superior no universitario y 2544878 con nivel superior universitario, representando un aumento del $85 \%$ y $105 \%$ respectivamente.

El aumento de las personas de la PEA en el nivel educativo superior, tanto universitario como no universitario, se puede explicar por el crecimiento económico, una mayor inversión en capital humano, la mayor inversión privada y la generación de empleo, el mercado demanda de empleados calificados o especializados. Asimismo, también es importante mencionar el aumento de instituciones educativas, que permite el acceso a este nivel educativo.

A continuación se muestra la evolución de la distribución de la PEA según el nivel de educación, desde el año 2001 al año 2013.

\section{Figura 2.5}

Distribución de la PEA ocupada según niveles de educación del año 2001 al año 2013

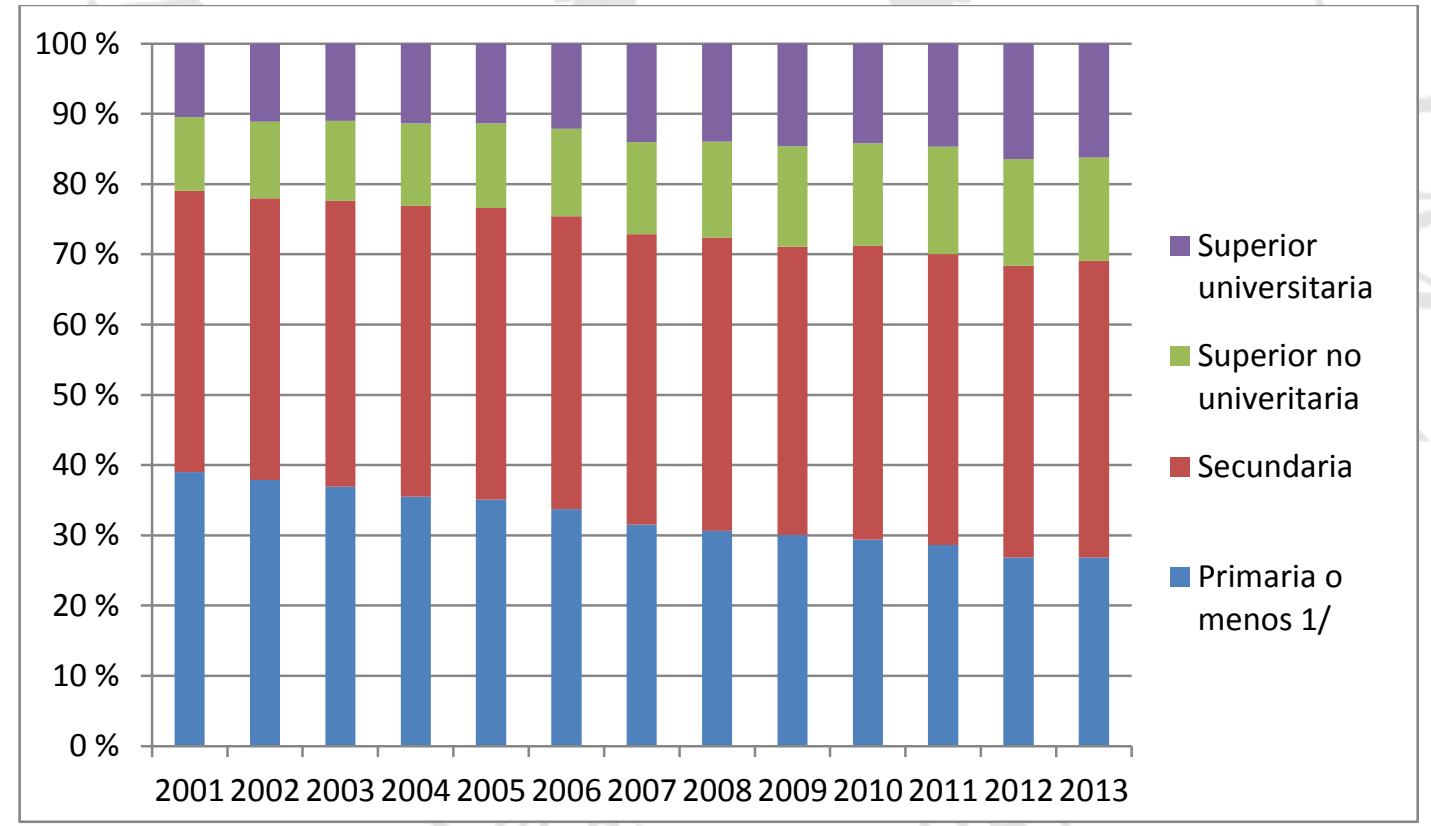

Fuente: Instituto Nacional de Estadística e Informática - Encuesta Nacional de Hogares Elaboración Propia 


\subsection{Educación}

A un mayor nivel educativo alcanzado se espera obtener un mayor nivel de ingresos; no obstante, cursar un nivel educativo no solo depende de la persona sino también de factores ajenos a cada nivel educativo que son oportunidades o limitantes. Mediante la educación es que se acortan las brechas iniciales y a su vez aumentan sus libertades.

La educación a nivel primario y nivel secundario es de carácter obligatorio para cursar la educación superior en el Perú. El estado ha logrado mejorar la cobertura y en menor grado la calidad educativa en el nivel primario y nivel secundario, mediante mayor inversión en educación y políticas sociales. Sin embargo, La educación superior es la más importante para el crecimiento económico, que se contrapone con el menor porcentaje de la población que accede a este nivel reflejado en el número de años promedio por grupos de edades.

Los años de educación promedio para el año 2005, según grupos de edades son los siguientes: en el grupo de edad de " 15 a 19 años" es de 9,2 años, en el grupo de edad de "20 a 29 años" es de 10,6 años, en el grupo de edad de "30 a 39 años" es de 10 años, en el grupo de edad de " 40 a 49 años" es de 9,5 años, en el grupo de edad de "50 a 59" años es de 8,5 años, y en el grupo de edad de "60 a más años" es de 7 años.

En tanto, los años de educación promedio para el año 2013 son: en el grupo de edad de "15 a 19 años" es de 9,8 años, en el grupo de edad de "20 a 29 años" es de 11,6 años, en el grupo de edad de "30 a 39 años" es de 10,4 años, en el grupo de edad de “40 a 49 años" es de 9,9 años, en el grupo de edad de "50 a 59 años" es de 9,3 años, y en el grupo de edad de" 60 a más años" es de 7,7 años.

La evolución del año 2005 al año 2013 muestra un incremento en el promedio de años de educación en cada grupo de edad analizado; esto puede estar relacionado al nivel educativo exigido dentro del mercado laboral, así como por efectos del crecimiento económico.

En la siguiente figura se muestra la evolución del promedio de años de estudio por grupos de edades del año 2005 al año 2013. 
Figura 2.6

Promedio de años de educación de la población de 15 años a más, por grupos de edades, del año 2005 al año 2013

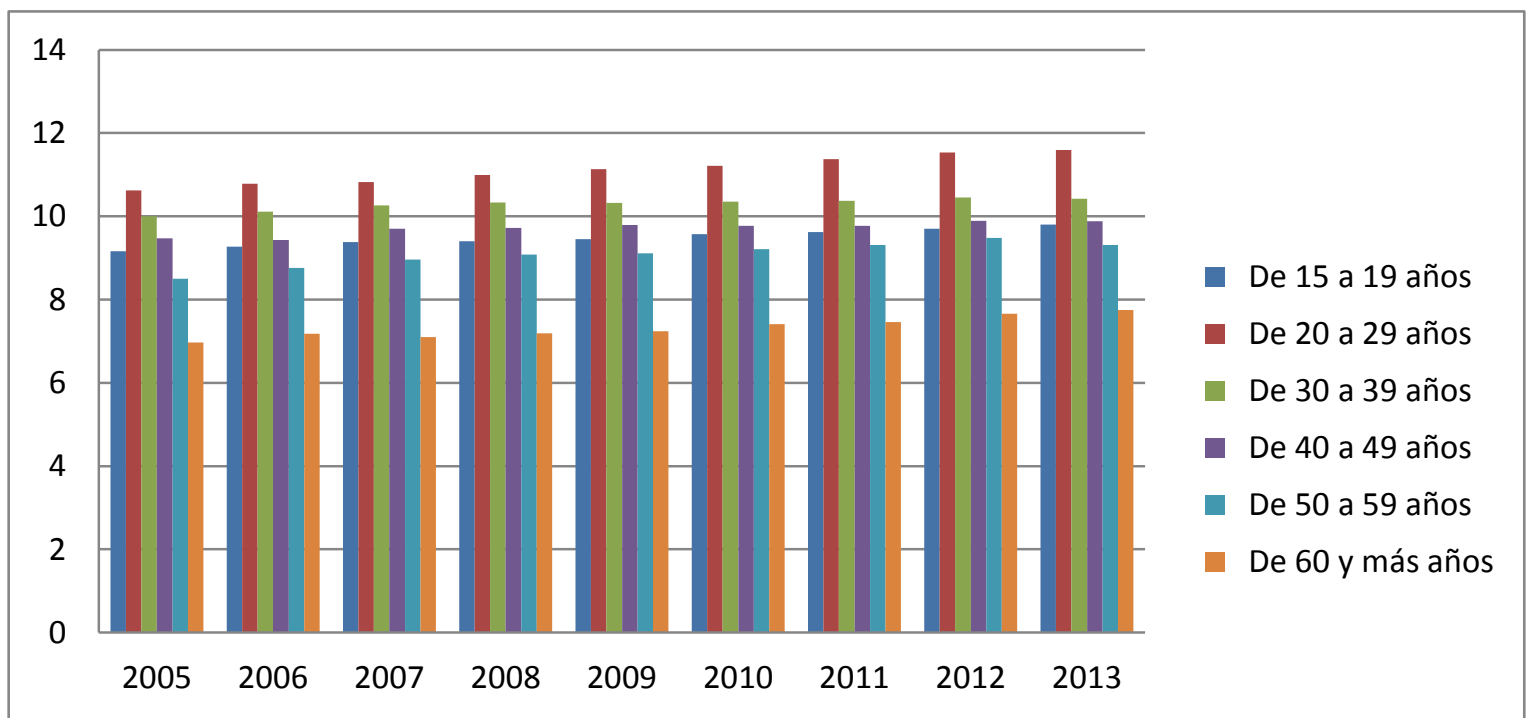

Fuente: Instituto Nacional de Estadística e Informática: Estimaciones y Proyecciones de Población, 1950 2050. Boletín de Análisis Demográfico No 36.

Elaboración Propia

En el año 2005, los promedios de los años de estudio son: 9,5 años para el total de la población, 10,8 años para Lima Metropolitana y 8,9 años para el resto del país. En tanto, para el año 2013, los promedios de los años de estudio son: 10,1 años para el total de la población, 11,1 años para Lima Metropolitana y 9,5 años para el resto del país.

El promedio de los años de estudio, diferenciándose en: el total de la población, en Lima metropolitana y en el resto del país, muestra que se ha incrementado del año 2005 al año 2013

A continuación se muestra la evolución de los promedios de los años de estudio, desde el año 2005 al año 2013; el incremento del promedio de años de estudio en Lima Metropolitana no se refleja en el total, toda vez que la población de Lima metropolitana representa aproximadamente un tercio de la población total. 


\section{Figura 2.7}

Promedio de años de educación alcanzado por la población de 15 años a más, según la residencia del año 2005 al año 2013

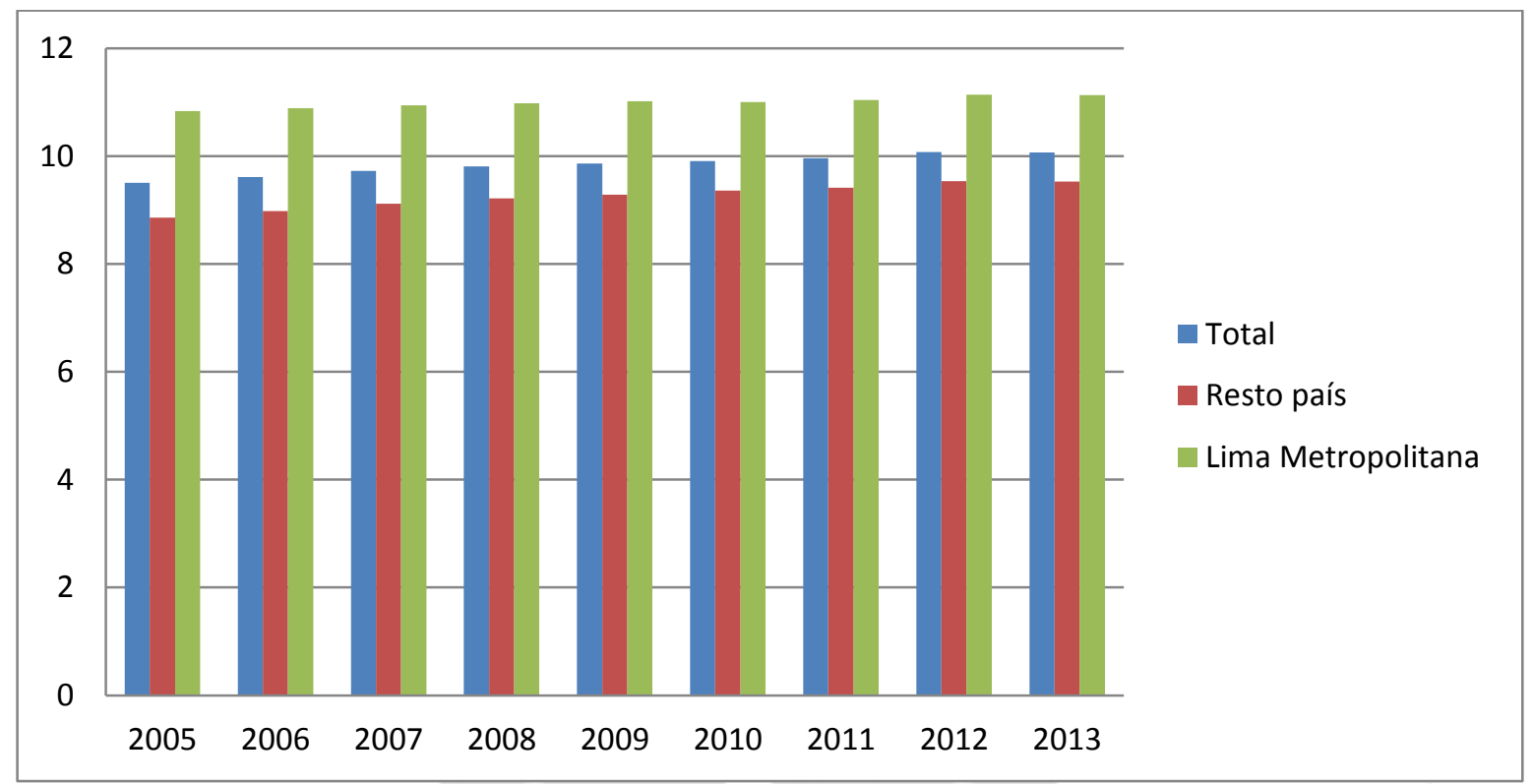

Fuente: Instituto Nacional de Estadística e Informática: Estimaciones y Proyecciones de Población, 1950 2050. Boletín de Análisis Demográfico N³6.

Elaboración Propia

\subsection{Estado civil o conyugal}

De inicio se presume que una persona casada o conviviente tiene una mayor participación en la actividad económica, de su ingreso depende la manutención de su familia, por lo tanto, las personas tienden a tener un nivel de ingreso superior.

El estado civil o conyugal de las personas está enfocado a determinar la situación de las persona respecto a sus relaciones de familia, siendo las siguientes: casado(a), conviviente, separado(a), viudo(a) y divorciado(a). La variación de estados civiles o conyugales, entre el año 2007 y el año 2013, es referencial para comprobar las variaciones del Censo de 1993.

Los datos del estado civil de las personas para el año $2007^{4}$ se distribuyen de la siguiente manera: un $39,0 \%$ de personas solteras, un $28,6 \%$ de personas casadas, un

\footnotetext{
${ }^{4}$ Se obtienen del Censo 2007.
} 
24,6 \% de personas convivientes. Asimismo, un 0,5\% de personas divorciadas, un 3,4\% de personas separadas y un $3,9 \%$ de personas viudas.

Los datos del estado civil de las personas para el año $2013^{5}$ se distribuyen de la siguiente manera: un $37,4 \%$ de personas solteras, un $28,1 \%$ de personas casadas, un $21,7 \%$ de personas convivientes. Asimismo, un 0,4\% de personas divorciadas, un $7 \%$ de personas separadas y un $5,3 \%$ de personas viudas.

La mayor variación en la distribución de estado civil o conyugal, entre el año 2007 y el año 2013, es para el estado civil de conviviente y el estado civil de separado(a).

En la siguiente figura se muestra la evolución en la distribución de los estados civiles o conyugales con la información del censo del año 1993 y 2007, y de la Enaho 2013.

\section{Figura 2.8}

Distribución de la población según el estado civil o conyugal, del año 1993, el año 2007 y el año 2013

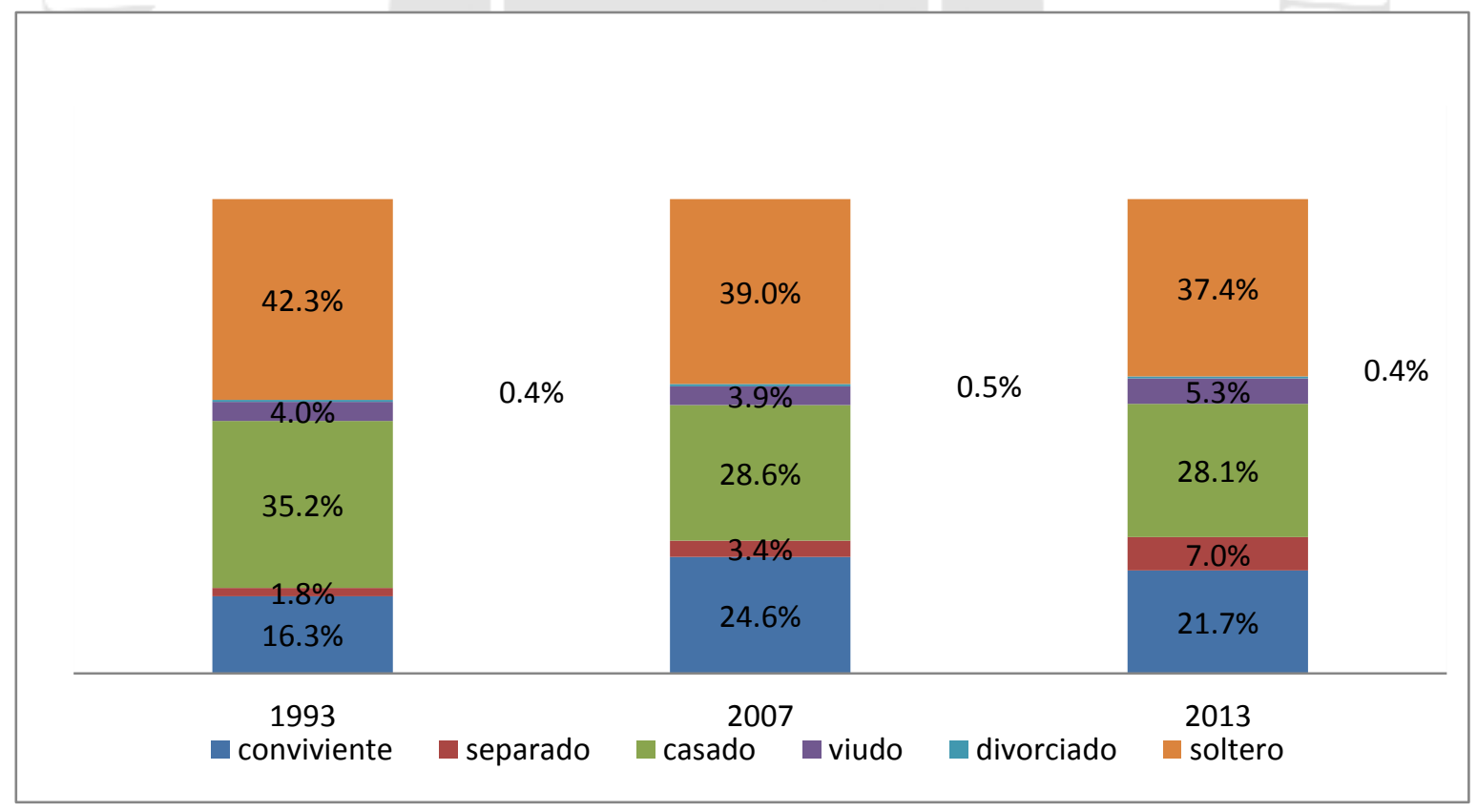

Fuente: Instituto Nacional de Estadística e Informática: Censo 2007, Enaho 2013. Elaboración Propia

\footnotetext{
${ }^{5}$ Se obtienen de la Enaho 2013.
} 


\subsection{Distribución de la población}

En la distribución entre hombres y mujeres, entre el año 2000 y el año 2013, se muestra un crecimiento casi constante en ambos sexos. Un crecimiento del 17,11\% en hombres y un 17,45\% en mujeres, siendo la población al año 2013 unos 15271062 hombres y unas 15204082 mujeres.

La relación Mujer/Hombre refleja un aumento, pasando de un 0,9927 en el año 2000, a un 0,9956 en el año 2013.

En la siguiente figura se muestra la evolución de la población según el sexo desde el año 2000 al año 2013.

Figura 2.9

Población total, según sexo del año 2000 al año 2013

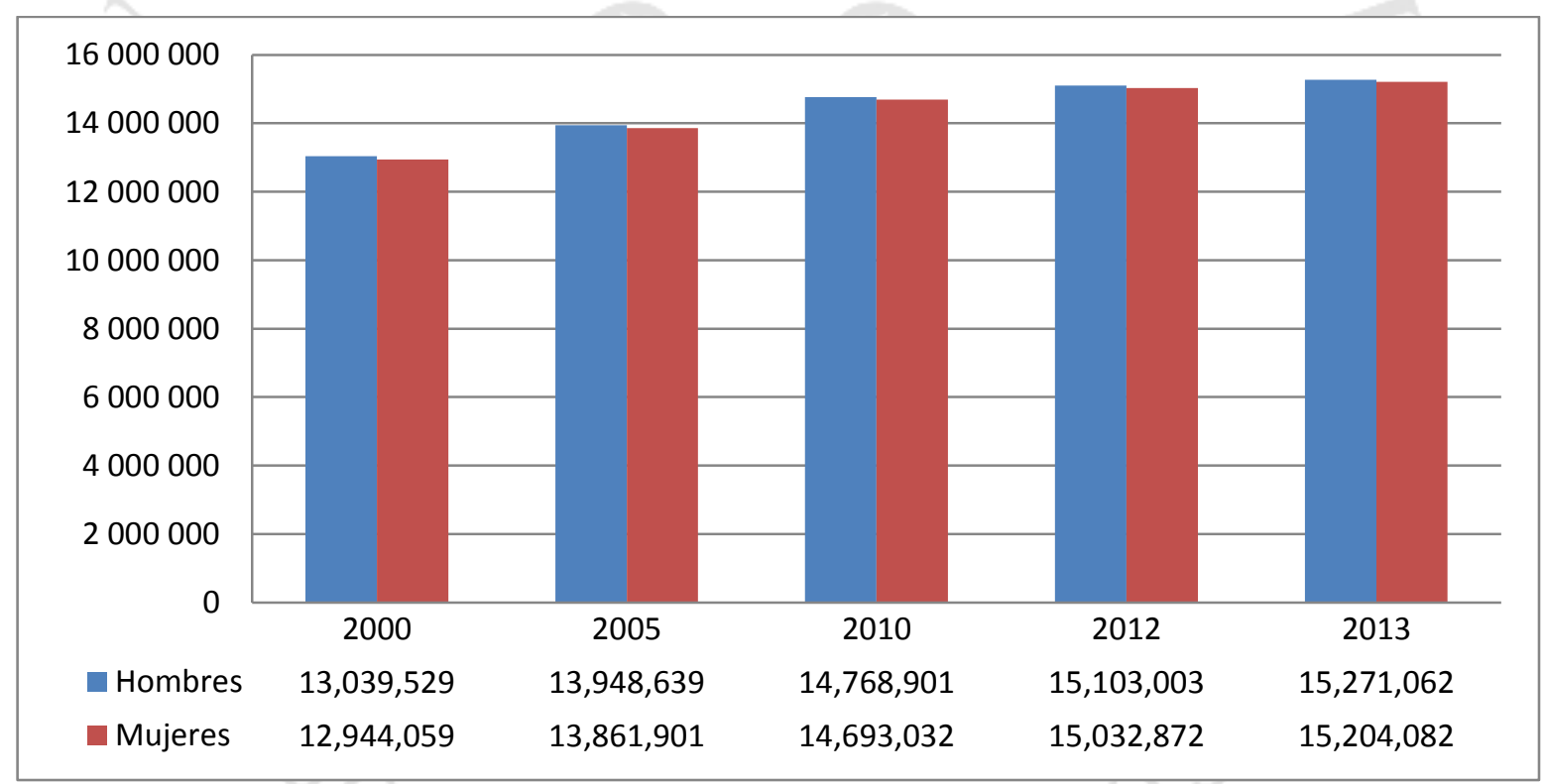

Fuente: Instituto Nacional de Estadística e Informática: Estimaciones y Proyecciones de Población, 1950 2050. Boletín de Análisis Demográfico N³6.

Elaboración Propia

En tanto la distribución de la población por género, distribuido por grupo de edad, muestra un incremento constante en cada grupo de edad. El incremento principal en ambos sexos está comprendido en la población de 15 años a 40 años. 
En la siguiente figura se muestra la evolución de la población de hombres según el grupo de edad, desde el año 2000 al año 2013.

Figura 2.10

Población de hombres según grupo de edades del año 2000 al año 2013

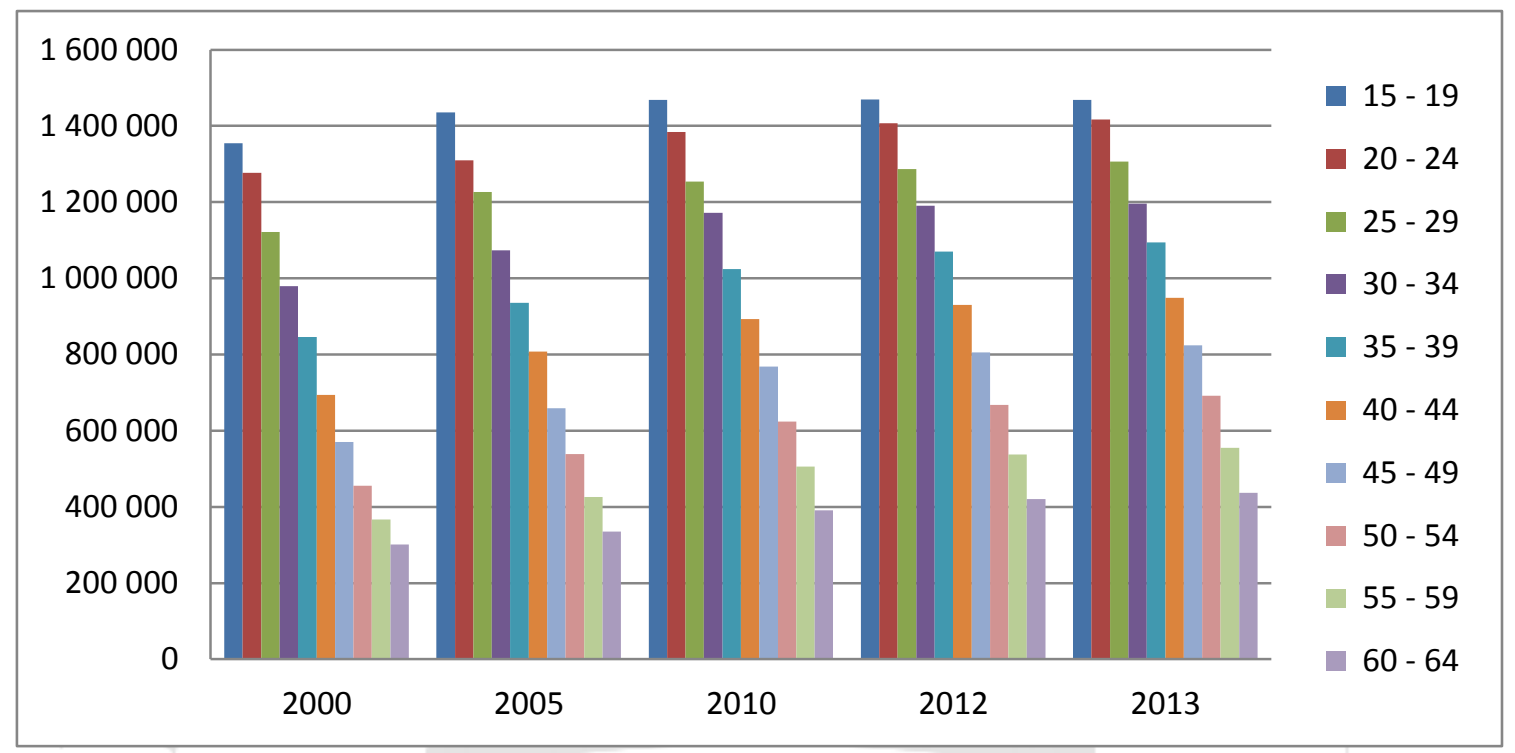

Fuente: Instituto Nacional de Estadística e Informática: Estimaciones y Proyecciones de Población, 1950 2050. Boletín de Análisis Demográfico N³6.

Elaboración Propia

En la siguiente figura se muestra la evolución de la población de mujeres según el grupo de edad, desde el año 2000 al año 2013. 
Figura 2.11

Población de mujeres según grupo de edades del año 2000 al año 2013

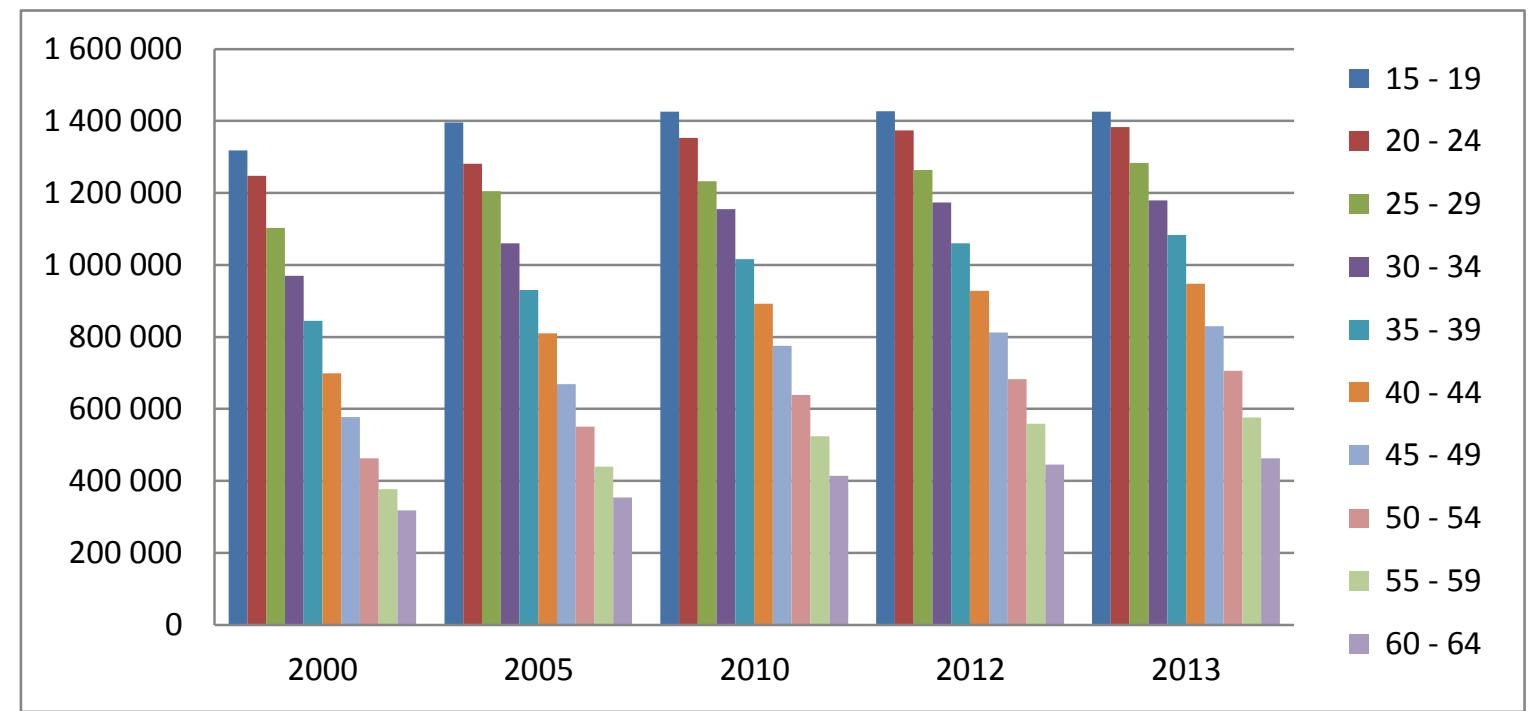

Fuente: Instituto Nacional de Estadística e Informática: Estimaciones y Proyecciones de Población, 1950 2050. Boletín de Análisis Demográfico N³6.

Elaboración Propia

El nivel de educación alcanzado, para hombres de 25 años a más, distribuidos en el año 2005, es el siguiente: sin nivel o nivel inicial el 3,3\%, con nivel primaria 30,3\% con nivel secundario el 40,0 \%, con nivel superior no universitario $11,9 \%$ y con superior universitario el 14,5 \%. En tanto para el año 2013: sin nivel o inicial el 2,4 \%, con nivel primaria $24,9 \%$ con nivel secundario el $40,8 \%$, con nivel superior no universitario $14,3 \%$ y con nivel superior universitario el $17,7 \%$.

Se muestra que los porcentajes de sin nivel o nivel inicial y de nivel primario han disminuido. Por otro lado los porcentajes de con nivel superior no universitario y con superior universitario han aumentado, manteniéndose constante el nivel secundario. En el nivel inicial y primario, las variaciones se explican desde las políticas de estado en relación a la educación escolar universal, dentro del Plan Bicentenario, la cobertura ha mejorado. En tanto el aumento del nivel superior no universitario y el nivel superior universitario, están relacionadas al crecimiento económico y la demanda del mercado laboral.

En la siguiente figura se muestra la distribución del nivel de educación alcanzado, para hombres de 25 años a más, del año 2005 al año 2013. 
Figura 2.12

Nivel de educación alcanzado por hombres de 25 años a más, en porcentajes, para el año 2005 y el año 2013

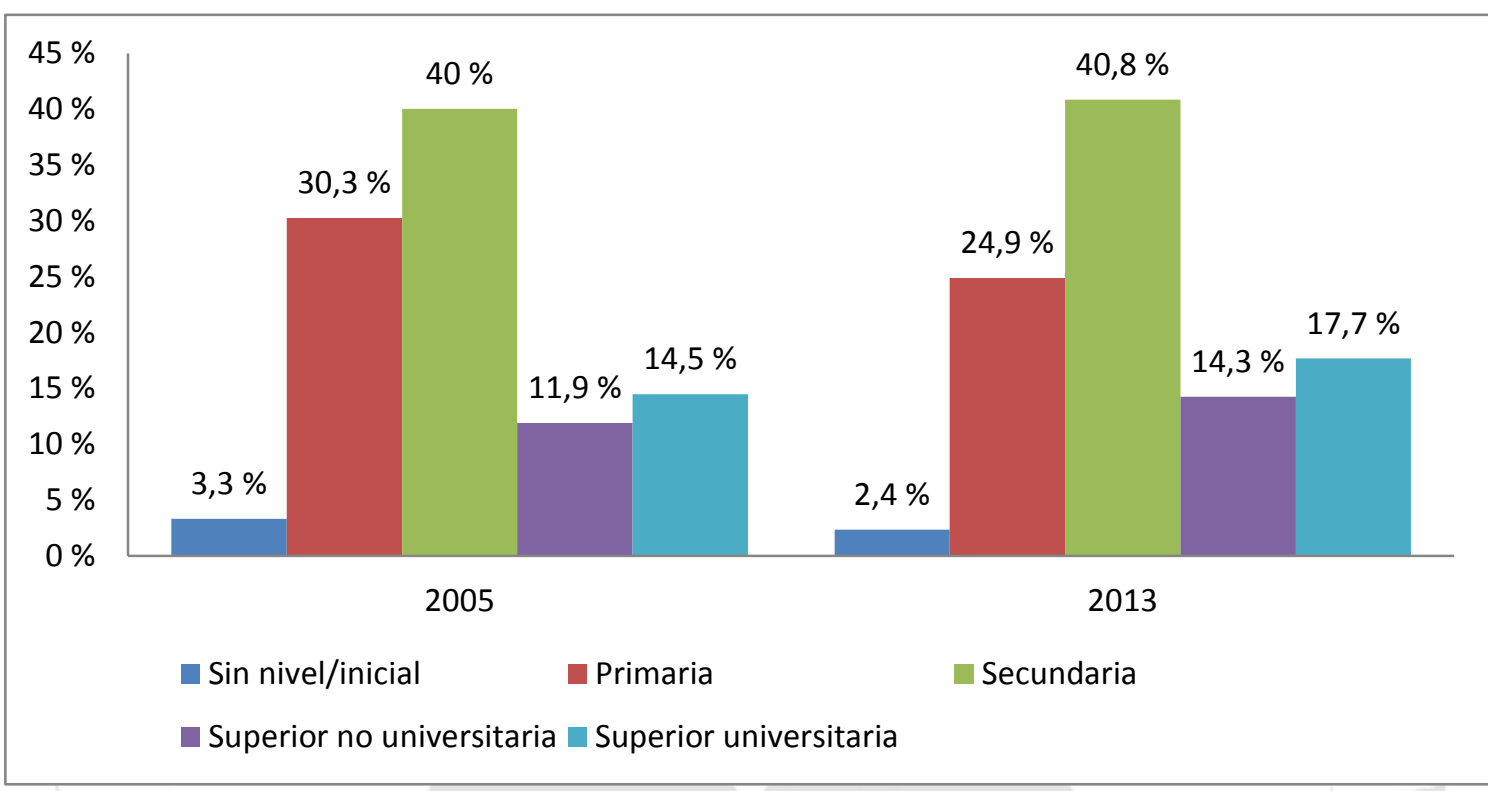

Fuente: Instituto Nacional de Estadística e Informática - Encuesta Nacional de Hogares Elaboración Propia

El nivel de educación alcanzado, para mujeres de 25 años a más, distribuidos en el año 2005, es el siguiente: sin nivel o nivel inicial el $13,1 \%$, con nivel primaria $32,6 \%$ con nivel secundario el $31,3 \%$, con nivel superior no universitario $12 \%$ y con superior universitario el 11,1 \%. En tanto para el año 2013: sin nivel o inicial el 9,2 \%, con nivel primaria $29,7 \%$ con nivel secundario el $32,5 \%$, con nivel superior no universitario $14,2 \%$ y con nivel superior universitario el 14,3\%.

Se muestra que el porcentaje de sin nivel o nivel inicial ha disminuido en mayor proporción; asimismo, el porcentaje de nivel primario ha disminuido. Por otro lado el porcentaje de con nivel superior no universitario y con superior universitario han aumentado, manteniéndose constante en el nivel secundario. Las variaciones muestran que hay mejoras en los niveles de educación para las mujeres, en el nivel inicial y primario, las variaciones se explican desde las políticas de estado en relación a la educación escolar universal y el acceso igualitario, dentro del Plan Bicentenario, la cobertura y la igualdad han mejorado. 
En la siguiente figura se muestra la distribución del nivel de educación alcanzado, para mujeres de 25 años a más, para el año 2005 y el año 2013.

Figura 2.13

Nivel de educación alcanzado por mujeres de 25 años a más, en porcentajes, para el año 2005 y el año 2013

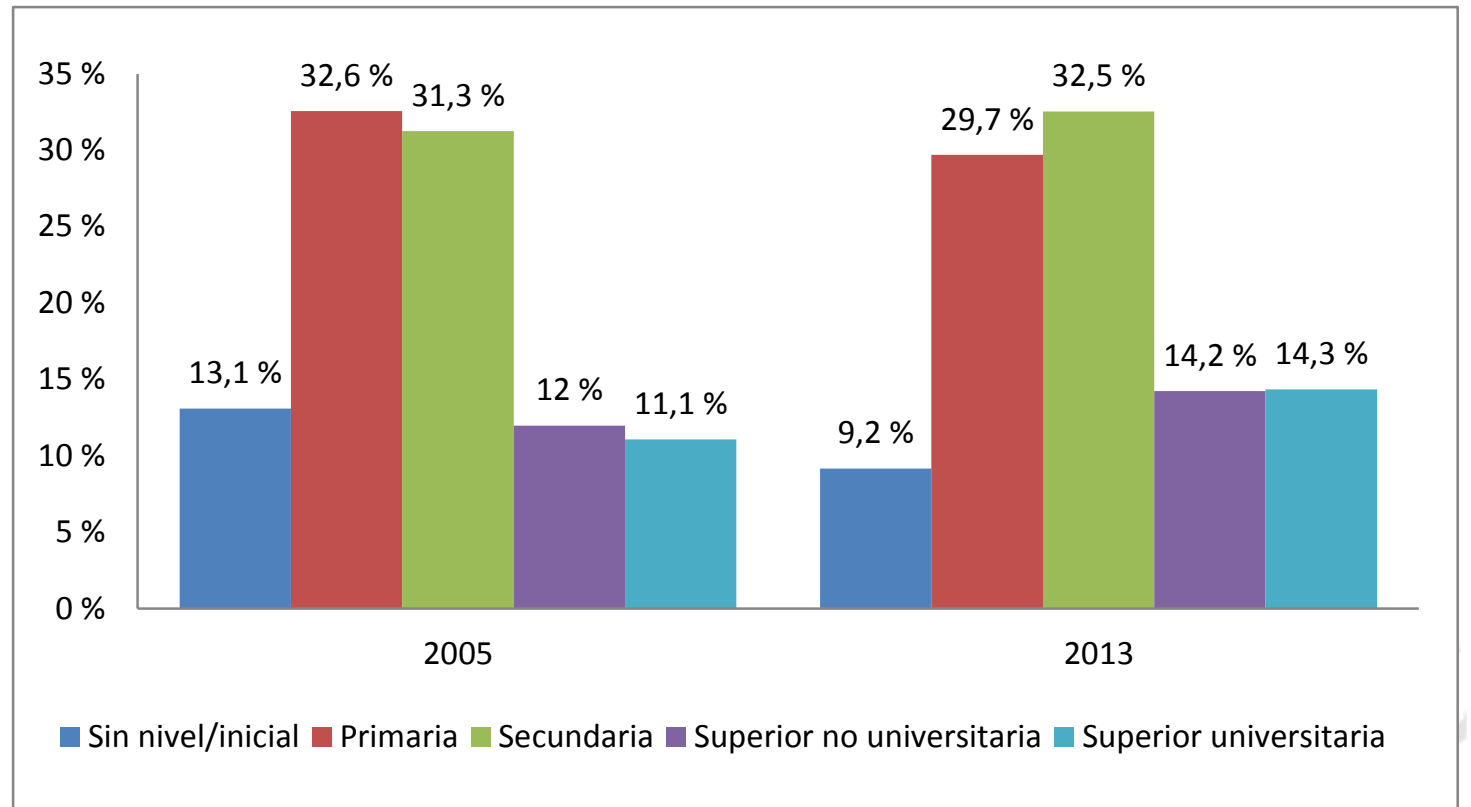

Fuente: Instituto Nacional de Estadística e Informática - Encuesta Nacional de Hogares Elaboración Propia

\subsection{Empleo}

El porcentaje de personas dependientes, a un empleo o trabajo, es alrededor del 52,0\% para el total de la PEA del año 2013. Al realizar una comparación de las variaciones del año 2001 al año 2013, se registra un incremento de $27 \%$ en personas empleadoras o patronos, un incremento de $24 \%$ en trabajadores independientes, un incremento de $67 \%$ en personas empleadas, y un incremento de $46 \%$ en obreros.

En el año 2001, el número de personas empleadoras o patronos era de 603 297, de trabajadores independientes era 4359 954, de personas empleadas era 2403390 y el de obreros era 2233 746. En tanto al año 2013, el número de personas empleadoras o patronos era de 768 020, de trabajadores independientes era 5413655 , de personas empleadas era 4024763 y el de obreros era 3252298. 
El incremento del empleo formal mejorará la participación de las personas en la economía nacional; y a su vez le permite tener mayores beneficios del crecimiento económico, a través de mayores retornos al capital humano, y un mejor acceso a la protección social y la salud.

El crecimiento económico impulsado por un mayor número de inversiones privadas y públicas, promovidas por el estado, genera que se mejore el mercado de factores, en especial es necesario un capital humano más productivo. Por otro lado, el crecimiento económico sostenido genera mayor empleo.

En la siguiente figura se muestra la evolución de la PEA ocupada, según categorías de ocupación, del año 2004 al año 2013.

\section{Figura 2.14}

Evolución de la PEA ocupada según categoría de ocupación del año 2004 al año 2013 (en miles de personas)

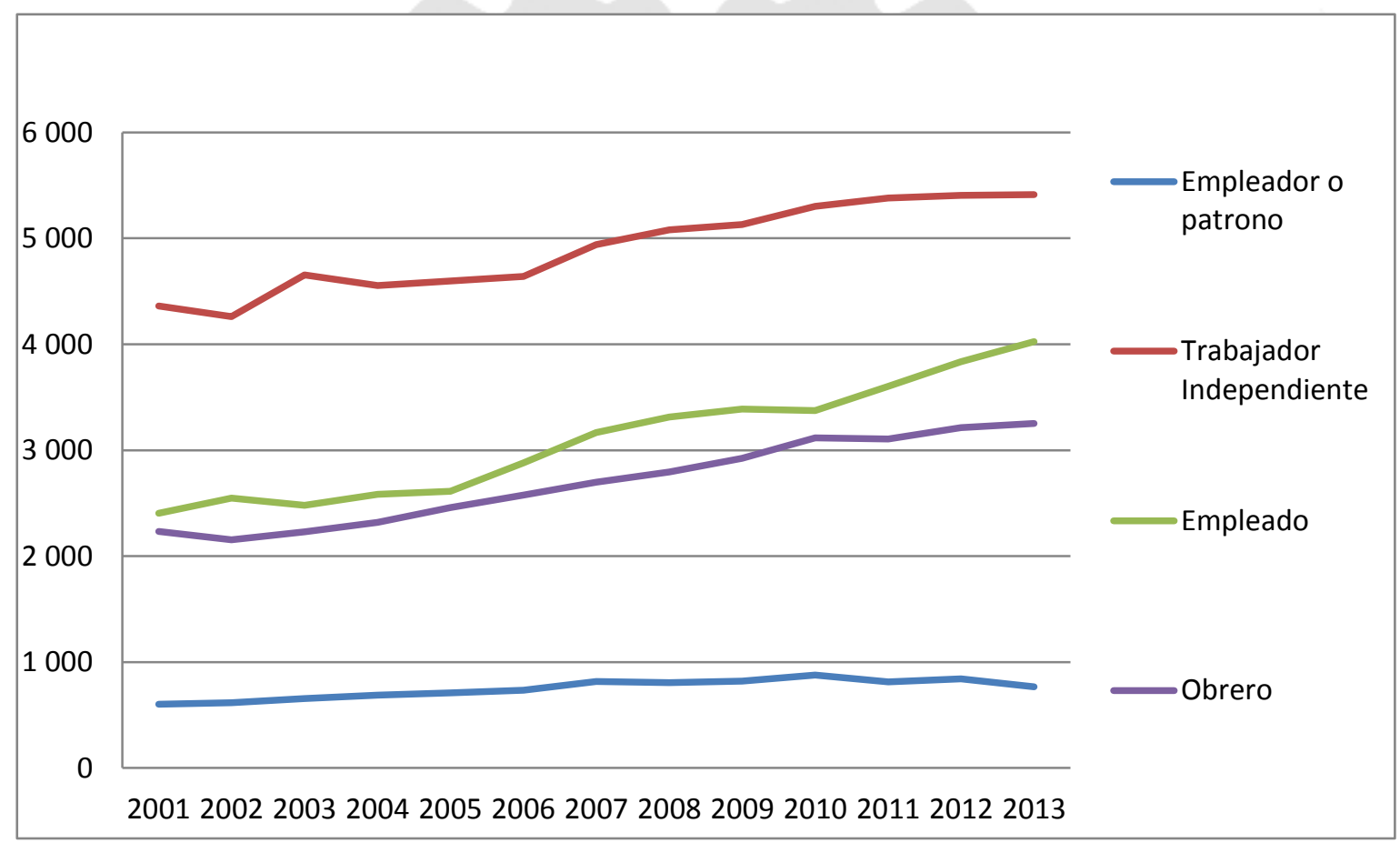

Fuente: Instituto Nacional de Estadística e Informática - Encuesta Nacional de Hogares Elaboración Propia 


\subsection{Educación pública y privada}

Entre el año 2004 y el año 2013, la matricula total en la educación primaria registra una disminución de un 15,86 \%; no obstante, la matricula en la educación primaria privada registra un incremento de 43,52 \%, de 592754 estudiantes matriculados en el 2004 a 850734 estudiantes matriculados en el 2013.

El descenso de la matriculas de nivel primario, se explica por la distribución demográfica por grupos de edades, ya que en este nivel la educación es universal. Otro aspecto importante es la tendencia a una mayor demanda de educación inicial privada.

En la siguiente figura se observa la evolución de las matriculas en educación primaria, del año 2004 al año 2013.

Figura 2.15

Evolución de las matriculas en educación primaria, del año 2004 al año 2013 (en miles de personas)

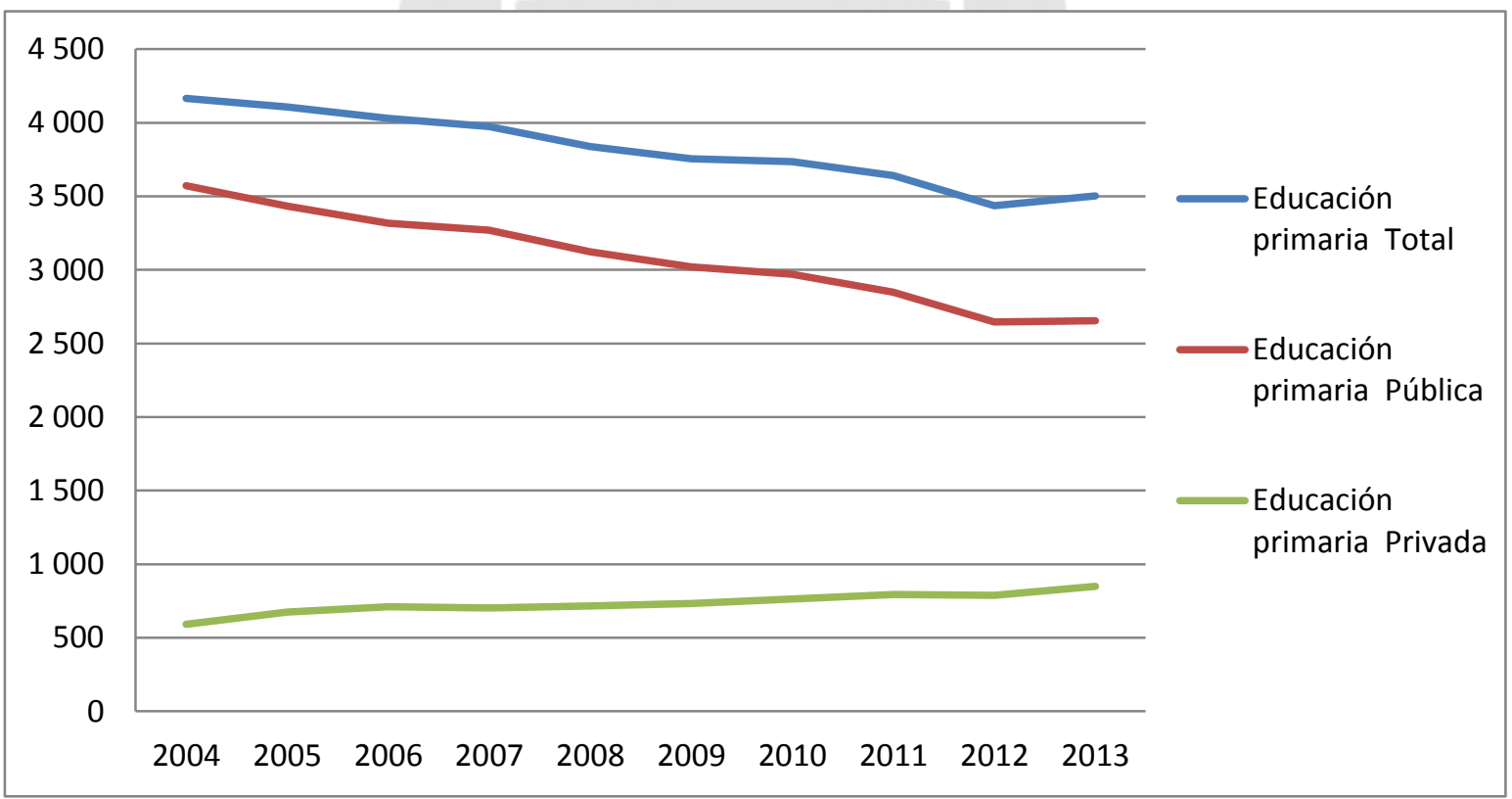

Fuente: Instituto Nacional de Estadística e Informática - Encuesta Nacional de Hogares.

Ministerio de Educación - Censo Escolar 2013

Elaboración Propia

En tanto para el mismo periodo, la educación secundaria registra una disminución de 3,89\% en la matricula total en la educación secundaria. Asimismo, la matricula en la 
educación secundaria privada registra un incremento de 36,77\%, de 461047 estudiantes matriculados en el 2004 a 630567 estudiantes matriculados en el 2013.

El descenso de la matriculas de nivel secundario es menor al nivel previo, el mismo que se explica por la distribución demográfica por grupos de edades. Por otro lado, es importante mencionar la tendencia de una mayor demanda de educación secundaria privada, relacionada a una mejor calidad en la educación.

En la siguiente figura se observa la evolución de las matriculas en educación primaria, del año 2004 al año 2013.

\section{Figura 2.16}

Evolución de las matriculas en educación secundaria, del año 2004 al año 2013 (en miles de personas)

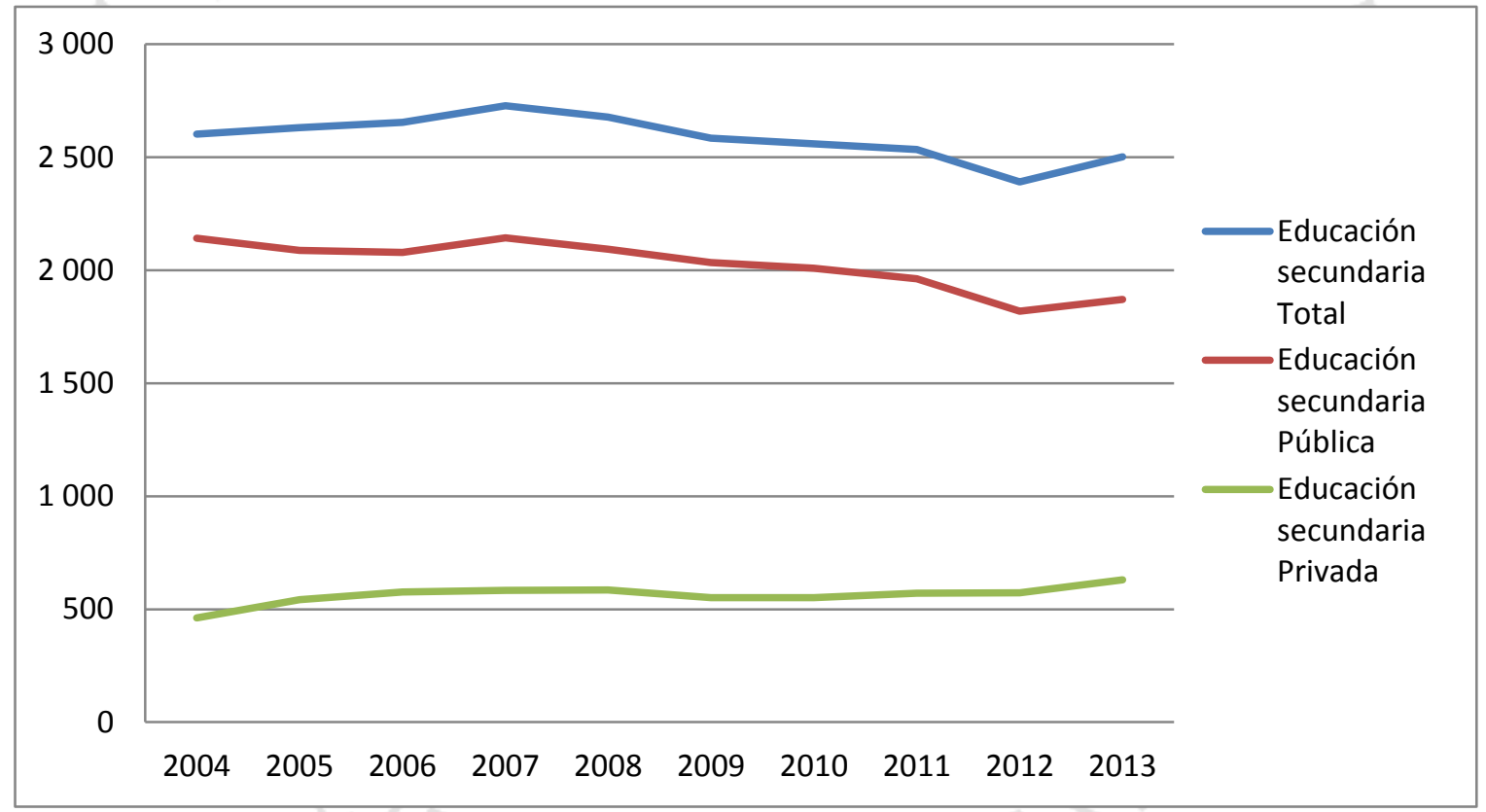

Fuente: Instituto Nacional de Estadística e Informática - Encuesta Nacional de Hogares.

Ministerio de Educación - Censo Escolar 2013

Elaboración Propia

En tanto para la educación no universitaria ${ }^{6}$, se registra una disminución de 0,21\% para la matricula total en la educación no universitaria.

\footnotetext{
${ }^{6}$ Incluye la formación magisterial, la educación tecnología y la educación artística.
} 
Cabe resaltar que se registra una disminución de $23,57 \%$ en la matricula en educación no universitaria publica de 195963 matriculados en el 2004 a 126847 en el 2013; en cambio la matricula en la educación no universitaria privada muestra un incremento de 17,04 \% de unos 224771 matriculados el año 2004 a unos 263079 matriculados el año 2013.

En la siguiente figura se observa la evolución de las matriculas en educación no universitaria, del año 2004 al año 2013.

Figura 2.17

Evolución de las matriculas en educación no universitaria, del año 2004 al año 2013 (en miles de personas)

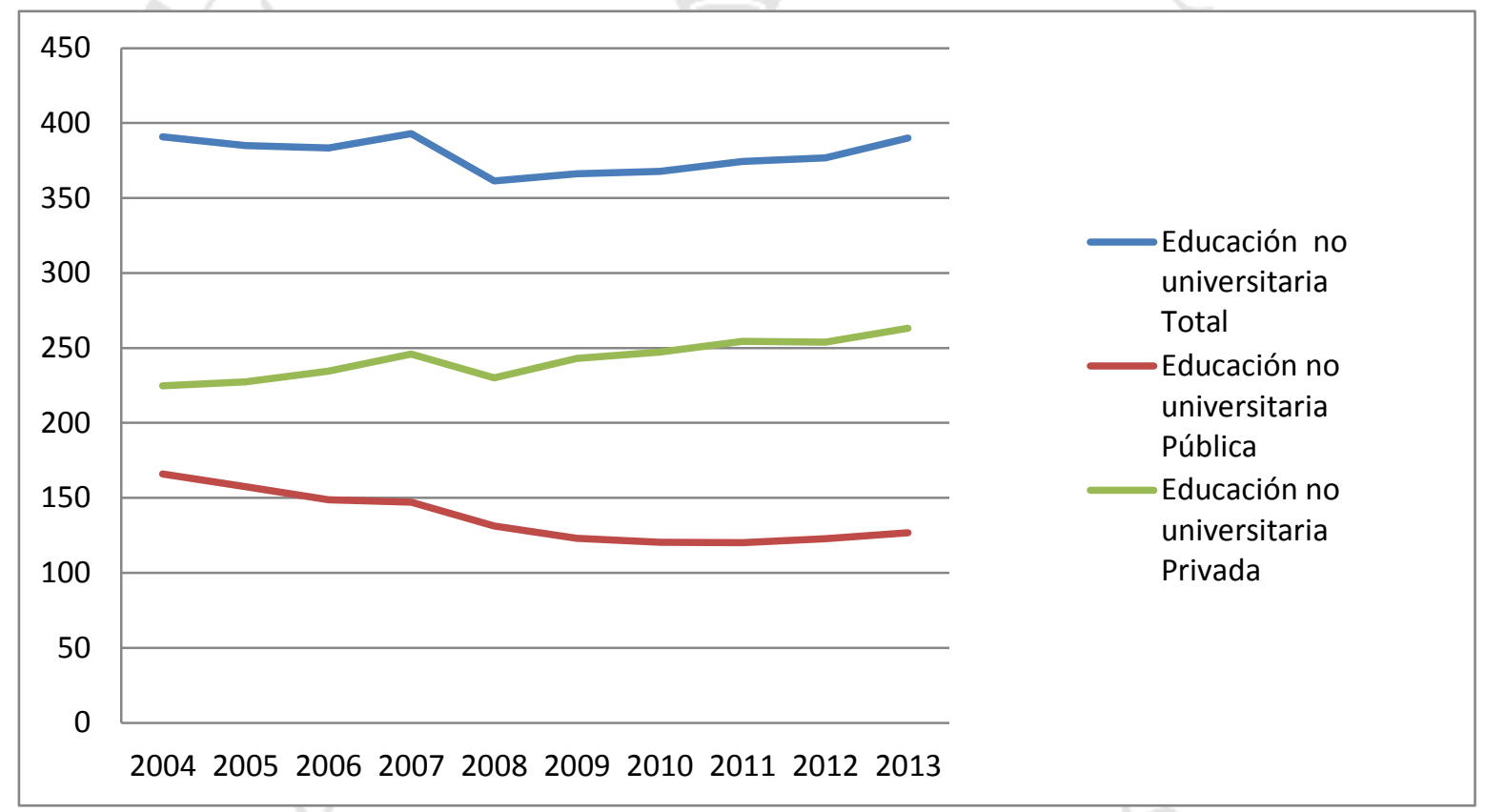

Fuente: Instituto Nacional de Estadística e Informática - Encuesta Nacional de Hogares. Ministerio de Educación - Censo Escolar 2013.

Elaboración Propia

Por último la matricula total en educación universitaria, entre el año 2004 y el año 2013, registra una incremento de un 95,59 \%; no obstante, la matricula en la educación universitaria publica solo registra un incremento de 13,61\%, de unos 282485 estudiantes matriculados en el 2004 a unos 320930 estudiantes matriculados en el 2013; contra un incremento de educación universitaria privada de 195,15\% de unos 232632 matriculados el año 2004 a unos 686607 matriculados el año 2013. 
El incremento de matrículas en el nivel universitario privado, como en el no universitario privado, están relacionados a la demanda del mercado laboral, las personas deciden cursar estudios superiores para mejorar sus ingresos, obtener beneficios del crecimiento económico. La menor variación en la educación universitaria pública es por el lado de la oferta educativa, casi constante, de las instituciones públicas y no es por una falta de demanda.

En la siguiente figura se observa la evolución de las matriculas en educación universitaria, del año 2004 al año 2013.

\section{Figura 2.18}

Evolución de las matriculas en educación universitaria, del año 2004 al año 2013 (en miles de personas)

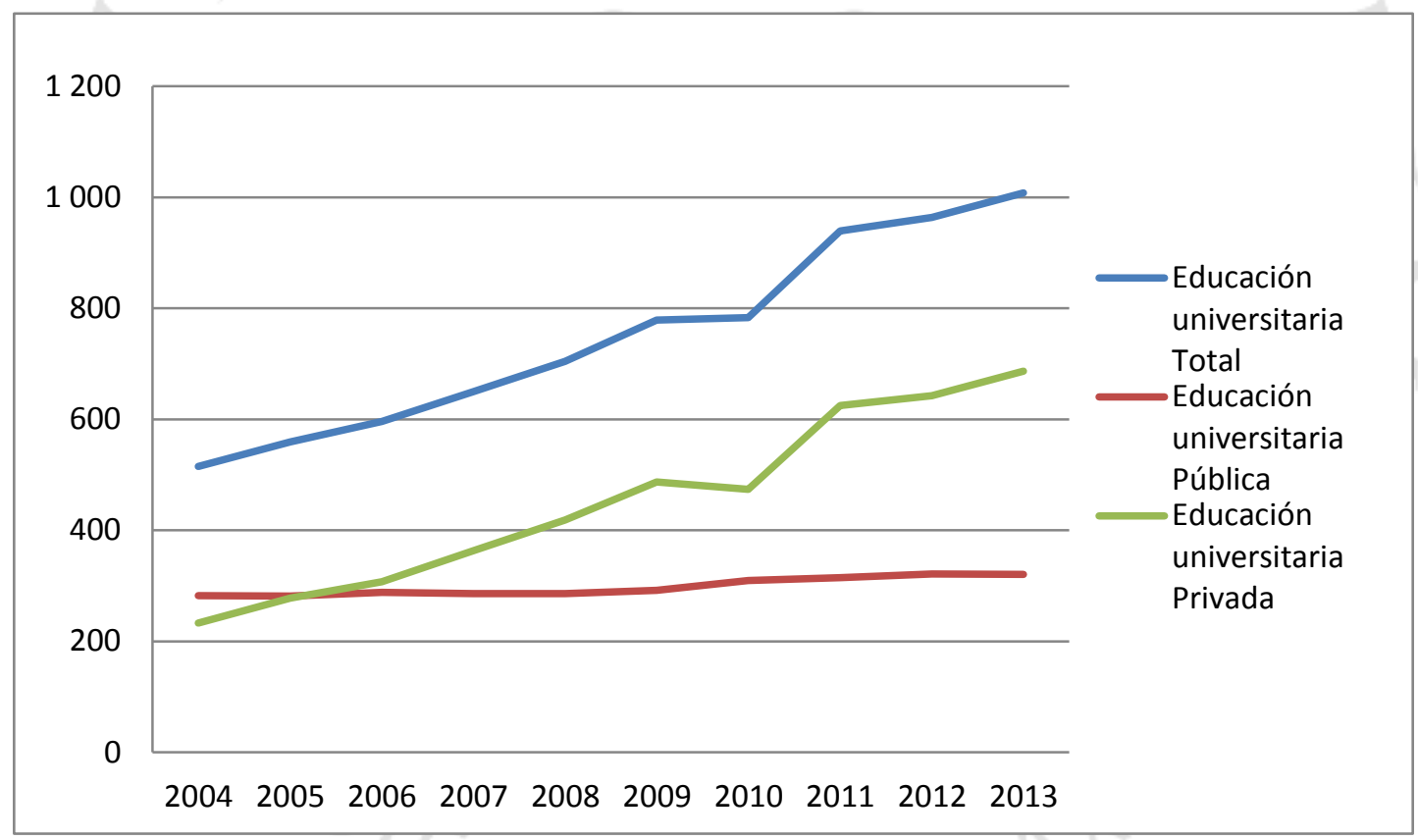

Fuente: Instituto Nacional de Estadística e Informática - Encuesta Nacional de Hogares Ministerio de Educación - Censo Escolar 2013. Elaboración Propia

El número de graduados del nivel superior universitario en el año 2004 es de 57923 , de los cuales 22330 corresponden a universidades privadas y 35593 a universidades públicas. Para el año 2013, se observa que el número de graduados es de 
109 234, de los cuales 60411 corresponde a universidades privadas y $48 \quad 823$ a universidades públicas.

Se observa que en el año 2012, egresan un mayor número de estudiantes de las universidades privadas. Asimismo el ritmo de crecimiento anual es de un $12 \%$ para los egresados de universidades privadas, frente a un $4 \%$ universidades públicas. La variación del 2013 respecto al 2004 muestra un incremento de $171 \%$ de graduados en universidades privadas frente a un $37 \%$ de universidades públicas.

Figura 2.19

Numero de graduados en el nivel superior universitario, del año 2004 al año 2013

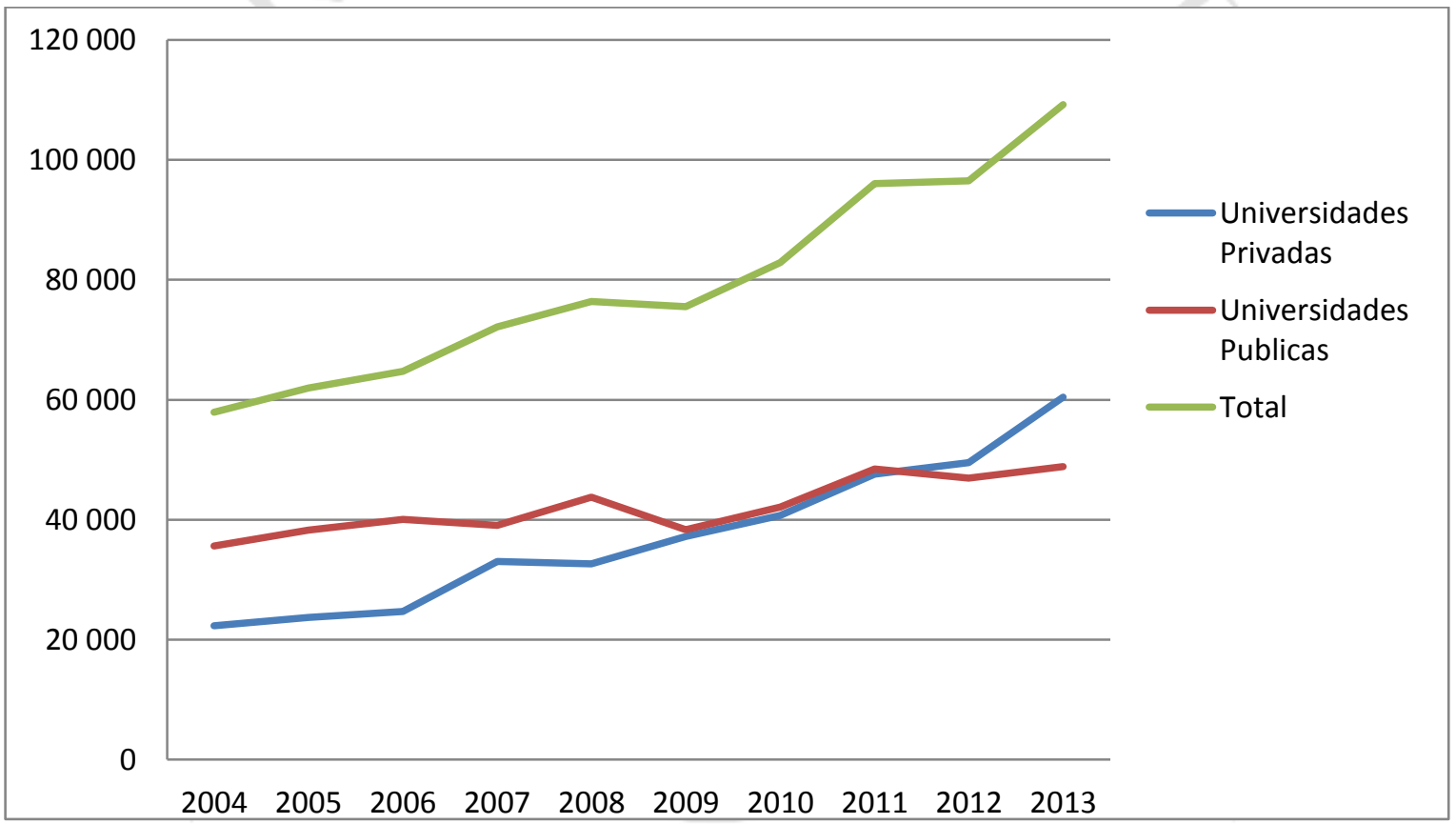

Fuente: Instituto Nacional de Estadística e Informática - Encuesta Nacional de Hogares Elaboración Propia

\subsection{Salud}

El porcentaje de personas de la población total que se ve afectado por una enfermedad crónica se ha incrementado, en el ámbito urbano de un 21,93\% en el 2005 a un 37,74 \%; en tanto, para Lima Metropolitana se registra un incremento mayor, de un 22,40 \% el año 2005 a un 40,80\% el año 2013. 
Se considera un problema de salud crónico al padecimiento de enfermedades crónicas como artritis, hipertensión, asma, reumatismo, diabetes, tuberculosis, VIH o malestares crónicos.

La salud de las personas es importante en el ámbito laboral, ya que el poseer una enfermedad limita el desarrollo potencial de sus actividades, asimismo se podría ver reflejado en un menor nivel de ingresos.

Figura 2.20

Porcentaje de la población que presentó algún problema de salud crónico, del año 2005 al año 2013

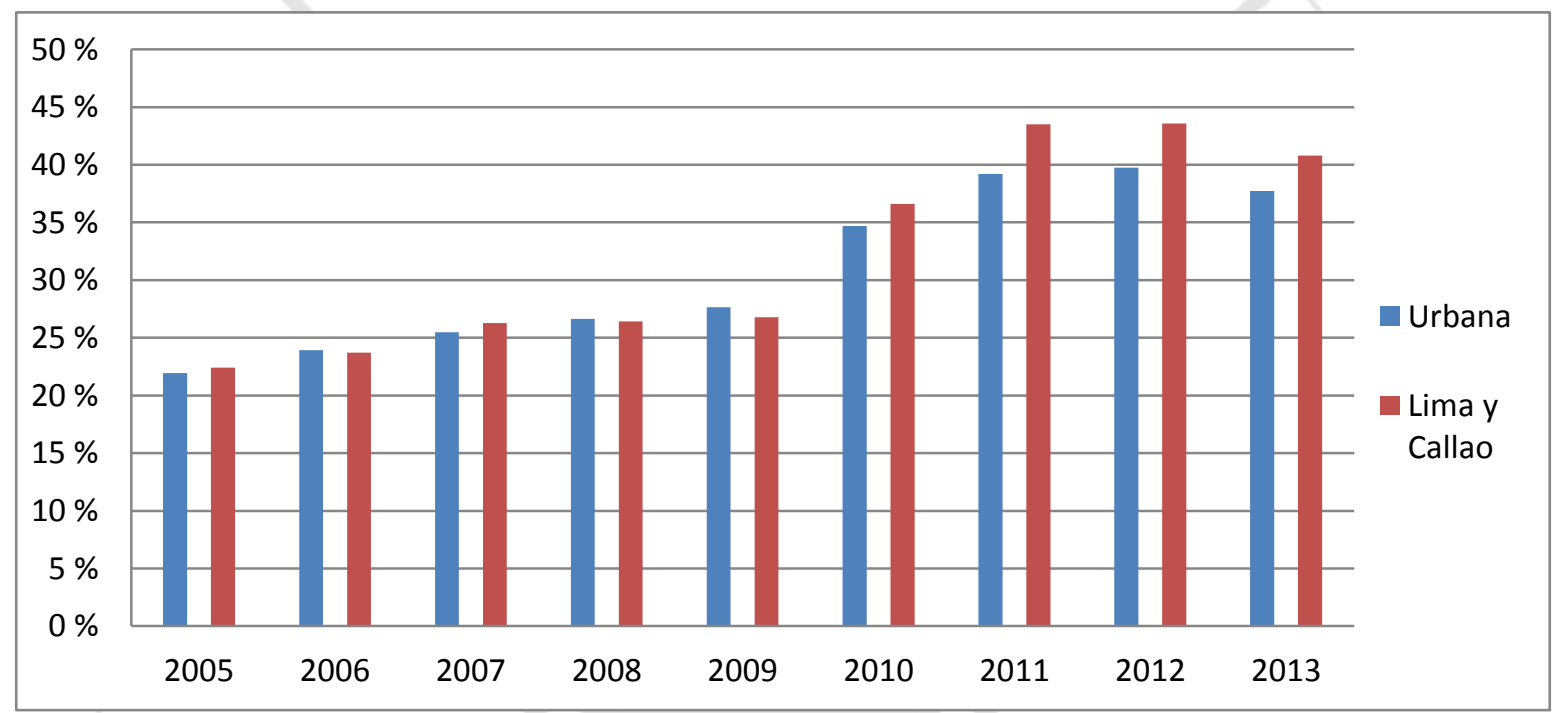

Fuente: Instituto Nacional de Estadística e Informática - Encuesta Nacional de Hogares Elaboración Propia

El desarrollo del presente capítulo se enfocó en dar una referencia global de la evolución de las variables relacionadas al ingreso, y a la vez sirve de partida para la explicación de las presuntas relaciones de algunas variables con el nivel de ingreso. En el siguiente capítulo se plantearan las relaciones esperadas de las variables dentro de una ecuación de ingreso. 


\section{CAPÍTULO III: CONTRASTACIÓN DE HIPÓTESIS}

En este capítulo se desarrolla la parte analítica de la investigación siguiendo con el objetivo general que es el estimar las tasas de retorno a la educación para cada nivel educativo en el año 2013, basándose en el modelo de Mincer y agregando otras variables explicativas al modelo. Mediante la elaboración de modelos econométricos de corte transversal ${ }^{7}$, con los datos tomados de la Enaho 2013 y se asume la variable educación como exógena ${ }^{8}$.

\footnotetext{
${ }^{7}$ Los modelos planteados se estimaran por MCO.

${ }^{8} \mathrm{Al}$ ser la variable educación endógena sería necesario utilizar variables instrumentales para reemplazarla; para la presente investigación se asume, necesariamente, como exógena.
} 


\subsection{Metodología aplicada}

Se utilizan los datos anualizados de la Encuesta Nacional de Hogares 2013 (Enaho 2013). El INEI recolecta la información anualmente desde el año 2004, esta información identifica la situación socio-económica de una muestra representativa de hogares en el Perú, tanto de áreas rurales y urbanas.

El tamaño anual de la muestra del Enaho 2013 es de 31690 viviendas particulares, correspondiendo 19410 viviendas al área urbana y 12280 viviendas al área rural. Asimismo, el tamaño de la muestra panel es de 8808 viviendas particulares mientras que el tamaño de la muestra no panel es de 22882 viviendas particulares. La muestra de conglomerados en el ámbito nacional es de 4 770, correspondiendo 3235 conglomerados al área urbana y 1535 conglomerados al área rural. Con respecto al tamaño de la muestra panel es de 1331 conglomerados mientras que el tamaño de la muestra no panel es de 3439 conglomerados. (Ver Anexo 1)

La base de datos de la encuesta está dividida por módulos, se tomaran variables del segundo módulo "Características de los miembros del hogar", del tercer módulo "Educación", del cuarto módulo "Salud", y del quinto modulo "Empleo e Ingresos". Del segundo módulo se utilizaran las variables del sexo, la edad y estado civil de la persona; en tanto del tercer módulo se utilizaran las variables del nivel educativo obtenido de las personas, y el tipo educación recibida; del cuarto módulo se obtendrá una variable del estado de salud actual y del quinto módulo se utilizaran la variable del ingreso y las horas de trabajo, tipo de empleo, y el sector económico de la ocupación. Se utilizaran las variables mencionadas y las variables encadenadas de la Enaho para la construcción de otras variables. (Ver Anexo 2)

El estudio se realiza para 32148 observaciones, esta se obtienen de realizar los filtros respectivos. Un primer filtro mediante la variable estrato de la Enaho 2013, para limitar el análisis al área urbana ${ }^{9}$; seguidamente, se realiza un segundo filtro de la edad (de 14 a 65 años); luego, se realiza un tercer filtro para la variable ingreso, aquellas que presenten un ingreso anual mayor a 0.00 soles; asimismo, se filtran y eliminan las observaciones con datos perdidos para las demás variables.

\footnotetext{
${ }^{9}$ La variable estrato, los valores de 1 a 5 son del Área Urbana, según Plan de Recodificaciones Enaho 2013, Mtpe (Ver Anexo 3).
} 
En la siguiente tabla se resume las variables a utilizar:

Tabla 3.1

\section{Definición de variables}

\begin{tabular}{|c|c|c|c|c|}
\hline Notación & Definición & Medición & Unidades & Fuente \\
\hline SALHR & Ingreso por hora. & $\begin{array}{l}\text { Cuantitativa } \\
\text { Continua }\end{array}$ & $\begin{array}{l}\text { Nuevos } \\
\text { soles. }\end{array}$ & Enaho 2013 \\
\hline EDAD & Edad en años. & $\begin{array}{l}\text { Cuantitativa } \\
\text { Continua }\end{array}$ & Años & Enaho 2013 \\
\hline EDUC & Número de años de Educación. & $\begin{array}{l}\text { Cuantitativa } \\
\text { Continua }\end{array}$ & Años & Enaho 2013 \\
\hline EXPER & Años de Experiencia Potencial. & $\begin{array}{l}\text { Cuantitativa } \\
\text { Continua }\end{array}$ & Años & - \\
\hline EXPER2 & Años de Experiencia al cuadrado. & $\begin{array}{l}\text { Cuantitativa } \\
\text { Continua }\end{array}$ & Años & - \\
\hline MATRIM & 1 si está casado o convive, 0 otro. & $\begin{array}{l}\text { Cualitativa } \\
\text { Dicotómica }\end{array}$ & 1,0 & Enaho 2013 \\
\hline MUJER & 1 si es mujer, 0 otro. & $\begin{array}{l}\text { Cualitativa } \\
\text { Dicotómica }\end{array}$ & 1,0 & Enaho 2013 \\
\hline LIMA & 1 si Reside en Lima Metropolitana, 0 otro. & $\begin{array}{l}\text { Cualitativa } \\
\text { Dicotómica }\end{array}$ & 1,0 & Enaho 2013 \\
\hline DEPEND & 1 si es trabajador dependiente, 0 otro. & $\begin{array}{l}\text { Cualitativa } \\
\text { Dicotómica }\end{array}$ & 1,0 & Enaho 2013 \\
\hline FENO & $\begin{array}{l}1 \text { si por sus antepasados se considera } \\
\text { Mestizo o blanco, } 0 \text { otro. }\end{array}$ & $\begin{array}{l}\text { Cualitativa } \\
\text { Dicotómica }\end{array}$ & 1,0 & Enaho 2013 \\
\hline
\end{tabular}

(continúa) 
(continuación)

\begin{tabular}{|c|c|c|c|c|}
\hline Notación & Definición & Medición & Unidades & Fuente \\
\hline PRIV & $\begin{array}{l}1 \text { si asistió Institución Educativa no estatal, } \\
0 \text { otro. }\end{array}$ & $\begin{array}{l}\text { Cualitativa } \\
\text { Dicotómica }\end{array}$ & 1,0 & Enaho 2013 \\
\hline SALUD & 1 si no sufre enfermedad crónica, 0 otro. & $\begin{array}{l}\text { Cualitativa } \\
\text { Dicotómica }\end{array}$ & 1,0 & Enaho 2013 \\
\hline PRIM & Número de años de Educación Primaria. & $\begin{array}{l}\text { Cuantitativa } \\
\text { Continua }\end{array}$ & Años & Enaho 2013 \\
\hline SECU & Número de años de Educación Secundaria & $\begin{array}{l}\text { Cuantitativa } \\
\text { Continua }\end{array}$ & Años & Enaho 2013 \\
\hline SUPE & Número de años de Educación Superior. & $\begin{array}{l}\text { Cuantitativa } \\
\text { Continua }\end{array}$ & Años & Enaho 2013 \\
\hline $\mathrm{S} / \mathrm{E}$ & 1 Sin Estudios, 0 otro. & $\begin{array}{l}\text { Cualitativa } \\
\text { Dicotómica }\end{array}$ & 1,0 & Enaho 2013 \\
\hline PRIM_I & 1 con Primaria Incompleta, 0 otro. & $\begin{array}{l}\text { Cualitativa } \\
\text { Dicotómica }\end{array}$ & 1,0 & Enaho 2013 \\
\hline PRIM_C & 1 con Primaria Completa, 0 otro. & $\begin{array}{l}\text { Cualitativa } \\
\text { Dicotómica }\end{array}$ & 1,0 & Enaho 2013 \\
\hline SECU_I & 1 con Secundaria Incompleta, 0 otro. & $\begin{array}{l}\text { Cualitativa } \\
\text { Dicotómica }\end{array}$ & 1,0 & Enaho 2013 \\
\hline SECU_C & 1 con Secundaria Completa, 0 otro. & $\begin{array}{l}\text { Cualitativa } \\
\text { Dicotómica }\end{array}$ & 1,0 & Enaho 2013 \\
\hline SUPE_NU_I & $\begin{array}{l}1 \text { con Superior no universitaria incompleta, } \\
0 \text { otro. }\end{array}$ & \begin{tabular}{|l|} 
Cualitativa \\
Dicotómica
\end{tabular} & 1,0 & Enaho 2013 \\
\hline SUPE_NU_C & $\begin{array}{l}1 \text { con Superior no universitaria completa, } 0 \\
\text { otro. }\end{array}$ & $\begin{array}{l}\text { Cualitativa } \\
\text { Dicotómica }\end{array}$ & 1,0 & Enaho 2013 \\
\hline SUPE_U_I & $\begin{array}{l}1 \text { con Superior universitaria incompleta, } 0 \\
\text { otro. }\end{array}$ & $\begin{array}{l}\text { Cualitativa } \\
\text { Dicotómica }\end{array}$ & 1,0 & Enaho 2013 \\
\hline SUPE_U_C & $\begin{array}{l}1 \text { con Superior universitaria completa, } 0 \\
\text { otro. }\end{array}$ & $\begin{array}{l}\text { Cualitativa } \\
\text { Dicotómica } \\
\end{array}$ & 1,0 & Enaho 2013 \\
\hline SUPE_NU & $\begin{array}{l}\text { Número de años de Educación Superior no } \\
\text { universitaria }\end{array}$ & $\begin{array}{l}\text { Cuantitativa } \\
\text { Continua }\end{array}$ & Años & Enaho 2013 \\
\hline
\end{tabular}


(continuación)

\begin{tabular}{|l|l|l|c|c|}
\hline Notación & Definición & Medición & Unidades & Fuente \\
\hline SUPE_U & $\begin{array}{l}\text { Número de años de Educación Superior } \\
\text { universitaria }\end{array}$ & $\begin{array}{l}\text { Cuantitativa } \\
\text { Continua }\end{array}$ & Años & Enaho 2013 \\
\hline AGRA & 1 sector Agricultura, 0 otro. & $\begin{array}{l}\text { Cualitativa } \\
\text { Dicotómica }\end{array}$ & 1,0 & Enaho 2013 \\
\hline MINE & 1 sector Mineria, 0 otro. & $\begin{array}{l}\text { Cualitativa } \\
\text { Dicotómica }\end{array}$ & 1,0 & Enaho 2013 \\
\hline MANU & 1 sector Manufactura, 0 otro. & $\begin{array}{l}\text { Cualitativa } \\
\text { Dicotómica }\end{array}$ & 1,0 & Enaho 2013 \\
\hline CONS & 1 sector Construcción, 0 otro. & $\begin{array}{l}\text { Cualitativa } \\
\text { Dicotómica }\end{array}$ & 1,0 & Enaho 2013 \\
\hline COME & 1 sector Comercio, 0 otro. & $\begin{array}{l}\text { Cualitativa } \\
\text { Dicotómica }\end{array}$ & 1,0 & Enaho 2013 \\
\hline
\end{tabular}

Fuente: INEI, Enaho 2013, Mtpe ${ }^{10}$

Elaboración Propia

${ }^{10}$ Ver Anexo 2 


\subsection{Análisis descriptivo}

Se realiza una análisis descriptivo de las 32148 observaciones de la Enaho 2013 del presente estudio: la edad promedio es de 38,64 años, los años de educación en promedio son de 11,17 años, el 77,95 \% reside fuera de Lima Metropolitana, el 22,58 \% asistió a un instituto educativo privado en su último nivel educativo. De estos datos se resalta el promedio de 11,17 años de educación que se encuentra por encima de los 11 años, son los que normalmente se necesitan para cursar nivel primario y secundario.

En tanto según el sexo se distribuyen en $44,16 \%$ mujeres y 55,84\% hombres, del total de los 32148 personas un 56,6 \% declara tener un estado civil de casado o conviviente, el 67,46\% se considera mestizo o blanco y el 59,04\% manifiesta no tener una enfermedad crónica.

Asimismo el Ingreso mensual promedio es de 1336,49 soles, las horas trabajadas semanalmente en promedio son de 47,15 horas, el 58,93 \% declara ser un empleado dependiente.

Según los datos del INEI para el periodo 2013, el nivel de ingresos promedio para el área urbana general es de 1 317,20 nuevos soles y el promedio de años de estudio es de 10,7 años. $^{11}$

A continuación se resume el análisis en la siguiente tabla, en base a las 32148 observaciones:

\footnotetext{
${ }^{11}$ Incluye una mayor cantidad de observaciones de las 32148 observaciones del estudio, datos disponibles del 2004 al 2013.
} 


\section{Tabla 3.2}

Resumen estadístico de las 32148 observaciones

\begin{tabular}{|llr|}
\hline Edad promedio en años & & 38,64 \\
\hline Sexo, \% del total & mujeres & $44,16 \%$ \\
& hombres & $55,84 \%$ \\
\hline Residencia \% del total & Lima & $22,05 \%$ \\
& otra & $77,95 \%$ \\
\hline Educación promedio en años & & 11,17 \\
\hline Tipo Educación, \% del total & no estatal & $22,58 \%$ \\
& estatal & $77,42 \%$ \\
\hline Estado Civil, \% del total & casado o conviviente & $56,60 \%$ \\
& otro & $43,40 \%$ \\
\hline Ingreso promedio mensual & & S/1 336,49 \\
\hline Experiencia promedio en años & & 21,47 \\
\hline Tipo de Empleo, \% del total & dependiente & $58,93 \%$ \\
& otro & $41,07 \%$ \\
\hline Salud, \% del total & sano & $59,04 \%$ \\
& otro & $40,96 \%$ \\
& & \\
\hline
\end{tabular}

Fuente: Enaho 2013

Elaboración Propia

De las 32148 observaciones, según el nivel educativo cursado o en curso, se presenta: el $0,02 \%$ no ha cursado el primer nivel educativo; el 15,93\% tiene una educación primaria, siendo un 7,32 \% para el nivel primario incompleto y un 8,61\% para el nivel primario completo; el 42,55 \% tiene una educación secundaria, siendo un 13,90\% para el nivel secundario incompleto y un 28,65 \% para el nivel secundario completo; el $22,65 \%$ tiene una educación superior universitaria, siendo un 7,0 \% para el nivel superior universitario incompleto y un $15,25 \%$ para el nivel superior universitario completo; el 18,82\% tiene una educación superior no universitaria, siendo un 5,88 \% para el nivel superior no universitario incompleto y un $12,94 \%$ para el nivel superior no universitario completo; y un 2,79 \% cuenta con estudios de post grado. 
A continuación se presenta un resumen de la distribución en porcentajes para las 32148 observaciones según el nivel educativo para el año 2013.

Tabla 3.3.

Distribución del nivel educativo de las 32148 observaciones

\begin{tabular}{|llr|}
\hline Ningún & & $0,02 \%$ \\
\hline Primaria & incompleta & $7,32 \%$ \\
& completa & $8,61 \%$ \\
\cline { 2 - 3 } & sub total & $15,93 \%$ \\
\hline Secundaria & incompleta & $13,90 \%$ \\
& completa & $28,65 \%$ \\
\cline { 2 - 3 } & sub total & $42,55 \%$ \\
\hline Superior & incompleta & $7,40 \%$ \\
\multirow{3}{*}{ Universitaria } & completa & $15,25 \%$ \\
\cline { 2 - 3 } & sub total & $22,65 \%$ \\
\hline Superior & incompleta & $5,88 \%$ \\
\multirow{2}{*}{ no } & completa & $12,94 \%$ \\
\cline { 2 - 3 } Universitaria & sub total & $18,82 \%$ \\
\hline Post-Grado & & $2,79 \%$ \\
\hline Total & & $100,00 \%$ \\
\hline
\end{tabular}

Fuente: Enaho 2013

Elaboración Propia 


\subsection{Modelo econométrico}

En el Capítulo 1 se desarrolló el proceso de formulación del modelo de "Schooling, experience and earnings" de Jacob Mincer, siendo la base para el modelo econométrico. A continuación se plantea el modelo econométrico general:

$$
\operatorname{Ln}\left[\operatorname{SALHR}(\text { EDUC, EXPER) }]=\beta_{0}+\beta_{1} \text { EDUC }+\beta_{2} \text { EXPER }+\beta_{3} \text { EXPER }^{2}+\varepsilon\right.
$$

$$
\begin{aligned}
\text { SALHR = } & \text { El ingreso por hora de la persona. } \\
\text { EDUC = } & \text { Los años de estudio de la persona. } \\
\text { EXPER = } & \text { La experiencia potencial de la persona. ("Edad - "EDUC" - "6") } \\
\beta_{0}= & \text { Parámetro cuya estimación se aproximará al valor del logaritmo del } \\
& \text { ingreso de las personas que no estudiaron, siendo el signo esperado } \\
& \text { "positivo" } \\
= & \text { Parámetro o tasa de retorno de la inversión en educación, siendo el signo } \\
\beta_{1} & \text { esperado "positivo" } \\
\beta_{2} & \text { Parámetro de la relación existente de la experiencia potencial y los } \\
& \text { ingresos, siendo el signo esperado "positivo" } \\
\beta_{3}= & \text { Parámetro de la relación existente del cuadrado se la experiencia } \\
& \text { potencial y los ingresos, siendo el signo esperado "negativo" } \\
= & \text { Un término de error, que se supone de media de cero. }
\end{aligned}
$$

Del modelo general, se planteara un primer modelo similar al modelo propuesto por Yamada (2007) para poder comparar las tasas de retorno del año 2013, de ahí se propondrán otros modelos incorporando variables dummies buscando obtener un modelo más explicativo y con un mayor grado de análisis. Asimismo, se desagregaran los años de escolaridad bajo la metodología de Chiswick usada por Yamada (2007) y Sapelli (2009). ${ }^{12}$

\footnotetext{
${ }^{12}$ Metodología desarrollada por Chiswick (1997).
} 


\subsection{Análisis de los resultados}

Se plantea un primer modelo por MCO similar al expuesto por Yamada (2007) ${ }^{13}$ para analizar la evolución de la tasa de retorno para el año 2013, descrito a continuación:

$$
\begin{aligned}
\operatorname{Ln}[\text { SALH }]= & \beta_{0}+\beta_{1} \text { EDUC }+\beta_{2} \text { EXPER }+\beta_{3} \text { EXPER }^{2}+\beta_{4} \text { MATRIM }+\beta_{5} \text { MUJER }+ \\
& \beta_{6} \text { LIMA }+\beta_{7} \text { DEPEND }+\varepsilon
\end{aligned}
$$

SALHR: El ingreso por hora de la persona.

EDUC: Los años de estudio de la persona.

EXPER: La experiencia potencial de la persona en años. (“EDAD” - "EDUC" - "6”)

EXPER2: La experiencia potencial al cuadrado.

MATRIM: 1 = casado o conviviente, $0=$ otro.

MUJER: 1 = mujer, 0 = otro.

LIMA: 1 = reside en Lima Metropolitana; 0 = otro.

DEPEND: 1 = trabajador dependiente; $0=$ otro.

$\beta_{0}$ : Parámetro cuya estimación se aproximará al valor del logaritmo del ingreso de las personas que no estudiaron.

$\beta_{1}$ : Parámetro cuyo valor representa la tasa de retorno de la inversión en educación.

$\beta_{2 \text { y }} \beta_{3:}$ Parámetros que relacionan la experiencia con el ingreso.

$\beta_{4}, \beta_{5}, \beta_{6}, \beta_{7}$ : Parámetros que relacionan las variables dummies con el ingreso.

$\varepsilon$ : Perturbación aleatoria que recoge todas las causas que influyen en la determinación del ingreso de la persona distintas a las variables especificadas.

A continuación se muestran los resultados:

\footnotetext{
${ }^{13}$ Se plantea un modelo similar al planteado en el año 2004 (Anexo 4).
} 
Tabla 3.4

Primer modelo econométrico

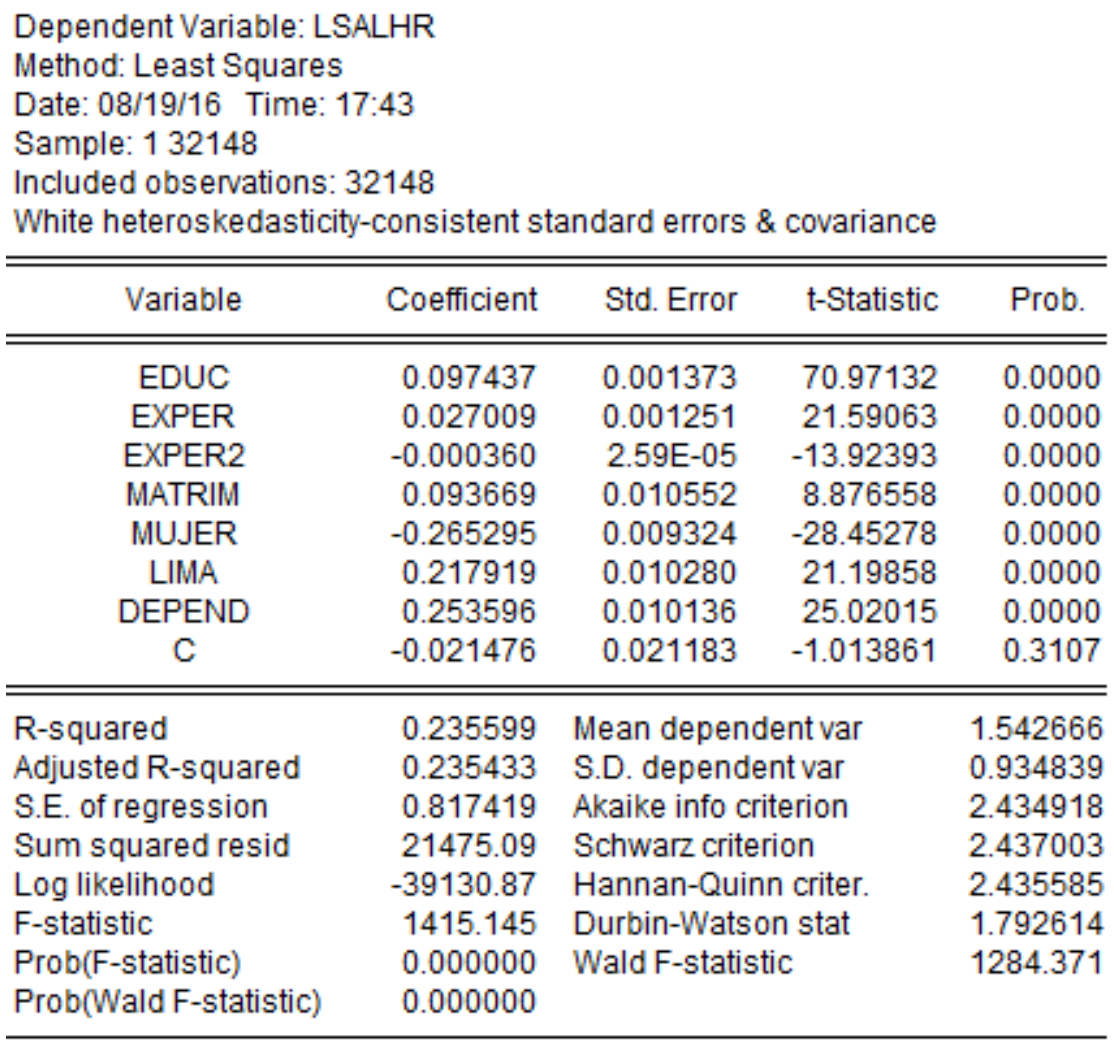

Fuente: Enaho 2013

Elaboración Propia

Del primer modelo planteado por $\mathrm{MCO}^{14}$ se obtiene que los coeficientes estimados de las variables son significativos ${ }^{15}$ y presentan los signos adecuados, la relación entre los años de educación y el ingreso es positivo; asimismo, la relación entre la experiencia potencial y el ingreso es positiva, frente al coeficiente del cuadrado de la experiencia que es negativo.

Los años de educación tienen un impacto positivo y significativo en los ingresos, la tasa de retorno de la inversión en educación es del 9,74 \% lo que implica que los ingresos crecen a medida que aumenta el número de años de educación de las personas. Un año de experiencia laboral potencial aumenta anualmente en 2,7 \% el ingreso.

\footnotetext{
${ }^{14}$ Los resultados son corregidos de heterocedasticidad

${ }^{15}$ Significativos con una probabilidad menor o igual al $5 \%$.
} 
En tanto ser casado o conviviente tiene una relación positiva con el ingreso, el ser mujer una relación negativa, el ser residente de Lima Metropolitana tiene una relación positiva, el tener un trabajo dependiente también tiene una relación positiva.

A partir de este primer modelo, se incluyen otras variables identificadas en la Enaho 2013 que tienen relación con el ingreso, siendo estas el fenotipo, la salud, el acceso a la de educación privada. Siendo estas variables y las del primer modelo las que forman parte de un segundo modelo. ${ }^{16}$

El planteamiento del segundo modelo se explica a continuación:

$$
\begin{aligned}
\operatorname{Ln}[\text { SALH }]= & \beta_{0}+\beta_{1} \text { EDUC }+\beta_{2} \text { EXPER }+\beta_{3} \text { EXPER }^{2}+\beta_{4} \text { MATRIM }+\beta_{5} \text { MUJER }+ \\
& \beta_{6} \text { LIMA }+\beta_{7} \text { DEPEND }+\beta_{8} \text { FENO }+\beta_{9} \text { SALUD }+\beta_{10} \text { PRIV }+\varepsilon
\end{aligned}
$$

SALHR: El ingreso por hora de la persona.

EDUC: Los años de estudio de la persona.

EXPER: La experiencia potencial de la persona en años. (“EDAD” - "EDUC" - “6”)

EXPER2: La experiencia potencial al cuadrado.

MATRIM: $1=$ casado o conviviente, $0=$ otro.

MUJER: 1 = mujer; 0 otro modo.

LIMA: 1 = reside en Lima Metropolitana, $0=$ otro.

DEPEND: $1=$ trabajador dependiente, $0=$ otro.

FENO: 1 = fenotipo blanca o mestizo, $0=$ otro.

SALUD: 1 = sano, sin enfermedad crónica, $0=$ otro.

PRIV: 1 = educación privada; $0=$ otro.

$\beta_{0}$ : Parámetro cuya estimación se aproximará al valor del logaritmo del ingreso de las personas que decidieron no seguir estudiando.

$\beta_{1}$ : Parámetro cuyo valor representa la tasa de retorno de la inversión en educación.

$\beta_{2 \text { y }} \beta_{3:}$ Parámetros que relacionan la experiencia con el ingreso.

$\beta_{4}, \beta_{5}, \beta_{6}, \beta_{7}, \beta_{8,}, \beta_{9}, \beta_{10}$ : Parámetros que relacionan las variables dummies con el ingreso.

\footnotetext{
${ }^{16}$ El segundo modelo es el aporte a la investigación realizada.
} 
$\varepsilon$ : Perturbación aleatoria que recoge todas las causas que influyen en la determinación del ingreso de la persona distintas a las variables especificadas.

A continuación se muestran los resultados:

Tabla 3.5

Segundo modelo econométrico planteado.

\begin{tabular}{|c|c|c|c|c|}
\hline Variable & Coefficient & Std. Error & t-Statistic & Prob. \\
\hline EDUC & 0.093087 & 0.001469 & 63.37252 & 0.0000 \\
\hline EXPER & 0.028444 & 0.001260 & 22.56910 & 0.0000 \\
\hline EXPER2 & -0.000383 & $2.59 \mathrm{E}-05$ & -14.77651 & 0.0000 \\
\hline MATRIM & 0.094850 & 0.010548 & 8.992328 & 0.0000 \\
\hline MUJER & -0.269689 & 0.009409 & -28.66420 & 0.0000 \\
\hline LIMA & 0.205494 & 0.010274 & 20.00042 & 0.0000 \\
\hline DEPEND & 0.252799 & 0.010129 & 24.95779 & 0.0000 \\
\hline FENO & 0.058560 & 0.021664 & 2.703039 & 0.0069 \\
\hline SALUD & 0.004583 & 0.009856 & 0.465037 & 0.6419 \\
\hline PRIV & 0.110305 & 0.011645 & 9.472480 & 0.0000 \\
\hline $\mathrm{C}$ & -0.014289 & 0.023605 & -0.605348 & 0.5450 \\
\hline R-squared & 0.237801 & \multicolumn{2}{|c|}{ Mean dependent var } & 1.542666 \\
\hline Adjusted R-squared & 0.237564 & \multicolumn{2}{|c|}{ S.D. dependent var } & 0.934839 \\
\hline S.E. of regression & 0.816279 & \multicolumn{2}{|c|}{ Akaike info criterion } & 2.432220 \\
\hline Sum squared resid & 21413.23 & \multicolumn{2}{|c|}{ Schwarz criterion } & 2.435087 \\
\hline Log likelihood & -39084.51 & \multicolumn{2}{|c|}{ Hannan-Quinn criter. } & 2.433137 \\
\hline F-statistic & 1002.653 & \multicolumn{2}{|c|}{ Durbin-Watson stat } & 1.796994 \\
\hline Prob(F-statistic) & 0.000000 & \multicolumn{2}{|c|}{ Wald F-statistic } & 914.3631 \\
\hline Prob(Wald F-statistic) & 0.000000 & & & \\
\hline
\end{tabular}

Fuente: Enaho 2013

Elaboración Propia

El planteamiento del segundo modelo por $\mathrm{MCO}^{17}$, muestra las variables significativas al $5 \%$ a excepción de la variable salud; variable que se procede a retirar del modelo planteado; en tanto, los coeficientes estimados de las demás variables presentan los signos adecuados.

\footnotetext{
${ }^{17}$ Resultados corregidos de heterocedasticidad.
} 
A continuación, se presenta los resultados del segundo modelo corregido:

Tabla 3.6

Segundo modelo econométrico.

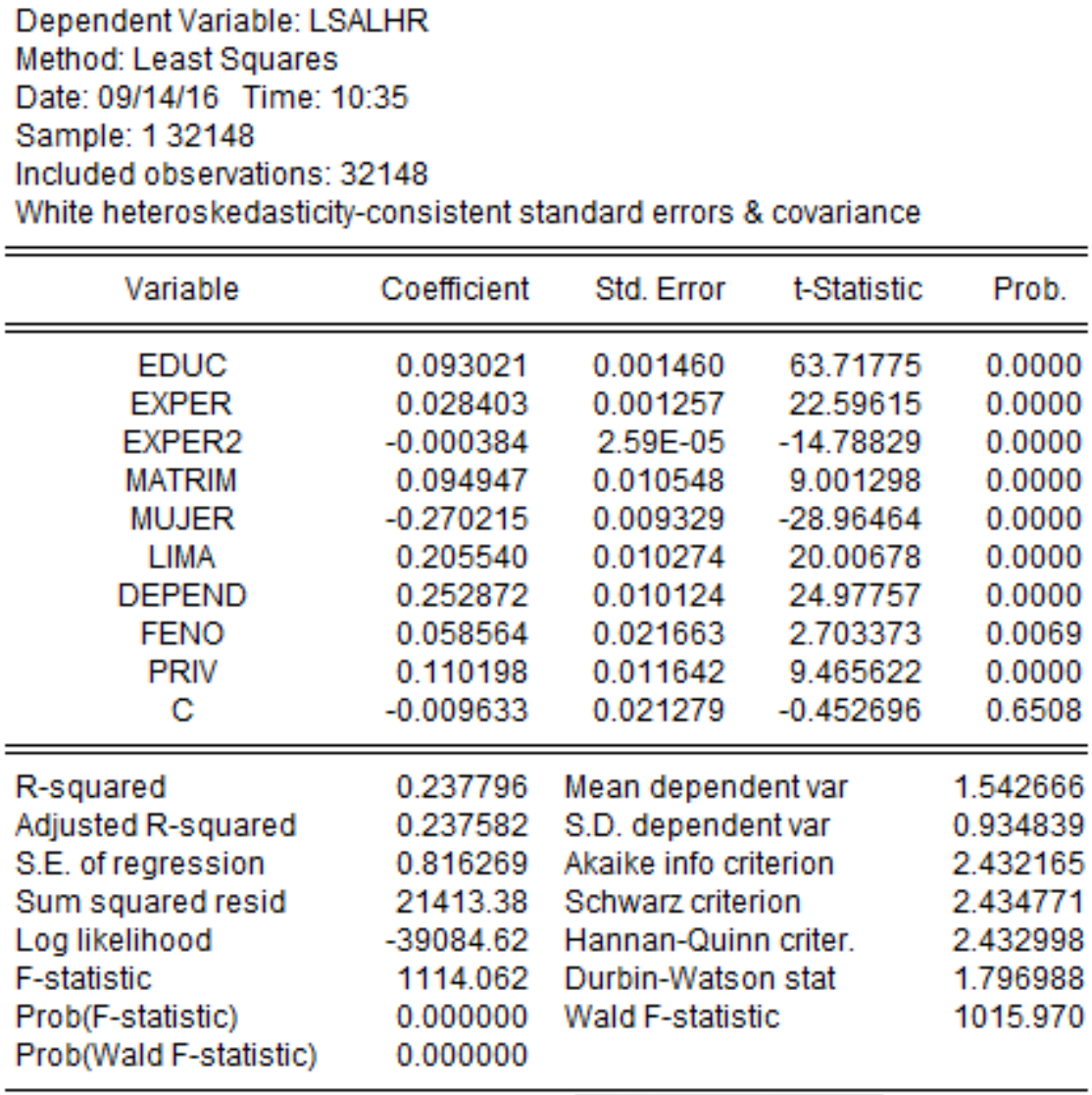

Fuente: Enaho 2013

Elaboración Propia

El segundo modelo por MCO, muestra que todas las variables son significativas al $5 \%$ y los coeficientes estimados presentan los signos adecuados.

Las aportaciones de la educación y de la experiencia a los ingresos son positivas, frente al coeficiente del cuadrado de la experiencia que es negativo.

Los años de educación tienen un impacto positivo y significativo en los ingresos, la tasa de retorno de la inversión en educación es del 9,30 \% lo que implica que los ingresos crecen a medida que aumenta el número de años de educación de las personas. Un año de experiencia laboral potencial aumenta en $2,84 \%$ el ingreso. 
En tanto ser casado o conviviente tiene una relación positiva con el ingreso, el ser mujer una relación negativa, ser residente de Lima Metropolitana tiene una relación positiva, tener un trabajo dependiente también tiene una relación positiva, mostrar un fenotipo blanco o mestizo tiene una relación positiva y haber recibido educación privada tiene una relación positiva.

Para la comprobación de la primera hipótesis específica se plantea un modelo modificando el primer modelo, siguiendo la metodología de Chiswick (1997).

Se reemplaza la variable EDUC, que se encuentra en años de estudio, del primer modelo por 6 variables dummies que son PRIM_I, PRIM_C, SECU_I, SECU_C, SUPE_NU, SUPE_U. Siendo el valor de "1" si es que cursa o curso el nivel respectivo y " 0 " caso contrario.

Primera hipótesis específica: "Los retornos a la educación en el Perú estimados para el año 2013 del nivel educativo superior, tanto universitario como no universitario, son mayores respecto a los retornos estimados para los años previos"

Asimismo, para la comprobación de la primera hipótesis específica es necesario comparar los retornos estimados para el año 2013 con los retornos estimados por Yamada (2007) para los años previos al 2004.

En la siguiente figura se aprecia la tendencia de los retornos educativos del nivel superior, desde el año 1985 al año 2004, estimados por Yamada (2007). Siendo los resultados estimados para el año 2004: el retorno a la educación superior no universitaria es de $10,8 \%$ y el retorno a la educación universitaria es de $17,3 \%$. 
Figura 3.1

Tendencia de los retornos, según el nivel educativo, desde el año 1985 al año 2004

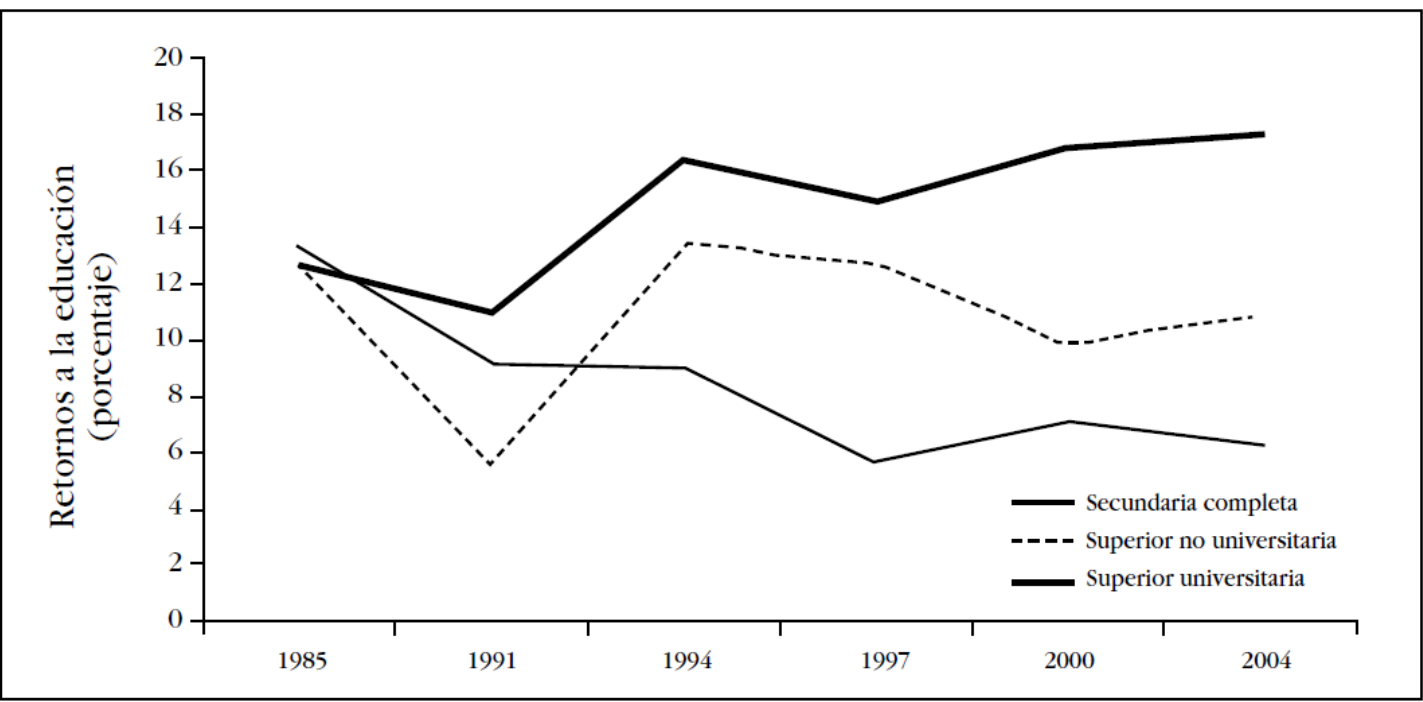

Fuente: Yamada (2007)

El primer modelo modificado, se explica a continuación:

$$
\begin{aligned}
\operatorname{Ln}[\text { SALH }]= & \beta_{0}+\beta_{1} \text { PRIM_I }+\beta_{2} \text { PRIM_C }+\beta_{3} \text { SECU_I }+\beta_{4} \text { SECU_C }+\beta_{5} \text { SUPE_NU + } \\
& \beta_{6} \text { SUPE_U }+\beta_{7} \text { EXPER }+\beta_{8} \text { EXPER }^{2}+\beta_{9} \text { MATRIM }+\beta_{10} \text { MUJER }+ \\
& \beta_{11} \text { LIMA }+\beta_{12} \text { DEPEND }+\varepsilon
\end{aligned}
$$

PRIM_I: Primaria incompleta toma valores: $1=$ cursa, $0=$ no.

PRIM_C: Primaria completa toma valores: 1 = cursó, $0=$ no.

SECU_I: Secundaria incompleta toma valores: $1=$ cursa, $0=$ no.

SECU_C: Secundaria incompleta toma valores: 1 = cursó, $0=$ no.

SUPER_NU: Superior no universitaria toma valores: $1=$ cursa, $0=$ no.

SUPER_U: Superior universitaria toma valores: 1 = cursó, 0 = no.

EXPER: La experiencia potencial de la persona en años. (“EDAD” - "EDUC" - “6”)

EXPER2: La experiencia potencial al cuadrado.

MATRIM: 1 = casado o conviviente, $0=$ otro.

MUJER: 1 = mujer, 0 = otro.

LIMA: 1 = reside en Lima Metropolitana, $0=$ otro. 
DEPEND: 1 = trabajador dependiente, $0=$ otro.

$\beta_{0}$ : Parámetro cuya estimación se aproximará al valor del logaritmo del ingreso de las personas que decidieron no seguir estudiando.

$\beta_{1}, \beta_{2}, \beta_{3}, \beta_{4}, \beta_{5}, \beta_{6}$ : Parámetros cuyo valor representa un coeficiente a partir del cual se obtiene la tasa de rentabilidad de la educación para cada nivel completo e incompleto.

$\beta_{7 \text { y }} \beta_{8:}$ Parámetros cuyo valor representan la relación de la experiencia.

$\beta_{9}, \beta_{10}, \beta_{11}, \beta_{12}$ : Parámetros que relacionan las otras variables dummies con el ingreso.

$\varepsilon$ : Perturbación aleatoria que recoge todas las causas que influyen en la determinación del ingreso de la persona distintas a las variables especificadas.

El resultado del primer modelo modificado se muestra a continuación:

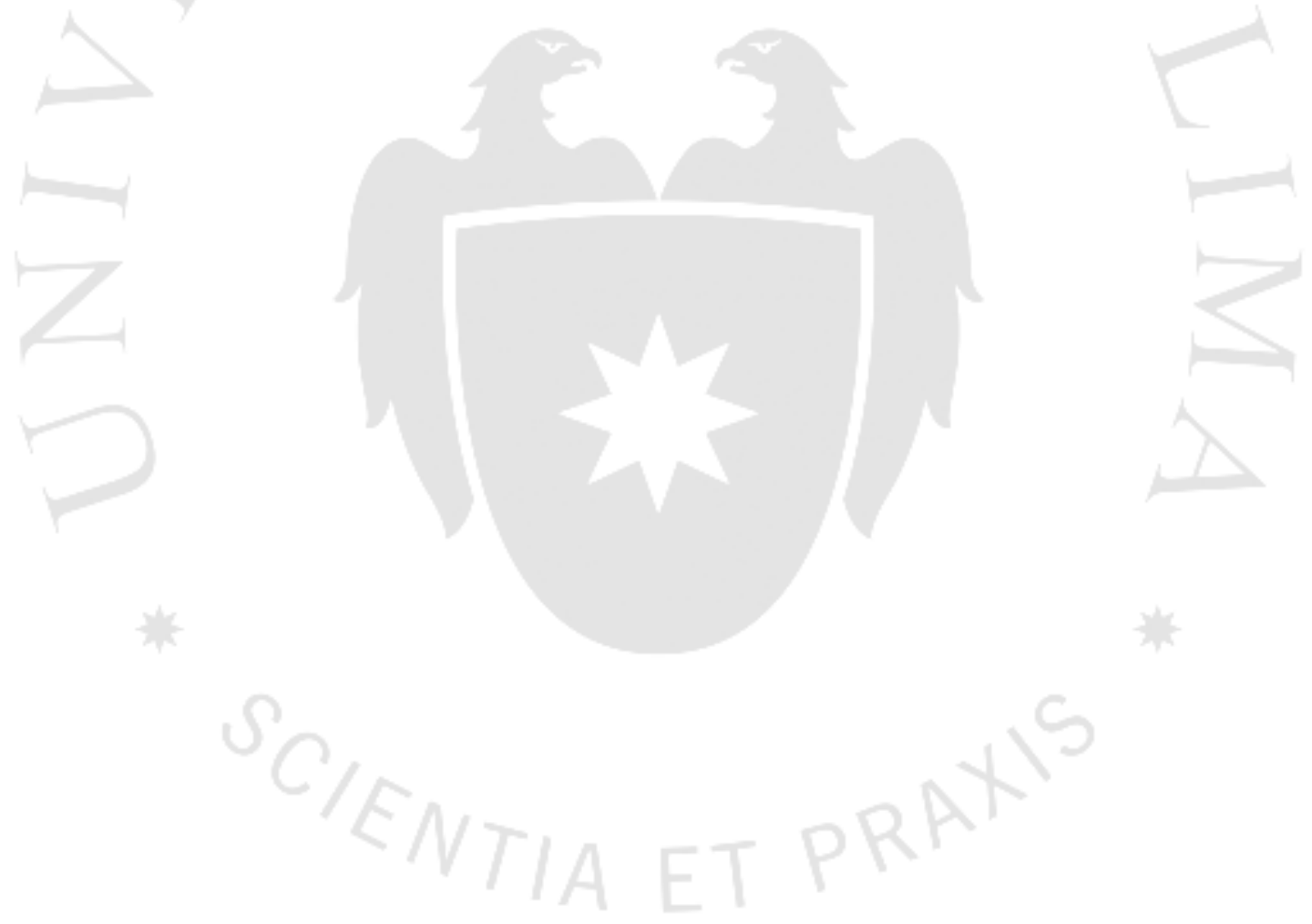


Tabla 3.7

Primer modelo modificado, reemplazando la variable EDUC por PRIM_I, PRIM_C, SECU_I, SECU_C, SUPER_NU y SUPER_U

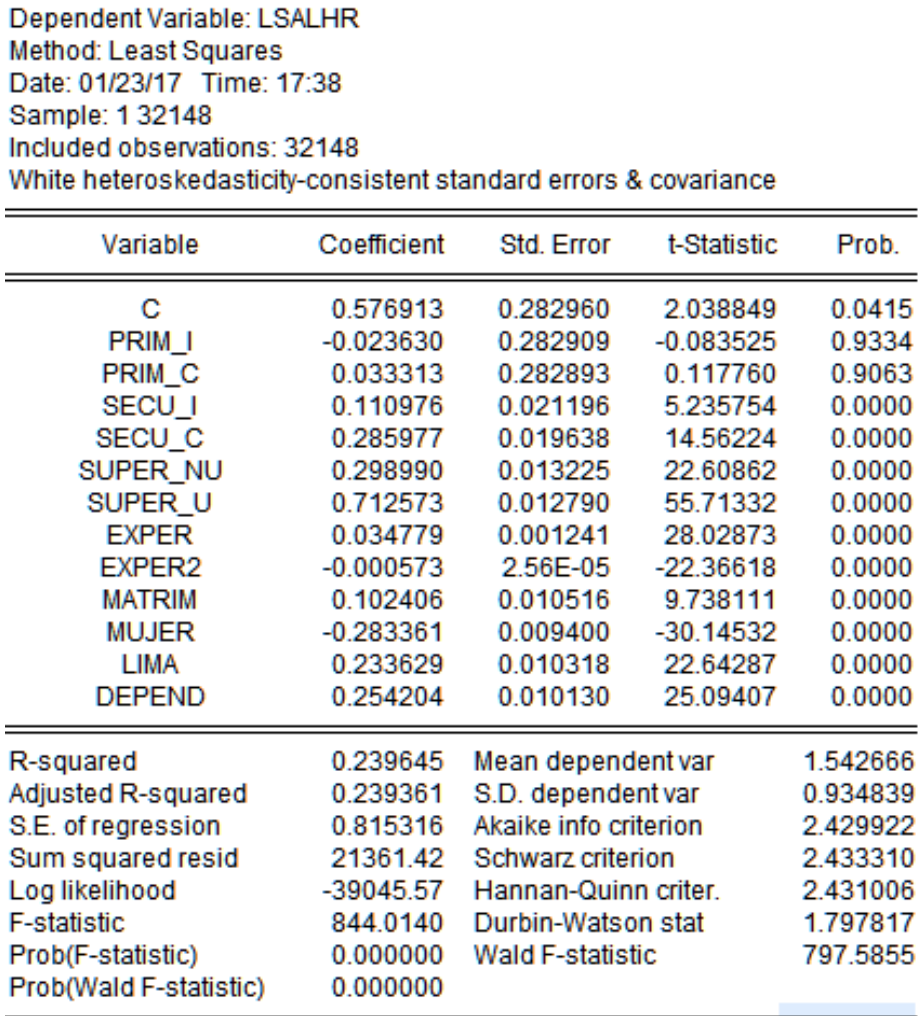

Fuente: Enaho 2013

Elaboración Propia

Seguidamente, con los años promedio de educación superior no universitaria y universitaria se estima las tasas de retorno a la educación del nivel educativo superior, tanto universitario como no universitario. Los años promedio de estudio son los siguientes ${ }^{18}$ :

1. El promedio de años de estudio del nivel educativo superior no universitario es de 2,84 años.

2. El promedio de años de estudio del nivel educativo superior universitario es de 4,46 años.

\footnotetext{
${ }^{18}$ El promedio de los años de estudio para el nivel universitario y no universitario, se obtienen de las 32148 observaciones.
} 
Con los coeficientes de las variables SUPER_NU y SUPER_U obtenidos del primer modelo modificado, se obtienen las tasas de retorno. Mediante la fórmula siguiente:

Tasa de retorno $=$ Coeficiente $/$ Años de estudio en promedio

Siendo las tasas de retorno estimadas para el año 2013:

1. Nivel superior no universitario de $10,52 \%$

2. Nivel superior universitario de $15,99 \%$

Las tasas de retorno estimadas para el año 2013 son menores a las estimadas en el año 2004: en el nivel superior no universitario es de $10,52 \%$, menor al $10,81 \%$ y la del nivel superior universitario es de $15,99 \%$, menor al $17,32 \%$.

Figura 3.2

Tendencia de los retornos, según el nivel educativo, desde el año 1985 al año 2013

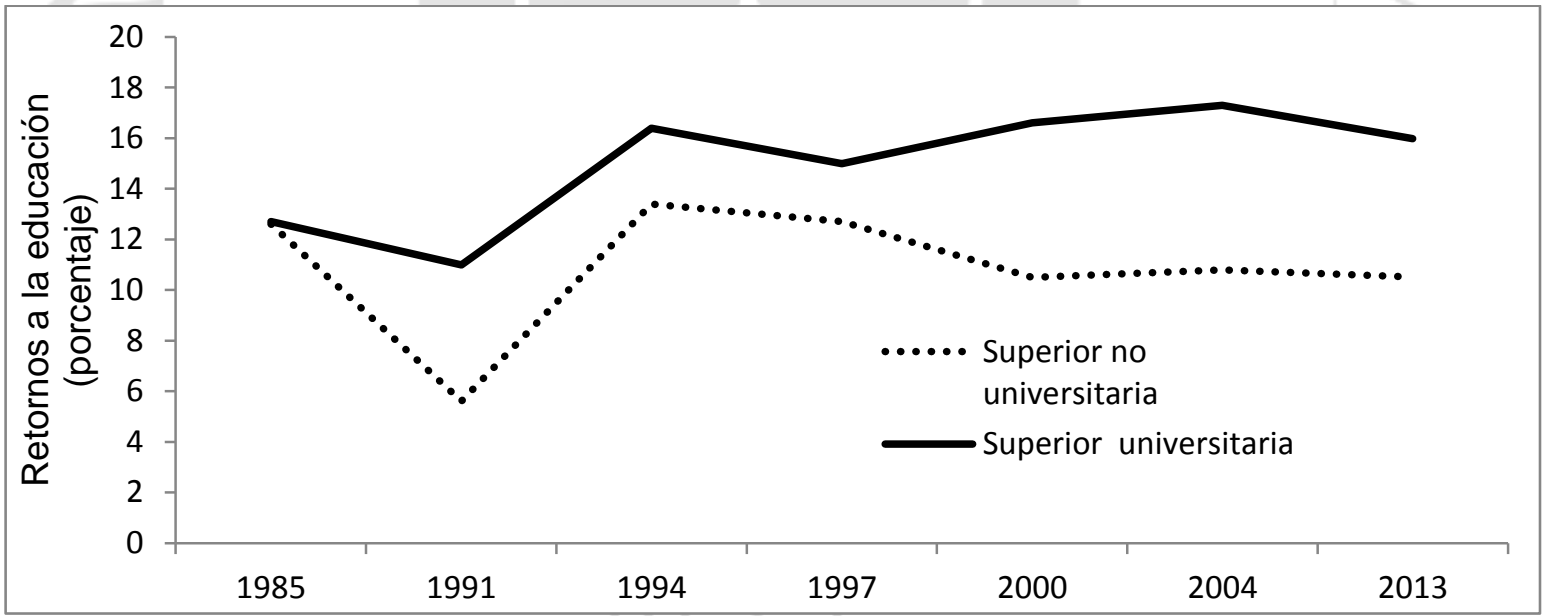

Fuente: Yamada (2007) del año 1985 al año 2004

Estimación propia para el año 2013

Por consiguiente, observando el grafico y con los resultados se concluye que la primera hipótesis específica no es verdadera. 
Para la comprobación de la segunda hipótesis especifica se plantea un modelo modificando el segundo modelo, aplicando la metodología de Chiswick (1997) explicada previamente.

Segunda hipótesis específica, "Los retornos a la educación en el Perú, de las personas con nivel superior completo, son mayores a las personas con educación superior incompleta en el sector agricultura, comercio, construcción, manufactura y minero, para el año 2013"

Por tanto es necesario realizar la estimación y comparar los retornos, para lo cual se parte del segundo modelo, se reemplaza la variable EDUC por 8 variables dummies (a cada nivel de educación competo e incompleto), se explica el modelo a continuación:

$$
\begin{aligned}
\operatorname{Ln}[\mathrm{SALH}]= & \beta_{0}+\beta_{1} \text { PRIM_I }+\beta_{2} \text { PRIM_C }+\beta_{3} \text { SECU_I }+\beta_{4} \text { SECU_C }+\beta_{5} \text { SUPE_NU_I + } \\
& \beta_{6} \text { SUPE_NU_C }+\beta_{7} \text { SUPE_U_I }+\beta_{8} \text { SUPE_U_C }+\beta_{9} \text { EXPER }+ \\
& \beta_{10} \text { EXPER }^{2}+\beta_{11} \text { MATRIM }+\beta_{12} \text { MUJER }+\beta_{13} \text { LIMA }+\beta_{14} \text { DEPEND }+ \\
& \beta_{15} \text { FENO }+\beta_{16} \text { PRIV }+\varepsilon
\end{aligned}
$$

PRIM_I: Primaria incompleta toma valores: $1=$ cursa, $0=$ no.

PRIM_C: Primaria completa toma valores: $1=$ cursó, $0=$ no.

SECU_I: Secundaria incompleta toma valores: $1=$ cursa, $0=$ no.

SECU_C: Secundaria incompleta toma valores: $1=$ cursó, $0=$ no.

SUPE_NU_I: Superior no universitaria incompleta toma valores: $1=$ cursa, $0=$ no.

SUPE_NU_C: Superior no universitaria completa toma valores: $1=$ cursó, $0=$ no.

SUPE_U_I: Superior universitaria incompleta toma valores: $1=$ cursa, $0=$ no.

SUPE_U_C: Superior universitaria completa toma valores: $1=$ cursó, $0=$ no.

EXPER: La experiencia potencial de la persona en años. ("EDAD" - "EDUC" - "6")

EXPER2: La experiencia potencial al cuadrado.

MATRIM: $1=$ casado o conviviente, $0=$ otro.

MUJER: $1=$ mujer, 0 = otro.

LIMA: 1 = reside en Lima Metropolitana, $0=$ otro. 
DEPEND: 1 = trabajador dependiente, $0=$ otro.

FENO: 1 = fenotipo persona blanca o mestizo, $0=$ otro.

PRIV: 1 = educación privada, 0 = otro.

$\beta_{0}$ : Parámetro cuya estimación se aproximará al valor del logaritmo del ingreso de las personas que decidieron no seguir estudiando.

$\beta_{1}, \beta_{2}, \beta_{3}, \beta_{4}, \beta_{5}, \beta_{6}, \beta_{7}$ y $\beta_{8}$ : Parámetros cuyo valor representa un coeficiente a partir del cual se obtiene la tasa de rentabilidad de la educación para cada nivel completo e incompleto.

$\beta_{9}, \beta_{10:}$ Parámetros cuyo valor representan la relación de la experiencia.

$\beta_{11}, \beta_{12}, \beta_{13}, \beta_{14}, \beta_{15}, \beta_{16}$ : Parámetros que relacionan las otras variables dummies con el ingreso.

$\varepsilon$ : Perturbación aleatoria que recoge todas las causas que influyen en la determinación del ingreso de la persona distintas a las variables especificadas.

El resultado del segundo modelo modificado, se muestra a continuación:
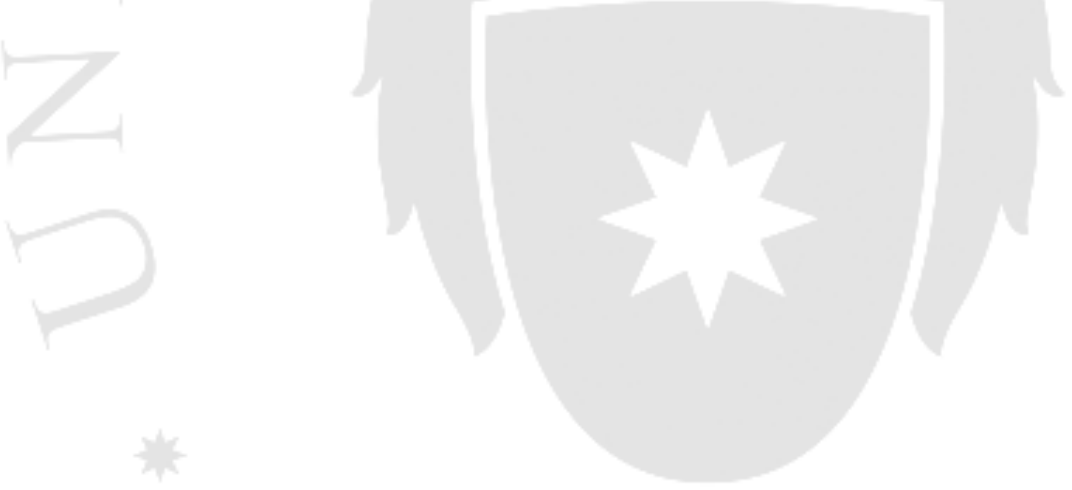
Tabla 3.8

Segundo modelo modificado, reemplazando la variable EDUC por PRIM_I, PRIM_C,

SECU_I, SECU_C, SUPE_NU_I, SUPE_NU_C, SUPE_U_I y SUPE_U_C

Dependent Variable: LSALHR

Method: Least Squares

Date: 09/14/16 Time: 13:06

Sample: 132148

Included observations: 32148

White heteroskedasticity-consistent standard errors \& covariance

\begin{tabular}{crrrr}
\hline \hline Variable & Coefficient & Std. Error & t-Statistic & Prob. \\
\hline C & 0.633126 & 0.279512 & 2.265111 & 0.0235 \\
PRIM_I & -0.021439 & 0.279451 & -0.076717 & 0.9388 \\
PRIM_C & 0.039204 & 0.279438 & 0.140297 & 0.8884 \\
SECU_I & 0.102732 & 0.021168 & 4.853222 & 0.0000 \\
SECU_C & 0.277936 & 0.019604 & 14.17738 & 0.0000 \\
SUPE_NU_I & 0.075915 & 0.021597 & 3.515139 & 0.0004 \\
SUPE_NU_C & 0.340925 & 0.015809 & 21.56537 & 0.0000 \\
SUPE_U_I & 0.341126 & 0.020425 & 16.70142 & 0.0000 \\
SUPE_U_C & 0.841726 & 0.014395 & 58.47375 & 0.0000 \\
EXPER & 0.031032 & 0.001241 & 25.00369 & 0.0000 \\
EXPER2 & -0.000507 & $2.56 E-05$ & -19.82078 & 0.0000 \\
MATRIM & 0.095882 & 0.010407 & 9.213354 & 0.0000 \\
MUJER & -0.298223 & 0.009306 & -32.04491 & 0.0000 \\
LIMA & 0.228644 & 0.010225 & 22.36079 & 0.0000 \\
DEPEND & 0.229646 & 0.010065 & 22.81671 & 0.0000 \\
FENO & 0.055024 & 0.021485 & 2.561073 & 0.0104 \\
PRIV & 0.092059 & 0.012650 & 7.277406 & 0.0000 \\
\hline R-squared & 0.256953 & Mean dependent var & 1.542666 \\
Adjusted R-squared & 0.256583 & S.D. dependent var & 0.934839 \\
S.E. of regression & 0.806033 & Akaike info criterion & 2.407145 \\
Sum squared resid & 20875.18 & Schwarz criterion & 2.411576 \\
Log likelihood & -38675.46 & Hannan-Quinn criter. & 2.408562 \\
F-statistic & 694.4505 & Durbin-Watson stat & 1.806312 \\
Prob(F-statistic) & 0.000000 & Wald F-statistic & 682.8579 \\
Prob(Wald F-statistic) & 0.000000 & & &
\end{tabular}

Fuente: Enaho 2013

Elaboración Propia

Seguidamente, al igual que lo trabajado previamente se utilizan los años promedios de educación superior no universitaria y universitaria, tanto completos como incompletos para estimar las tasas de retorno a la educación. 
Los años promedio de estudio son los siguientes ${ }^{19}$ :

1. El promedio de años de estudio del nivel educativo superior no universitario incompleto es de 1,61 años.

2. El promedio de años de estudio del nivel educativo superior no universitario completo es de 3,40 años.

3. El promedio de años de estudio del nivel educativo superior universitario incompleto es de 2,48 años.

4. El promedio de años de estudio del nivel educativo superior universitario completo es de 5,42 años

Con los coeficientes de las variables SUPE_NU_I, SUPE_NU_C, SUPE_U_I y SUPE_U_C obtenidos del segundo modelo modificado, se obtienen las tasas de retorno mediante la fórmula siguiente:

Tasa de retorno $=$ Coeficiente $/$ Años de estudio en promedio

Siendo las tasas de retorno estimadas para el año 2013:

1. Nivel superior no universitario completo de $10,02 \%$.

2. Nivel superior no universitario incompleto de $4,72 \%$.

3. Nivel superior universitario completo de $15,54 \%$.

4. Nivel superior universitario incompleto de $13,76 \%$.

De manera general, la tasa de retorno de las personas con nivel superior no universitario completo es de 10,02\%, mayor al 4,72\% de las personas con nivel superior no universitario incompleto. Asimismo, la tasa de retorno de las personas con nivel superior universitario completo es de 15,54 \%, superior al 13,76\% de las personas con nivel superior universitario incompleto.

\footnotetext{
${ }^{19}$ El promedio de los años de estudio se obtienen de las 32148 observaciones.
} 
Para la comparación para cada sector económico se agrega una variable dummie del sector productivo respectivo.

Del segundo modelo modificado, agregando la variable del sector productivo, se explica el modelo a continuación:

$$
\begin{aligned}
\operatorname{Ln}[\text { SALH }]= & \beta_{0}+\beta_{1} \text { PRIM_I }+\beta_{2} \text { PRIM_C }+\beta_{3} \text { SECU_I }+\beta_{4} \text { SECU_C }+\beta_{5} \text { SUPE_NU_I + } \\
& \beta_{6} \text { SUPE_NU_C }+\beta_{7} \text { SUPE_U_I }+\beta_{8} \text { SUPE_U_C }+\beta_{9} \text { EXPER }+ \\
& \beta_{10} \text { EXPER }^{2}+\beta_{11} \text { MATRIM }+\beta_{12} \text { MUJER }+\beta_{13} \text { LIMA }+\beta_{14} \text { DEPEND + } \\
& \beta_{15} \text { FENO }+\beta_{16} \text { PRIV }+\beta_{17} \text { "SECTOR X" }{ }^{20}+\varepsilon
\end{aligned}
$$

PRIM_I: Primaria incompleta toma valores: $1=$ cursa, $0=$ no.

PRIM_C: Primaria completa toma valores: $1=$ cursó, $0=$ no.

SECU_I: Secundaria incompleta toma valores: $1=$ cursa, $0=$ no.

SECU_C: Secundaria incompleta toma valores: $1=$ cursó, $0=$ no.

SUPE_NU_I: Superior no universitaria incompleta toma valores: $1=$ cursa, $0=$ no.

SUPE_NU_C: Superior no universitaria completa toma valores: $1=$ cursó, $0=$ no.

SUPE_U_I: Superior universitaria incompleta toma valores: $1=$ cursa, $0=$ no.

SUPE_U_C: Superior universitaria completa toma valores: $1=$ cursó, $0=$ no.

EXPER: La experiencia potencial de la persona en años. ("EDAD" - "EDUC" - "6")

EXPER2: La experiencia potencial al cuadrado.

MATRIM: 1 = casado o conviviente, $0=$ otro.

MUJER: 1 = mujer; $0=$ otro.

LIMA: 1 = reside en Lima Metropolitana, $0=$ otro.

DEPEND: $1=$ trabajador dependiente, $0=$ otro.

FENO: $1=$ fenotipo persona blanca o mestizo, $0=$ otro.

PRIV: 1 = educación privada, $0=$ otro.

"SECTOR": 1 = sector (AGRA, COME, CONS, MANU, MINE); 0 = otro.

$\beta_{0}$ : Parámetro cuya estimación se aproximará al valor del logaritmo del ingreso de las personas que decidieron no seguir estudiando.

\footnotetext{
${ }^{20}$ Se modifica en cada modelo con los sectores productivos: Agricultura, Comercio, Construcción, Manufactura y Minería. Utilizando el Anexo 5.
} 
$\beta_{1}, \beta_{2}, \beta_{3}, \beta_{4}, \beta_{5}, \beta_{6}, \beta_{7}$ y $\beta_{8}$ : Parámetros cuyo valor representa un coeficiente a partir del cual se obtiene la tasa de rentabilidad de la educación para cada nivel completo e incompleto.

$\beta_{9}, \beta_{10:}$ Parámetros cuyo valor representan la relación de la experiencia.

$\beta_{11}, \beta_{12}, \beta_{13}, \beta_{14}, \beta_{15}, \beta_{16}, \beta_{17}$ : Parámetros que relacionan las otras variables dummies con el ingreso.

$\varepsilon$ : Perturbación aleatoria que recoge todas las causas que influyen en la determinación del ingreso de la persona distintas a las variables especificadas.

Los resultados considerando cada sector mencionado, se muestran a continuación:

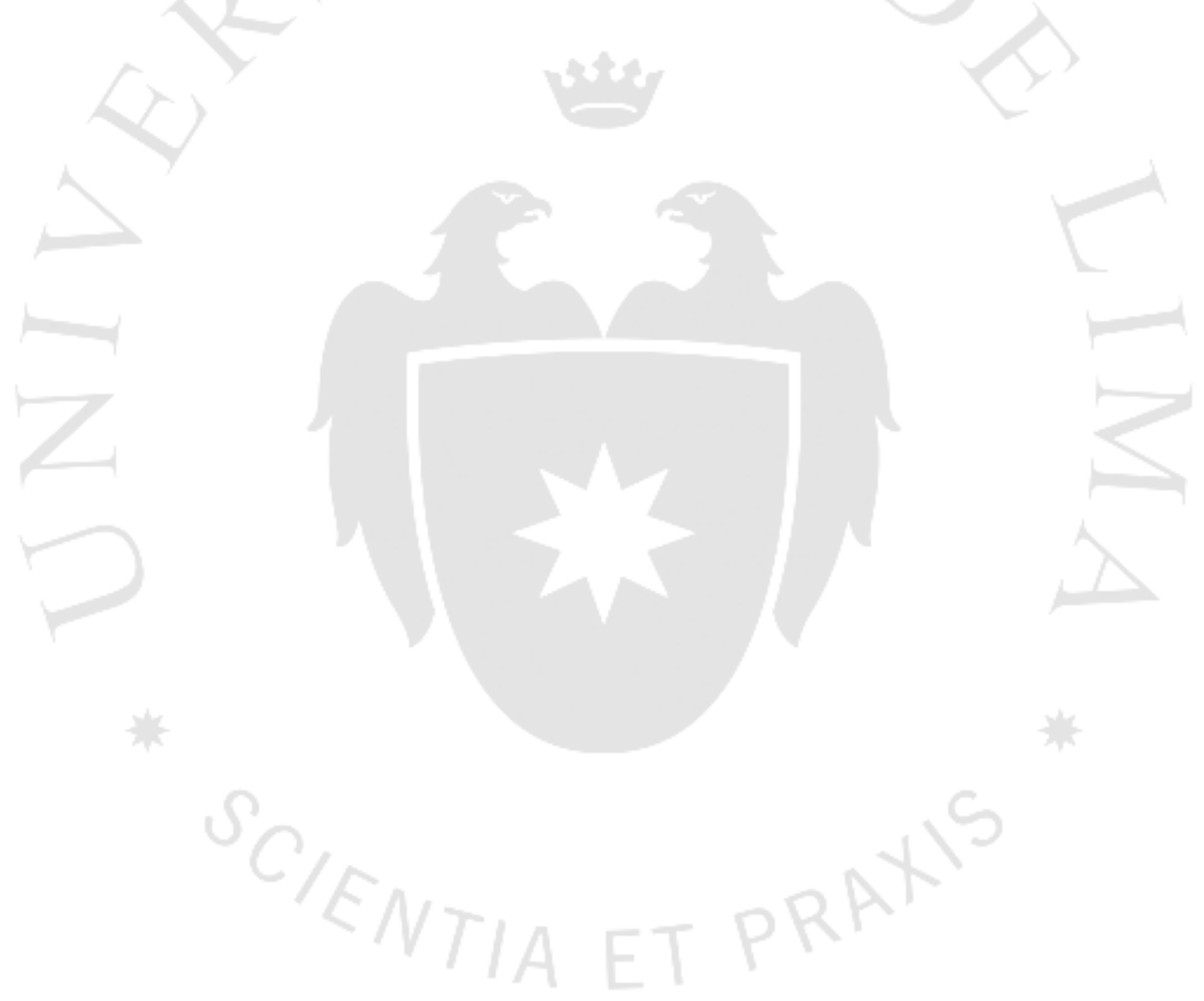


En la siguiente tabla se muestra los resultados considerando el sector Agricultura dentro del modelo.

Tabla 3.9

Segundo modelo modificado, agregando variable AGRA

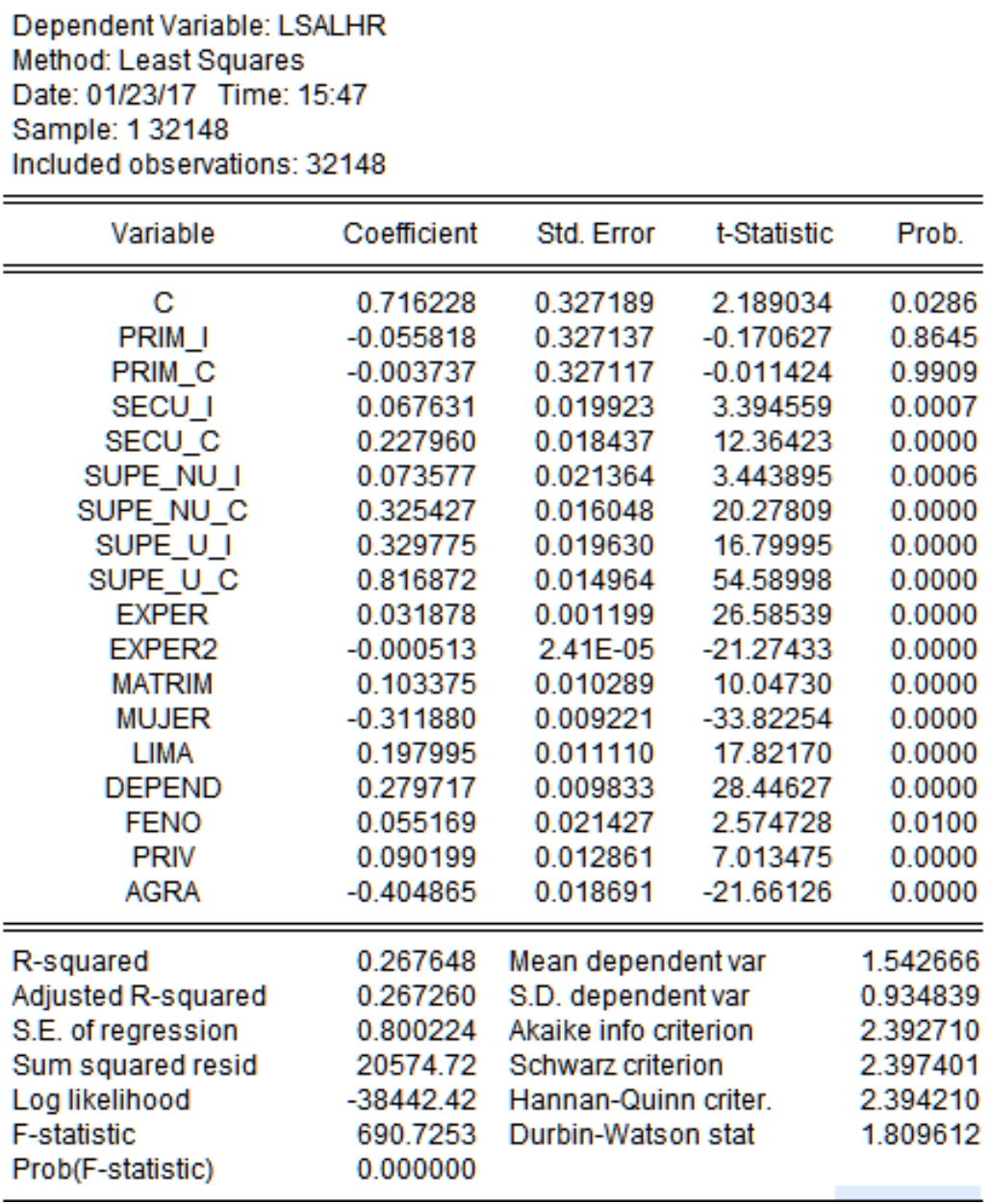

Fuente: Enaho 2013

Elaboración Propia

El modelo muestra que desenvolverse en el sector Agricultura tiene una relación negativa frente al ingreso. 
Considerando el sector Agricultura en el modelo se obtiene que la tasa de retorno de las personas con nivel superior no universitario completo es de 9,57 \%, mayor a al 4,57 \% de las personas con nivel superior no universitario incompleto. Asimismo, la tasa de retorno de las personas con nivel superior universitario completo es de $15,08 \%$, superior al $13,30 \%$ de las personas con nivel superior universitario incompleto.

Asimismo, los retornos estimados son menores a la estimación general realizada previamente, resumida en la siguiente tabla:

\section{Tabla 3.10}

Tabla resumen sector Agricultura

\begin{tabular}{|c|c|c|c|c|c|}
\hline \multicolumn{2}{|c|}{ Agricultura } & Super_NU_I & Super_NU_C & Super_U_I & Super_U_C \\
\hline \multicolumn{2}{|c|}{ Promedio de años } & 1,6089 & 3,4015 & 2,4794 & 5,4167 \\
\hline \multicolumn{2}{|c|}{ Coeficiente } & 0,0736 & 0,3254 & 0,3298 & 0,8169 \\
\hline \multirow[t]{2}{*}{ Retornos } & AGRA & $4,57 \%$ & $9,57 \%$ & $13,30 \%$ & $15,08 \%$ \\
\hline & General & $4,72 \%$ & $10,02 \%$ & $13,76 \%$ & $15,54 \%$ \\
\hline
\end{tabular}

Fuente: Enaho 2013

Elaboración Propia 
La siguiente tabla muestra los resultados considerando el sector Comercio dentro del modelo.

Tabla 3.11

Segundo modelo modificado, agregando variable COME

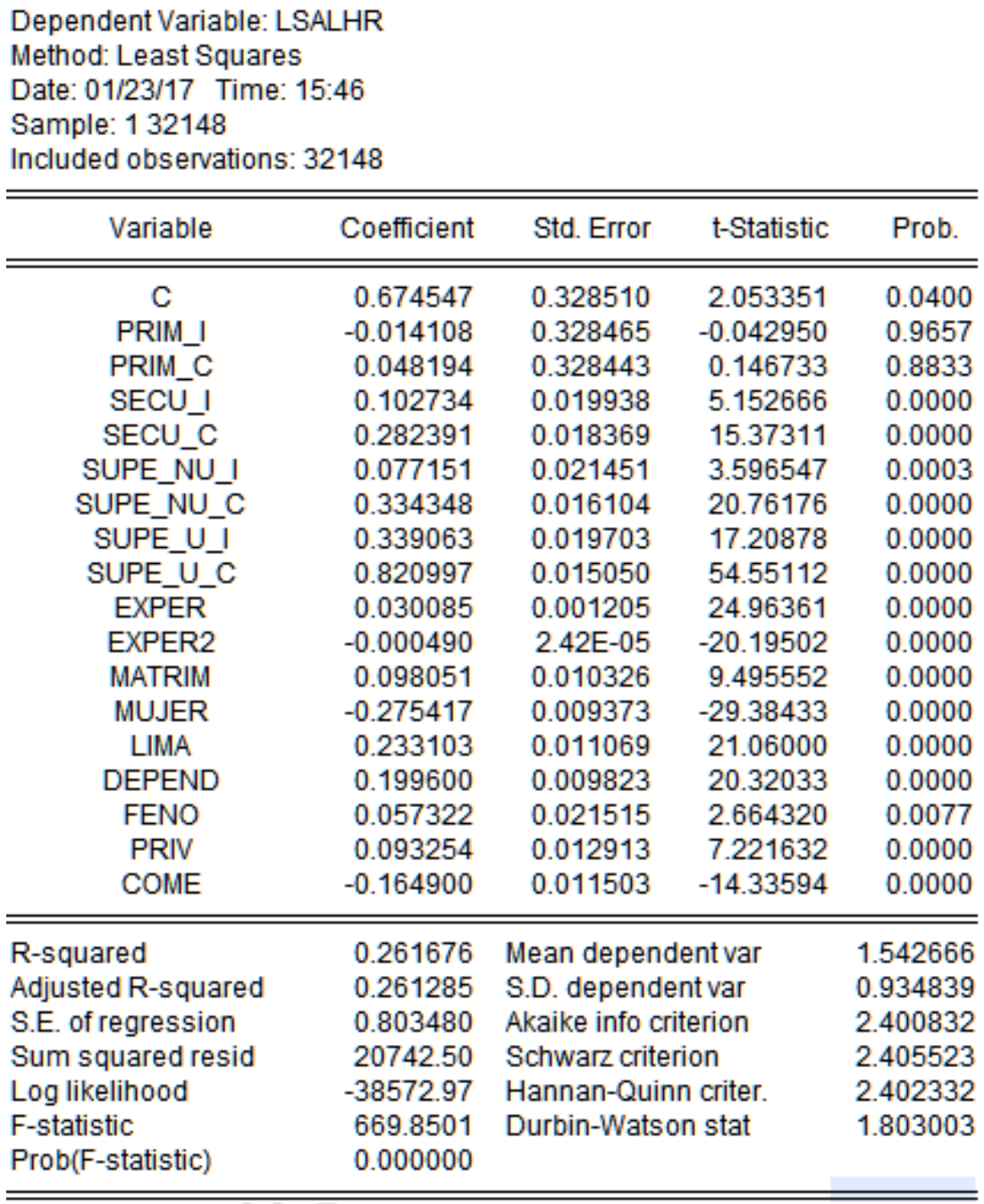

Fuente: Enaho 2013

Elaboración Propia

El modelo muestra que desenvolverse en el sector Comercio tiene una relación negativa frente al ingreso. 
Considerando el sector Comercio en el modelo se obtiene que la tasa de retorno de las personas con nivel superior no universitario completo es de $9,83 \%$, mayor al 4,80 \% de las personas con nivel superior no universitario incompleto. Asimismo, la tasa de retorno de las personas con nivel superior universitario completo es de $15,16 \%$, superior al $13,68 \%$ de las personas con nivel superior universitario incompleto.

Asimismo, los retornos estimados son menores a la estimación general realizada previamente, a excepción del nivel superior no universitario incompleto; resumida en la siguiente tabla:

Tabla 3.12

Tabla resumen sector Comercio

\begin{tabular}{|c|c|c|c|c|c|}
\hline \multicolumn{2}{|l|}{ Comercio } & Super_NU_I & Super_NU_C & Super_U_I & Super_U_C \\
\hline \multicolumn{2}{|c|}{ Promedio Años } & 1,6089 & 3,4015 & 2,4794 & 5,4167 \\
\hline \multicolumn{2}{|c|}{ Coeficiente } & 0,0772 & 0,3343 & 0,3391 & 0,8210 \\
\hline \multirow[t]{2}{*}{ Retornos } & COME & $4,80 \%$ & $9,83 \%$ & $13,68 \%$ & $15,16 \%$ \\
\hline & General & $4,72 \%$ & $10,02 \%$ & $13,76 \%$ & $15,54 \%$ \\
\hline
\end{tabular}

Fuente: Enaho 2013

Elaboración Propia 
La siguiente tabla muestra los resultados considerando el sector Construcción dentro del modelo.

Tabla 3.13

Segundo modelo modificado, agregando variable CONS

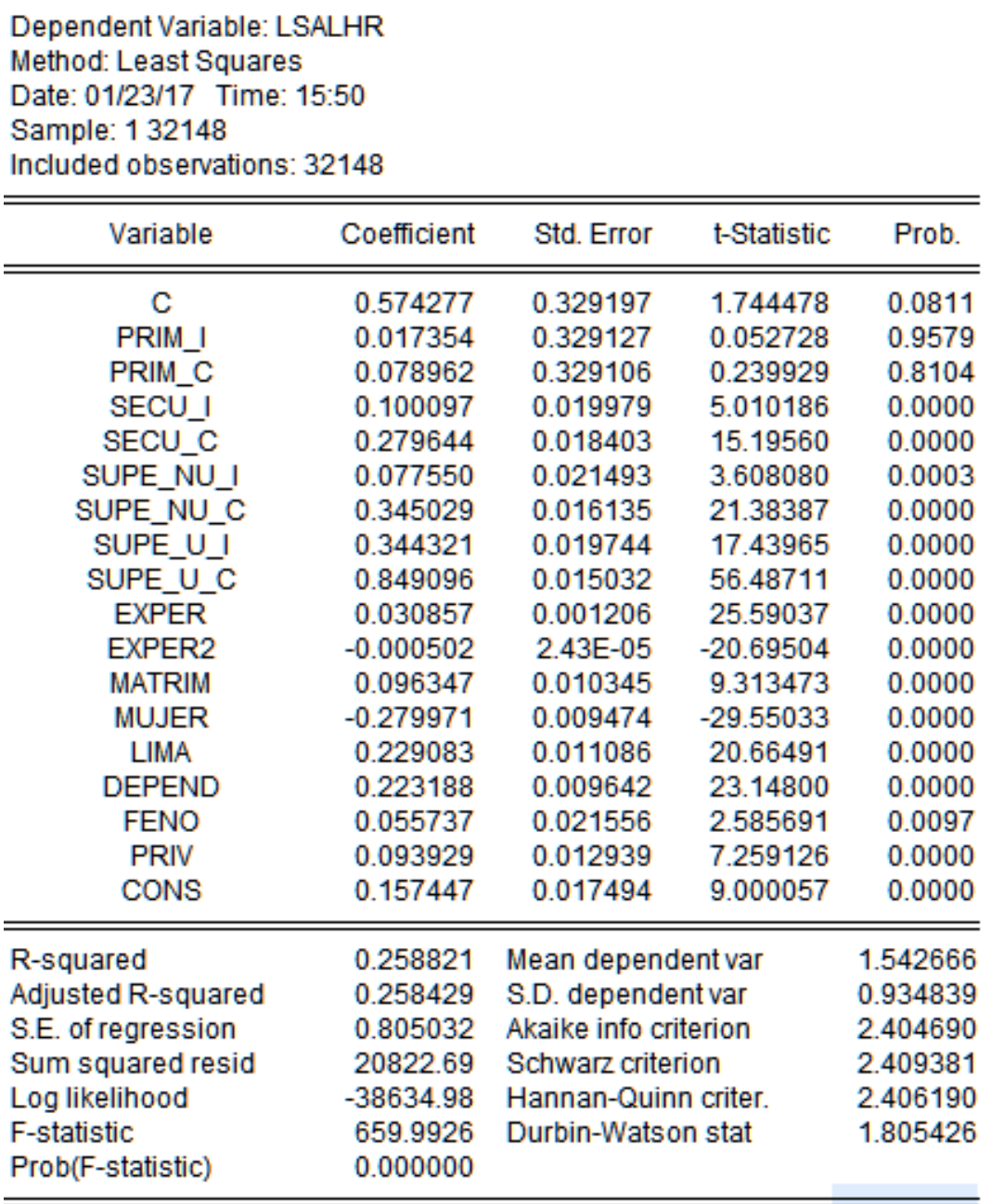

Fuente: Enaho 2013

Elaboración Propia

El modelo muestra que desenvolverse en el sector Construcción tiene una relación positiva frente al ingreso. 
Considerando el sector Construcción en el modelo se obtiene que la tasa de retorno de las personas con nivel superior no universitario completo es de 10,14\%, mayor a al $4,82 \%$ de las personas con nivel superior no universitario incompleto. Asimismo, la tasa de retorno de las personas con nivel superior universitario completo es de 15,68 \%, superior al 13,89\% de las personas con nivel superior universitario incompleto.

Asimismo, los retornos estimados con este sector son mayores a la estimación general realizada previamente; resumido en la siguiente tabla:

\section{Tabla 3.14}

Tabla resumen sector Construcción

\begin{tabular}{|c|c|c|c|c|}
\hline Construcción & Super_NU_I & Super_NU_C & Super_U_I & Super_U_C \\
\hline Promedio Años & 1,6089 & 3,4015 & 2,4794 & 5,4167 \\
\hline Coeficiente & 0,0776 & 0,3450 & 0,3443 & 0,8491 \\
\hline Retornos & $4,82 \%$ & $10,14 \%$ & $13,89 \%$ & $15,68 \%$ \\
\hline General & $4,72 \%$ & $10,02 \%$ & $13,76 \%$ & $15,54 \%$ \\
\hline
\end{tabular}

Fuente: Enaho 2013

Elaboración Propia 
La siguiente tabla muestra los resultados considerando el sector Manufactura dentro del modelo.

Tabla 3.15

Segundo modelo modificado, agregando variable MANU

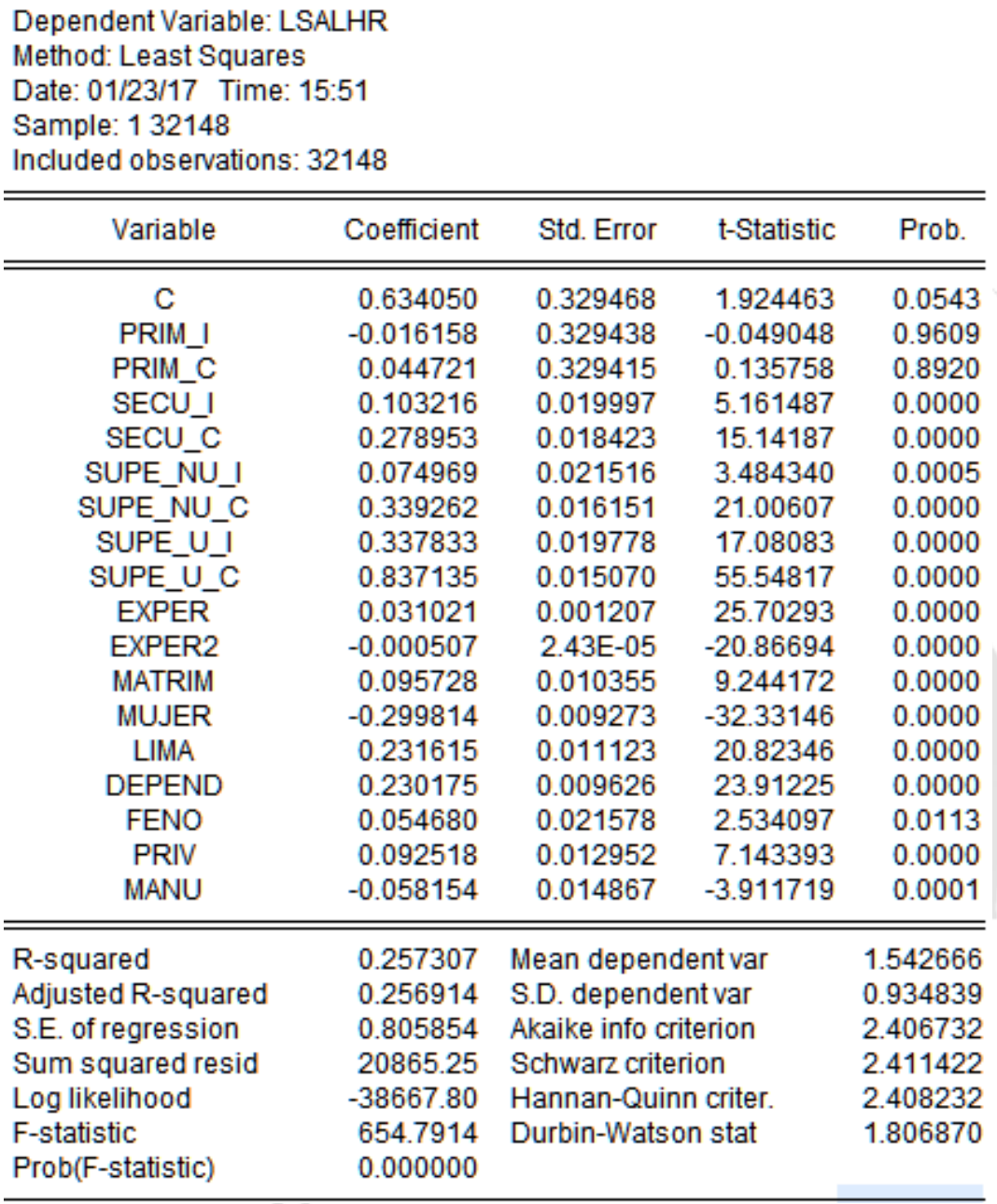

Fuente: Enaho 2013

Elaboración Propia

El modelo muestra que desenvolverse en el sector Manufactura tiene una relación negativa frente al ingreso. 
Considerando el sector Manufactura en el modelo se obtiene que la tasa de retorno de las personas con nivel superior no universitario completo es de 9,97 \%, mayor a al $4,66 \%$ de las personas con nivel superior no universitario incompleto. Asimismo, la tasa de retorno de las personas con nivel superior universitario completo es de 15,45\%, superior al 13,63\% de las personas con nivel superior universitario incompleto.

Asimismo, los retornos estimados son menores a la estimación general realizada previamente; resumido en la siguiente tabla:

\section{Tabla 3.16}

Tabla resumen sector Manufactura

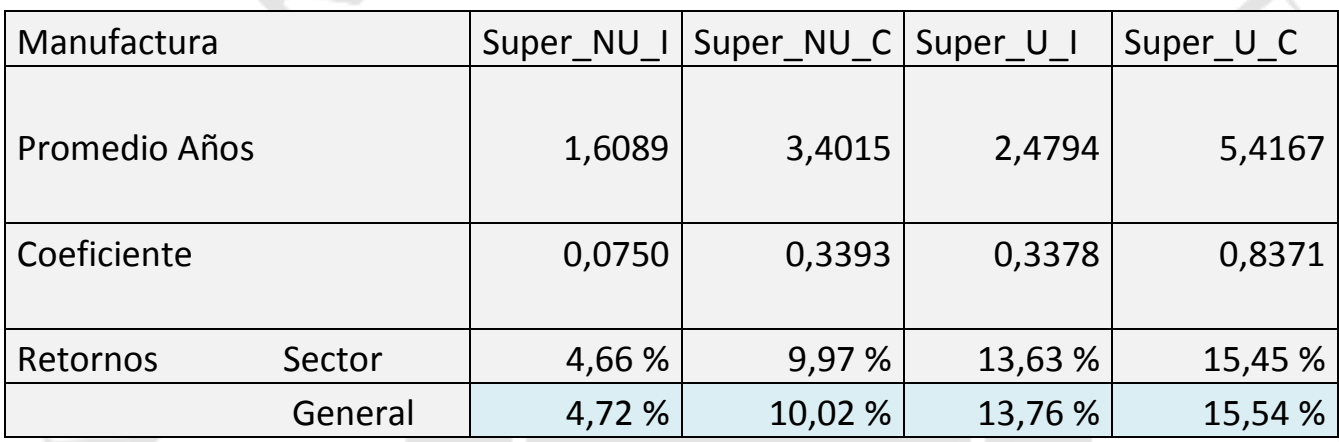

Fuente: Enaho 2013

Elaboración Propia 
La siguiente tabla muestra los resultados considerando el sector Minería dentro del modelo.

Tabla 3.17

Segundo modelo modificado, agregando variable MINE

Dependent Variable: LSALHR

Method: Least Squares

Date: 01/23/17 Time: 15:48

Sample: 132148

Included observations: 32148

\begin{tabular}{|c|c|c|c|c|}
\hline Variable & Coefficient & Std. Error & t-Statistic & Prob. \\
\hline $\mathrm{C}$ & 0.641498 & 0.327464 & 1.958986 & 0.0501 \\
\hline PRIM_I & -0.031587 & 0.327431 & -0.096469 & 0.9231 \\
\hline PRIM_C & 0.031621 & 0.327409 & 0.096579 & 0.9231 \\
\hline SECU_I & 0.101335 & 0.019875 & 5.098504 & 0.0000 \\
\hline SECU_C & 0.271985 & 0.018311 & 14.85358 & 0.0000 \\
\hline SUPE_NU_I & 0.075425 & 0.021384 & 3.527241 & 0.0004 \\
\hline SUPE_NU_C & 0.338525 & 0.016047 & 21.09544 & 0.0000 \\
\hline SUPE_U_I & 0.343037 & 0.019641 & 17.46572 & 0.0000 \\
\hline SUPE_U_C & 0.843936 & 0.014934 & 56.51221 & 0.0000 \\
\hline EXPER & 0.030485 & 0.001200 & 25.40710 & 0.0000 \\
\hline EXPER2 & -0.000496 & $2.41 E-05$ & -20.53346 & 0.0000 \\
\hline MATRIM & 0.088908 & 0.010298 & 8.633372 & 0.0000 \\
\hline MUJER & -0.283269 & 0.009237 & -30.66525 & 0.0000 \\
\hline LIMA & 0.239550 & 0.011042 & 21.69348 & 0.0000 \\
\hline DEPEND & 0.213763 & 0.009598 & 22.27067 & 0.0000 \\
\hline FENO & 0.058755 & 0.021447 & 2.739508 & 0.0062 \\
\hline PRIV & 0.093660 & 0.012872 & 7.275973 & 0.0000 \\
\hline MINE & 0.715720 & 0.035348 & 20.24757 & 0.0000 \\
\hline R-squared & 0.266314 & \multicolumn{2}{|c|}{ Mean dependent var } & 1.542666 \\
\hline Adjusted R-squared & 0.265926 & \multicolumn{2}{|c|}{ S.D. dependent var } & 0.934839 \\
\hline S.E. of regression & 0.800952 & \multicolumn{2}{|c|}{ Akaike info criterion } & 2.394529 \\
\hline Sum squared resid & 20612.18 & \multicolumn{2}{|c|}{ Schwarz criterion } & 2.399220 \\
\hline Log likelihood & -38471.66 & \multicolumn{2}{|c|}{ Hannan-Quinn criter. } & 2.396029 \\
\hline F-statistic & 686.0350 & \multicolumn{2}{|c|}{ Durbin-Watson stat } & 1.810535 \\
\hline Prob(F-statistic) & 0.000000 & & & \\
\hline
\end{tabular}

Fuente: Enaho 2013

Elaboración Propia

El modelo muestra que desenvolverse en el sector Minería tiene una relación positiva frente al ingreso. 
Considerando el Sector Minería en el modelo se obtiene que la tasa de retorno de las personas con nivel superior no universitario completo es de 9,95\%, mayor a al 4,69 \% de las personas con nivel superior no universitario incompleto. Asimismo, la tasa de retorno de las personas con nivel superior universitario completo es de $15,58 \%$, superior al $13,84 \%$ de las personas con nivel superior universitario incompleto.

Asimismo, los retornos estimados del nivel superior universitario son mayores a la estimación general realizada previamente; resumido en la siguiente tabla:

\section{Tabla 3.18}

Tabla resumen sector Minería

\begin{tabular}{|l|r|r|r|r|}
\hline Minería & Super_NU_I & Super_NU_C & Super_U_I & Super_U_C \\
\hline Promedio Años & 1,6089 & 3,4015 & 2,4794 & 5,4167 \\
\cline { 1 - 5 } & 0,0754 & 0,3385 & 0,3430 & 0,8439 \\
\hline Coeficiente & $4,69 \%$ & $9,95 \%$ & $13,84 \%$ & $15,58 \%$ \\
\hline Retornos Sector & $4,72 \%$ & $10,02 \%$ & $13,76 \%$ & $15,54 \%$ \\
\hline
\end{tabular}

Fuente: Enaho 2013

Elaboración Propia 
Por lo tanto, la segunda hipótesis específica es verdadera, existe el efecto señalización. De modo que ser graduado en el nivel superior, tanto universitario como no universitario, tiene una mayor tasa de retorno en el ingreso de las personas en los sectores Agricultura, Comercio, Construcción, Manufactura y Minería en base a las estimaciones realizadas. Tanto la teoría del capital humano, como la teoría del filtro o señalización, concuerdan que a mayor nivel educativo alcanzado mayor es el ingreso

Finalmente para la comprobación de la hipótesis general: "Las variables años de educación, años de experiencia, el estado civil, el sexo de las personas, el lugar de residencia, el ser trabajador dependiente, el haber recibido una educación privada, la salud, el fenotipo y el sector económico; explican el ingreso de una persona, en la estimación para el año 2013"

En base a las estimaciones realizadas se toma el segundo modelo modificado ${ }^{21}$ el cual presenta un $\mathrm{R}^{2}$ de 0,2663 frente a un Modelo básico de Mincer que presenta un $\mathrm{R}^{2}$ de $0,1798^{22}$ y al primer modelo que presenta con $\mathrm{R}^{2}$ de 0,2355 . Se concluye que no solo las variables años de educación y años de experiencia potencial son las que explican el ingreso (Mincer), además, se suman a ellas la variables del estado civil, el sexo de las persona, el lugar de residencia, el ser trabajador dependiente (Yamada); así como el haber recibido una educación privada, el fenotipo y el sector económico.

Por lo tanto, se comprueba que la hipótesis general es verdadera.

\footnotetext{
${ }^{21}$ El segundo modelo modificado que incluye la variable del Sector Minero.

${ }^{22}$ El modelo solo considera la educación y la experiencia (Ver Anexo 5)
} 


\section{CONCLUSIONES}

Una persona con mayor nivel educativo presenta una mayor tasa de retorno a la educación producto de su inversión reflejada en un mayor nivel de ingreso, como se mostro en las estimaciones realizadas para el año 2013. La relación entre el nivel de ingreso y el nivel de educación se centra en el interés de analizar a la persona y la importancia de la educación para incorporarse al mercado laboral. Asimismo, a través de la educación tener un mayor grado de participación en la economía, medido por el ingreso; y mejorar su condición de vida, un efecto no monetario.

La intención de estimar las tasas de retorno para la educación, en especial para el nivel educativo superior tenía el fin de encontrar variaciones positivas respecto a las tasas de retornos a la educación estimados por Yamada para el año 2004; asimismo, comprobar que a un mayor nivel educativo sea completo o incompleto, las tasas de retorno son mayores. Las conclusiones son las siguientes:

1. La menor tasa de retorno del nivel superior universitario y no universitario entre los años 2004 y 2013, se puede explicar desde el mercado laboral, la oferta de empleo para las personas con carreras universitarias (Figura 2.14) no crece al mismo ritmo de las personas egresadas (Figura 2.19). Asimismo, otro factor seria desde el sistema educativo que no responde a la demanda de los sectores productivos, y por tanto no se ve un efecto positivo de la educación en el ingreso, en algunos sectores económicos (Tabla 3.9, Tabla 3.11 y Tabla 3.15).

2. La teoría de la señalización, se cumple en el caso del Perú según la estimación del año 2013, presente en los cinco sectores analizados (Tabla 3.10, Tabla 3.12, Tabla 3.14, Tabla 3.16 y Tabla 3.18), una persona con estudios concluidos tiene una mayor tasa de retorno. Desarrollarse en el sector Minería presenta un mayor efecto en el ingreso, seguido del sector Construcción y Manufactura. 


\section{RECOMENDACIONES}

En el trabajo de investigación se aproximó la tasa de retorno a la educación relacionada al ingreso individual mediante el análisis econométrico, con énfasis en el nivel superior universitario y no universitario; por lo cual se presenta las siguientes recomendaciones:

1. Establecer políticas de estado para la educación superior enfocadas en promover y resguardar por la calidad educativa brindada en las universidades, tanto públicas y privadas, e institutitos superiores no universitarios.

2. Incentivar a los jóvenes que obtén por carreras científicas y tecnológicas, tanto universitarias como técnicas; los sectores en los que se utiliza mayor tecnología y sus aplicaciones son los que presentan mayores tasas de retorno a la educación superior.

Continuando con la línea de investigación, se deberían realizar estudios de los últimos años aplicando la metodología de Chiswick (1997) u otras variantes desarrolladas, el INEI ofrece una base de dato anual a través de la Enaho. 


\section{REFERENCIAS}

Becker, G. (1975). Human capital: a theoretical and empirical analysis, with special reference to education (2. ' ed.). New York: National Bureau of Economic Research Recuperado de http://www.nber.org/chapters/c3730

Brunner, J. y Elacqua, G. (2003). Informe Capital Humano en Chile. Santiago: Universidad Adolfo Ibáñez. Recuperado de http://www.oei.es/etp/informe_capital_humano_chile_brunner.pdf,

Calónico, S. y Ñopo, Hugo (2007). Retornos a la Educación Privada en el Perú. (DT. N ${ }^{\circ}$ 2007-603). Washington DC: Banco Interamericano de Desarrollo. Recuperado de http://repositorio.minedu.gob.pe/handle/123456789/99

Castro, J., Casavilca, P. y Lizarzaburu, R. (2010). Crecimiento económico y demanda por educación superior en el Perú: un estudio para el período 2004-2006. Lima: Universidad del Pacifico. Recuperado de http://repositorio.minedu.gob.pe/handle/123456789/798

Chiswick, B (1997). Interpreting the Coefficient of Schooling in the Human Capital Earnings Function. (DT. N 1997-1790). Washington DC: Banco Mundial. Recuperado de http://documents.worldbank.org/curated/en/635641468766205366/pdf/multipage.pdf

Díaz, J. (2008). Educación superior en el Perú: tendencias de la demanda y la oferta. En M. Benavides (Eds.), Análisis de programas, procesos y resultados educativos en el Perú: contribuciones (pp. 83-129). Lima: GRADE. Recuperado de http://www.grade.org.pe/download/pubs/analisis-2.pdf,

Destinobles, A. (2006). El capital humano en las teorías del crecimiento económico. Recuperado de http://www.eumed.net/libros-gratis/2006a/agd/,

Galassi, G. y Andrada, M. (2011). Relación entre educación e ingresos en las regiones geográficas de Argentina. Papeles de población, 17(69), 257-290. Recuperado de http://www.redalyc.org/pdf/112/11221117009.pdf,

Giménez, G. (2005). La dotación de capital humano de América Latina y el Caribe. Revista de la CEPAL. Recuperado de http://www.cepal.org/es/publicaciones/11071-ladotacion-de-capital-humano-de-america-latina-y-el-caribe,

Instituto Nacional de Estadística de Chile (2011). Vigencia del Concepto de Capital Humano. Autor. Recuperado del Instituto Nacional de Estadística de Chile http://www.ine.cl/canales/menu/publicaciones/estudios_y_documentos/documentost rabajo/capital_humano.pdf, 
Instituto Nacional de Estadística e Informatica - CEPAL (2010). Perú: Estimaciones y Proyecciones de Población, 1950-2050. Boletín de Análisis Demográfico, (36).

Instituto Nacional de Estadística e Informática. (2007). Censos Nacionales 2007: XI de Población y VI de Vivienda. Recuperado de https://www.inei.gob.pe/

Instituto Nacional de Estadística e Informática (2013). Encuesta nacional de hogares sobre condición de vida y pobreza: 2013. Recuperado de https://www.inei.gob.pe/

Lassibille, G. y Navarro, M. (2012). Un compendio de investigaciones en economía de la educación. Presupuesto y gasto público, 67(2012), 9-28. Recuperado de http://www.ief.es/documentos/recursos/publicaciones/revistas/presu_gasto_publico/ 67_01.pdf

Madrigal Torres, B. (2009). Capital humano e intelectual: su evaluación. Observatorio Laboral Revista Venezolana, 2 (3), 65-81. Recuperado de http://www.redalyc.org/articulo.oa?id=219016838004

Marshall, Alfred. (1920). Principles of Economics (8. ${ }^{\mathrm{a}}$ ed.). Londres: Editorial Macmillan

Martínez, A. y Sarmiento, M. (2005). Capital Humano y Crecimiento Económico en Venezuela, Recuperado de http://www.eumed.net/libros/2005/mpst.

Mincer, J. (1974). Schooling, Experience and Earnings. Human Behavior \& Social Institutions, 2. Recuperado de http://papers.nber.org/books/minc74-1

Ministerio de Educación - MINEDU (7 de Agosto, 2014). Censo Escolar 2013. Recuperado de http://sistemas02.minedu.gob.pe/anda/index.php/catalog/31

Ministerio de Trabajo y Promoción del Empleo (2000). Competencia laboral: eje de una Formación Profesional que promueva el desarrollo de los recursos humanos. Boletín de Economía Laboral 15, Lima: Autor. Recuperado de Mtpe http://www.mintra.gob.pe/portalinclusivo/mostrarContenido.php?id=90\&tip=548

Oroval, E. y Escardivul, O. (1998). Economía de la educación. Madrid: Encuentro Ediciones.

Romer, P. (1990). Human capital and growth: theory and evidence. Carnegie-Rochester conference series on public policy, 32, 251-286.

Sala-i-Martin, X. (2000). Apuntes de Crecimiento Económico (2. ${ }^{\mathrm{a}}$ ed.). Barcelona: Antoni Bosch.

Samuelson, P. y Nordhaus, W. (2005). Economía (18. ${ }^{\mathrm{a}}$ ed.), Madrid: McGraw Hill.

Sapelli, C. (2009). Los retornos a la educación en Chile: Estimaciones por corte transversal y por cohortes. 349. Recuperado de la Universidad Católica de Chile http://www.economia.puc.cl/docs/dt_349.pdf 
Schultz, Theodore. (1961). Invesment in Human Capital. The American Economic Review, $51(1), 1-17$.

Schultz, T. W. (1962). Reflections on investment in man. Journal of political economy, 70(5, Part 2), 1-8. Recuperado de http://www.nber.org/chapters/c13570

Vásquez, F. (2012). La relación entre crecimiento económico y desarrollo humano en el Perú. Revista Moneda, (151), 8-12. Recuperado del sitio de internet del Banco Central de Reserva http://www.bcrp.gob.pe/docs/Publicaciones/RevistaMoneda/moneda-151/moneda-151-02.pdf

Vera Tudela, R. (2013). Productividad en el Perú: evolución histórica y la tarea pendiente. Revista Moneda, (153), 24-27. Recuperado del sitio de internet del Banco Central de Reserva http://www.bcrp.gob.pe/docs/Publicaciones/Revista-Moneda/moneda153/moneda-153-06.pdf

Yamada, G. (2007). Retornos a la Educación Superior en el Mercado Laboral: ¿Vale la pena el esfuerzo?. Lima: Universidad del Pacífico.
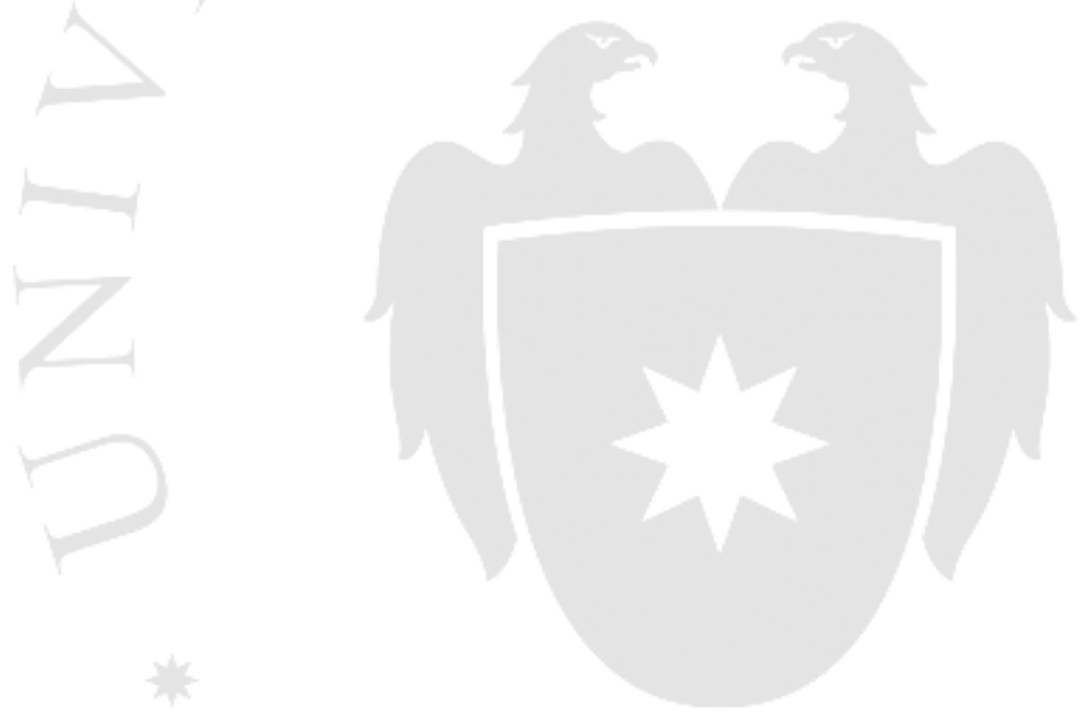


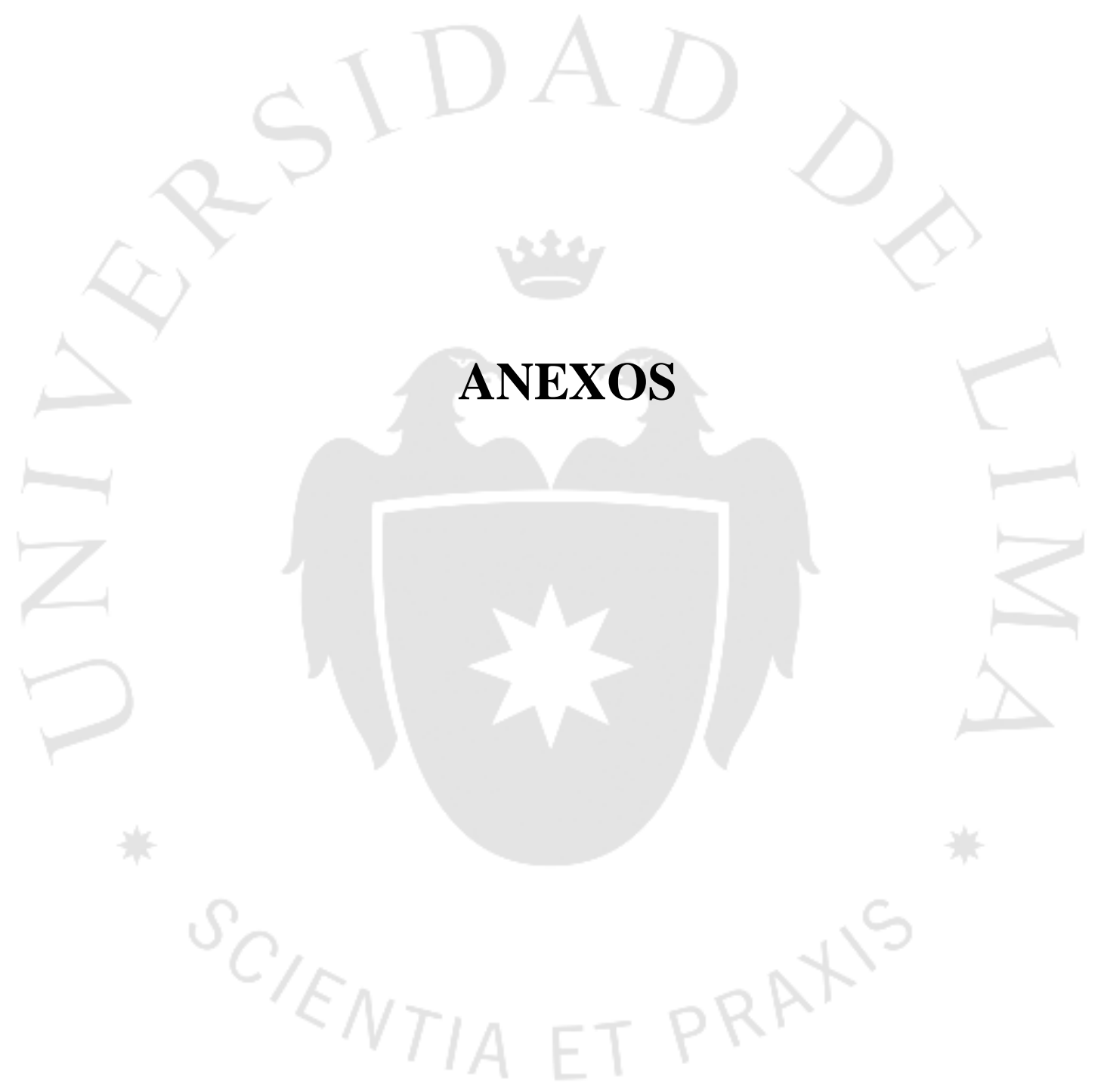




\section{ANEXO 1: Ficha Técnica Enaho 2013}

La Encuesta Nacional de Hogares (ENAHO) es la investigación que permite al Instituto Nacional de Estadística e Informática (INEI) desde el año 1995, efectuar el seguimiento de los indicadores sobre las condiciones de vida.

A inicios del año 2007, con el auspicio del Banco Mundial (BM), el INEl convocó a un Comité Asesor especializado conformado por representantes de organismos internacionales, de organismos gubernamentales nacionales, representantes de la comunidad académica y de centros de investigación. El Comité Asesor de Pobreza ha venido participando cada año en verificar la calidad de la ENAHO y la medición de la pobreza.

A partir del año 2010, mediante Resolución Suprema № 097-2010-PCM, publicado en el diario oficial El Peruano el 13 de abril del 2010, el Comité Asesor de Pobreza se constituye en Comisión Consultiva para Estimación de la Pobreza y otros indicadores relacionados en el país; cuyo objetivo es garantizar la calidad, transparencia y confianza de la información en el campo de la medición de la pobreza y otros indicadores relacionados.

En el mismo año a iniciativa del Ministerio de Economía y Finanzas se inician las coordinaciones para conformar una Comisión Técnica Interinstitucional que tendría a cargo la Tercera Revisión del Cuestionario de la ENAHO. Durante los años 2010 y 2011 se realizaron las reuniones del Comité de Revisión y posteriormente se validaron las propuestas de modificación en pruebas de campo. Finalmente en octubre del 2011 se aprobaron los cambios para el cuestionario que rigen a partir del año 2012.

\section{OBJETIVOS}

- Generar indicadores que permitan conocer la evolución de la pobreza, del bienestar y de las condiciones de vida de los hogares.

- Efectuar diagnósticos sobre las condiciones de vida y pobreza de la población.

- Medir el alcance de los programas sociales alimentarios y no alimentarios en la mejora de las condiciones de vida de la población.

- Servir de fuente de información a instituciones públicas y privadas, así como a investigadores.

- Permitir la comparabilidad con investigaciones similares, en relación con las variables investigadas.

\section{COBERTURA}

La encuesta se realiza en el ámbito nacional, en el área urbana y rural, en los 24 departamentos del país y en la Provincia Constitucional del Callao.

\section{PERIODO DE EJECUCIÓN}

En forma continua, iniciándose a partir de mayo del 2003. 


\section{PERIODO DE REFERENCIA}

Los períodos de referencia para las variables a investigarse en la Encuesta Nacional de Hogares 2013, son los siguientes:

- Características de la vivienda y del hogar:

- Día de la entrevista

- Últimos 12 meses

- Último gasto mensual

- Características de los miembros del hogar:

- Día de la entrevista

Residencia habitual: Últimos 30 días

Trabajo infantil: Semana pasada

- Educación

- Día de la entrevista

- Presente año

- Últimos 12 meses

Mes anterior

- Salud

- Día de la entrevista

- Últimas 4 semanas

- Últimos 3 meses

- Últimos 12 meses

- Empleo

Condición de actividad: Semana pasada

- Sistema de pensiones: Día de la entrevista

- Ingreso por trabajo:

Ordinarios: Día, semana, quincena, mes anterior

En especie: Últimos 12 meses

Extraordinarios por trabajo dependiente: Últimos 12 meses

- Trabajo anterior para los desocupados: Último trabajo realizado

- Ingresos por transferencias corrientes: Últimos 6 meses

- Ingresos por rentas de la propiedad: Últimos 12 meses

- Otros ingresos extraordinarios: Últimos 12 meses

- Ingreso por actividad agropecuaria: Últimos 12 meses

- Ingresos del trabajador independiente o empleador o patrono: Mes anterior, últimos 12 meses

- Gastos:

Últimos 15 días

- Mes anterior

Últimos 3 meses 
Últimos 12 meses

Día de la entrevista

Semana anterior

- Programas sociales de ayuda alimentaria:

Últimos 3 meses

- Programas sociales no alimentarios:

Últimos 3 años

- Participación ciudadana:

- Día de la entrevista

- Gobernabilidad, democracia y transparencia

- Día de la entrevista

Últimos 12 meses

- Percepción del hogar

- Día de la entrevista

- Últimos 12 meses

- Discriminación

Últimos 5 años

\section{POBLACIÓN OBJETIVO}

La población de estudio está definida como el conjunto de todas las viviendas particulares y sus ocupantes residentes en el área urbana y rural del país.

Por no ser parte de la población de estudio, se excluye a los miembros de las fuerzas armadas que viven en cuarteles, campamentos, barcos, y otros. También se excluye a las personas que residen en viviendas colectivas (hoteles, hospitales, asilos y claustros religiosos, cárceles, etc.).

\section{DISEÑO Y MARCO MUESTRAL}

\section{Marco muestral:}

El marco muestral para la selección de la muestra lo constituye la información estadística proveniente de los Censos de Población y Vivienda y material cartográfico actualizado para tal fin.

\section{Unidades de Muestreo:}

\section{En el Área Urbana}

- La Unidad Primaria de Muestreo (UPM) es el centro poblado urbano con 2 mil y más habitantes.

- La Unidad Secundaria de Muestreo (USM) es el conglomerado que tiene en promedio 120 viviendas particulares.

- La Unidad Terciaria de Muestreo (UTM) es la vivienda particular. 


\section{En el Área Rural}

- La Unidad Primaria de Muestreo (UPM) es de dos tipos:

- El centro poblado urbano con 500 a menos de 2 mil habitantes.

- El Área de Empadronamiento Rural (AER) el cual tiene en promedio 100 viviendas particulares.

- La Unidad Secundaria de Muestreo (USM) es de dos tipos:

- El conglomerado que tiene en promedio 120 viviendas particulares.

- La vivienda particular

- La Unidad Terciaria de Muestreo (UTM) es la vivienda particular.

Tipo de muestra:

La muestra es del tipo probabilística, de áreas, estratificada, multietápica e independiente en cada departamento de estudio.

A fin de medir los cambios en el comportamiento de algunas características de la población, desde el año 2008 se viene implementando muestras panel de viviendas, en la cual viviendas encuestadas son nuevamente investigadas cada año.

En la muestra no panel se visitan cada año los mismos conglomerados en el mismo mes de encuesta pero se seleccionan distintas viviendas.

El nivel de confianza de los resultados muestrales, es del 95\%.

\section{Tamaño de la muestra:}

El tamaño anual de la muestra 2013 es de 31690 viviendas particulares, correspondiendo 19410 viviendas al área urbana y 12280 viviendas al área rural.

Así mismo, el tamaño de la muestra panel es de $8 \mathbf{8 0 8}$ viviendas particulares mientras que el tamaño de la muestra no panel es de 22882 viviendas particulares.

La muestra de conglomerados en el ámbito nacional es de 4770 , correspondiendo 3235 conglomerados al área urbana y 1535 conglomerados al área rural. Con respecto al tamaño de la muestra panel es de 1331 conglomerados mientras que el tamaño de la muestra no panel es de 3439 conglomerados.

\section{Distribución de la muestra:}

A continuación se presenta la distribución de la muestra ENAHO 2013 según departamentos de estudio: 


\begin{tabular}{|c|l|c|c|}
\hline \multirow{2}{*}{ № } & \multirow{2}{*}{ DEPARTAMENTO } & \multicolumn{2}{|c|}{ MUESTRA 2013 } \\
\cline { 3 - 4 } & \multicolumn{1}{|c|}{ TOTAL } & $\mathbf{4 7 7 0}$ & $\mathbf{3 1 6 9 0}$ \\
\hline & COMGLOMERADOS & VIVIENDAS \\
\hline 2 & ÁNCASH & 167 & 1200 \\
\hline 3 & APURÍMAC & 171 & 1178 \\
\hline 4 & AREQUIPA & 130 & 956 \\
\hline 5 & AYACUCHO & 213 & 1360 \\
\hline 6 & CAJAMARCA & 163 & 1146 \\
\hline 7 & CUSCO & 174 & 1280 \\
\hline 8 & HUANCAVELICA & 175 & 1228 \\
\hline 9 & HUÁNUCO & 138 & 1034 \\
\hline 10 & ICA & 171 & 1224 \\
\hline 11 & JUNÍN & 212 & 1344 \\
\hline 12 & LA LIBERTAD & 200 & 1350 \\
\hline 13 & LAMBAYEQUE & 197 & 1348 \\
\hline 14 & LIMA & 861 & 1264 \\
\hline 15 & LORETO & 190 & 5286 \\
\hline 16 & MADRE DE DIOS & 100 & 1254 \\
\hline 17 & MOQUEGUA & 142 & 668 \\
\hline 18 & PASCO & 126 & 918 \\
\hline 19 & PIURA & 221 & 850 \\
\hline 20 & PUNO & 164 & 1430 \\
\hline 21 & SAN MARTÍN & 189 & 1270 \\
\hline 22 & TACNA & 154 & 984 \\
\hline 23 & TUMBES & 136 & 1102 \\
\hline 24 & UCAYALI & 169 & \\
\hline & & & 1154 \\
\hline
\end{tabular}

\section{NIVELES DE INFERENCIA}

La muestra de la ENAHO permite obtener estimaciones de las características sociodemográficas de la población para los niveles de inferencia siguientes:

\section{a. De la muestra Integrada (panel y no panel)}

Anual

- Nacional

- Urbano Nacional

- Rural Nacional

- 24 departamentos, cada uno como dominio de estudio

- Costa Urbana

- Costa Rural

- Sierra Urbana

- Sierra Rural

- Selva Urbana

- Selva Rural

- Área Metropolitana de Lima y Callao 


\section{Trimestral}

- Nacional

- Urbano Nacional

- Rural Nacional

\section{b. De la muestra panel}

\section{Anual}

- Nacional

- Urbano Nacional

- Rural Nacional

- Costa

- Sierra

- Selva

De acuerdo con el diseño muestral, se podrá producir resultados para diferentes "arreglos" de unidades y su nivel de desagregación dependerá fundamentalmente de la precisión (error de muestreo) con que se estime el dato, y este del tamaño de la muestra para cada caso.

\section{UNIDAD DE INVESTIGACIÓN}

La unidad de investigación está constituida por:

- Los integrantes del hogar familiar,

- Los trabajadores del hogar con cama adentro, reciban o no pago por sus servicios,

- Los integrantes de una pensión familiar que tienen como máximo 9 pensionistas, y

- Las personas que no son miembros del hogar familiar, pero que estuvieron presentes en el hogar los últimos 30 días.

No serán investigados:

- Los integrantes de una pensión familiar que tiene de 10 a más pensionistas, y

- Los trabajadores del hogar con cama afuera.

\section{INFORMANTES}

- Jefe del Hogar

- Cónyuge

- Perceptores (se refiere a la población de 14 años y más de edad que recibe ingresos monetarios)

- Personas de 12 años y más (a partir de esta edad de realiza la entrevista directa de la población, con respecto a los menores de 12 años la información la proporciona una persona responsable del hogar)

- Personas de 18 años y más (corresponde a la población que es seleccionada para proporcionar información del módulo de opinión).

\section{NÚMERO DE PREGUNTAS E ITEMS: 344 preguntas y 324 ítems}

\section{Preguntas:}

ENAHO. $01=132$

ENAHO. 01-A $=128$

ENAHO. 01-B $=37$

ENAHO. $02=25$

ENAHO. $04=22$ 
Items:

Gastos $601 \quad=203$ ítems

Gastos 602-612= $=121$ ítems

\section{CARACTERÍSTICAS DE LA ENCUESTA}

- Método de Entrevista: Directa utilizando equipos móviles para captura de datos (PDA).

- Tipo de Encuesta: Encuesta de Derecho, es decir, la población de estudio estará constituida por todos los residentes habituales del hogar.

- Personal de Campo: Coordinadores Departamentales, Supervisores y Encuestadores.

\section{TEMAS INVESTIGADOS}

\section{Características de la vivienda y del hogar (26 preguntas)}

- Vivienda (7 preguntas)

- Tipo de vivienda

- Material de construcción predominante: paredes, pisos y techos

- Número total de habitaciones

- Número de habitaciones para dormir

- Licencia de construcción / Asistencia técnica

- Hogar (19 preguntas)

- Régimen de tenencia

- Alquiler mensual y alquiler imputado

- Título de propiedad

- Registro del título de propiedad en la SUNARP

- Obtención de créditos para compra de vivienda, mejoramiento, o construcción de vivienda nueva

- Institución que le otorga el crédito y monto total del crédito

- Abastecimiento de agua en el hogar

- Potabilidad del agua

- Evaluación de la calidad bacteriológica del agua

- Disponibilidad de servicio higiénico

- Tipo de alumbrado del hogar

- Tipo de servicio eléctrico del hogar según tipo de medidor

- Tipo de combustible para cocinar los alimentos

- Tenencia de teléfono fijo, celular, TV. cable y/o internet

- Ultimo gasto mensual por abastecimiento de agua, alumbrado, combustible para cocinar, teléfono, celular, Internet, etc.

2. Características de los miembros del hogar (22 preguntas)

- Número de orden de los miembros del hogar

- Identificación de los miembros de hogar

- Relación de parentesco

Número de núcleo familiar

- Relación de parentesco con el jefe del núcleo familiar

- Miembros del Hogar 
- Tiempo de ausencia en el hogar (últimos 30 días)

- Tiempo de permanencia en el hogar (últimos 30 días)

Sexo

Edad

Provincia y distrito donde nació

- Estado civil o conyugal

- Condición de ocupación menores de 5 a 17 años de edad

- Condición de actividad menores de 5 a 17 años de edad

- Descripción de tareas realizadas en el hogar o fuera del hogar

- Número de horas que realizó las tareas

- Número de orden de personas de 3 años y más de edad que son residentes habituales, que les corresponde aplicar el capítulo educación

- Número de orden de todas las personas residentes habituales que les corresponde aplicar el capítulo salud

- Número de orden de personas de 14 años y más de edad que son residentes habituales que les corresponde aplicar el capítulo empleo e ingreso

- Número de orden en el cap. 200 de la ENAHO 2012

- Persona nueva en la ENAHO 2012

- Motivo por el que la persona ya no vive en el hogar (Vivienda PANEL)

\section{Educación - Para personas de 3 años y más de edad (35 preguntas)}

- Número de orden del informante

- Lengua materna que aprendió en su niñez

- Año o grado de estudios y nivel alcanzado

- Carrera superior universitaria o no universitaria que estudia o ha estudiado

- Nivel de alfabetismo

- Programa de alfabetización

- Matriculados en algún programa de educación básica o superior el año pasado

- Año o grado de estudios al que asistió el año pasado

- Resultado que obtuvo el año pasado

- Matriculado en algún centro o programa de educación básica o superior en este año

- Año o grado de estudios al que está matriculado actualmente

- Asistencia actual a algún centro o programa de educación básica o superior

- Opinión sobre el servicio educativo

- Asistencia en los últimos 12 meses a algún centro de enseñanza cuya duración sea menor a 3 años como academia, CEOS u otros

- En el presente año o años anteriores estudia(ó) en programas de capacitación técnico productiva

- Nombre del último programa de capacitación técnico productiva

- Gasto en estudios realizado en los últimos 12 meses

- Gasto en estudios en el mes anterior

- Razón por la que no asiste a un Centro de Enseñanza Regular (para menores de 25 años)

- Uso del servicio de Internet

- Donde uso el servicio de Internet

- Lugar donde usa Internet con mayor frecuencia

Frecuencia de uso del servicio de Internet

Como obtuvo el servicio de Internet en la cabina pública

- Monto mensual por servicio de Internet en cabina pública

- Monto estimado por servicio de Internet en cabina pública

- Para qué uso el Internet

- Le enseñaron a leer y escribir en su lengua materna en la escuela dónde asistió al 2do grado el año 2011

Participación en la evaluación censal de estudiantes (ECE) 2011 
- Recepción de reporte individual con los resultados de la ECE 2011

- Forma de entrega de los reportes de resultados ECE 2011

\section{Salud - Para todas las personas (21 preguntas)}

- Número de orden del informante

- Fecha de nacimiento

- Razones por las que no tiene DNI

- Razones por las que no tiene partida de nacimiento

- Personas con alguna enfermedad o malestar crónico

Sufrió algún síntoma, enfermedad o accidente en las últimas 4 semanas

- Lugar de la consulta

Personal que le dio atención

- Tiempo para obtener la cita de atención

Tiempo de desplazamiento hasta el establecimiento de salud

- Tiempo de espera para ser atendido

- Razones por las que no acudió a un centro o establecimiento de salud

- Consulta por control del niño sano, programa de vacunas en los últimos 3 meses

- Consulta por planificación familiar, suplemento de hierro en los últimos 12 meses

- Servicios de consulta, medicinas, análisis, etc., que recibió en las últimas 4 semanas. Servicio dental y conexos, oftalmológico, vacunas, etc., que recibió en los últimos 3 meses. Servicio de hospitalización, controles de embarazo o parto en los últimos 12 meses.

- Quien efectuó el gasto de los servicios de: consulta, dental, hospitalización, etc.

Monto total de la compra o servicio

- Lugar donde adquirió los servicios de consulta, dental, hospitalización, etc.

- El monto estimado de los servicios de consulta, dental, hospitalización, etc.

- Afiliación al sistema de prestaciones de salud

- Aportación de las cuotas de afiliación

\section{Empleo e Ingreso - Para personas de 14 años y más de edad (119 preguntas)}

- Período de referencia, número de orden de la persona, nombre de la persona y número de orden del informante (4 preguntas)

- Condición de actividad - Semana Pasada (4 preguntas)

- Tenencia de trabajo

- Tenencia de algún empleo fijo o negocio propio al que próximamente volverá

- Actividad realizada al menos una hora para obtener ingresos (Incluye trabajador familiar no remunerado)

- Ocupados

- Ocupación principal (14 preguntas)

- Ocupación

- Tareas realizadas en su ocupación

- Rama de actividad

- Categoría de ocupación

- Tenencia de trabajador familiar no remunerado

- Tenencia de trabajadores remunerados

- Empresa o entidad donde trabaja en su actividad

- Registrado como persona jurídica

- Negocio o empresa que lleva los libros de ingresos y gastos de la SUNAT

- Tipo de pago o ingreso

- Tipo de contrato

- Tamaño del establecimiento 
- Total Horas trabajadas

- Tiempo que trabaja en esta ocupación principal

- Ocupación secundaria (9 preguntas)

- Tenencia de ocupación secundaria

- Actividad realizada al menos una hora para obtener ingresos

- Rama de actividad

- Categoría de ocupación

- Empresa o entidad donde trabaja en su actividad

- Registrado como persona jurídica

- Negocio o empresa que lleva los libros de ingresos y gastos de la SUNAT

- Tamaño del establecimiento

- Total de horas trabajadas

- Total Horas (6 preguntas)

- Total horas trabajadas en la actividad principal y secundaria

- Horas trabajadas normalmente

- Razón por la que no trabajó el número total de horas

- Deseo de trabajar más horas de lo normal

- Disponibilidad para trabajar más horas

- Número de horas adicionales que hubiera trabajado

- Búsqueda de otro empleo (2 preguntas)

- Deseó y realización de acciones para cambiar de empleo

- Motivo de búsqueda de otro trabajo

- Desocupados (7 preguntas)

- Búsqueda de trabajo

- Actividades que realizó la semana pasada

- Deseo de trabajar

- Disponibilidad para trabajar

- Razón por la que no buscó trabajo

- Actividades que realizó para conseguir trabajo

- Tiempo de búsqueda de trabajo

- Trabajo anterior (3 preguntas)

- Trabajó o no anteriormente

- Rama de actividad

- Categoría de ocupación

\section{- INGRESOS POR TRABAJO DEL HOGAR}

a. Ocupación Principal (7 preguntas)

- Por trabajo dependiente

- Ingreso monetario

- Frecuencia de obtención de ingreso

- Ingreso total, según la frecuencia con que recibe (diario, semana, quincena o mes anterior)

- Descuento de ley

- Impuestos

- Otros descuentos

- Ingreso líquido

- Pago en especie

- Valor estimado 
- Frecuencia con que recibe

- Por trabajo independiente

- Ingreso monetario

- Ganancia Neta en el mes anterior

- Autoconsumo o autosuministro

- Utilización de Bienes Producidos y/o Adquiridos con fines comerciales

- Valor de los productos utilizados por Autoconsumo o autosuministro

b. Ocupación Secundaria (7 preguntas)

- Ingresos por trabajo dependiente

- Ingreso ordinario en el mes anterior

- Ingreso total

- Descuento de ley

- Impuestos

- Otros descuentos

- Ingreso líquido

- En especie en los últimos 12 meses

- Frecuencia con que recibe

- Valor estimado

- Ingresos por trabajo independiente

- Ingreso monetario y/o en especie

- Ganancia neta en el mes anterior

- Utilización de bienes producidos y/o adquiridos con fines comerciales

- Valor de los productos utilizados por autoconsumo o autosuministro

c. Ingresos Extraordinarios por Trabajo Dependiente (ocupación principal y/o secundaria) - (1 pregunta)

> INGRESO POR TRABAJO DEL PRODUCTOR AGROPECUARIO (25 preguntas)

- Tipo de actividad agropecuaria

- Actividad agropecuaria permanente o eventual

- Superficie total de la explotación agropecuaria

- Total de parcelas que trabaja

- Número de parcela

- Extensión de la parcela

- Uso de la parcela, en los últimos 12 meses

- Régimen de tenencia

- Parcelas que cuentan con titulo de propiedad

- Tipo de riego de las tierras agropecuarias

- Total de la producción agrícola

- Total de los subproductos agrícolas

- Total de la producción forestal

- Total de gastos en actividad agrícola y/o forestales

- Total de la producción pecuaria 
- Total de los subproductos pecuarios

- Total de gastos en actividades pecuarias

> INGRESO POR TRABAJO DEL TRABAJADOR INDEPENDIENTE INFORMAL (22 preguntas)

Estas preguntas se aplican para aquellas personas que el capítulo de empleo fueron identificadas como "empleador/patrono o trabajador independiente, declaran ser personas naturales o no están registrados en la SUNAT y además tener ingreso por negocio/servicio", sea en la ocupación principal o secundaria.

- Características básicas del negocio o establecimiento

- Negocio o establecimiento registrado en el registro público

- Cómo lleva las cuentas de su negocio o actividad

- Lugar donde desempeña su negocio o su actividad

- Régimen de tenencia

- Servicios básicos con que cuenta el local o establecimiento

- Motivos por el cual inició dicho negocio o actividad

- Tiempo de trabajo en su negocio o establecimiento

- Total de personas remuneradas y/o no remuneradas que trabajan en el negocio o actividad

- Funcionamiento del negocio en los últimos 12 meses

- Tipo de actividad que realizó en su negocio o establecimiento la semana pasada

- Producción de Bienes

- Ventas

- Autoconsumo

- Gasto en materia prima e insumos

- Comercio

- Ventas

- Autosuministro

- Compra de mercaderías

- Servicios

- Ingresos totales

- Autosuministro

- Gastos

- Otros gastos

- Envases, embalajes, combustible, electricidad, agua, etc.

- Características de la mano de obra y el empleo

- Hoja de control

- INGRESOS POR TRANSFERENCIAS CORRIENTES (ÚLTIMOS 6 MESES) - 1 pregunta

- Frecuencia con que lo recibe

- Monto recibido por vez (del país o extranjero)

- Lugar donde cobra (Del extranjero)

- Destino del envío (Del extranjero)

- INGRESOS POR RENTAS DE LA PROPIEDAD (ÚLTIMOS 12 MESES) - 1 pregunta

- Frecuencia con que lo recibe

- Monto recibido por vez 
- INGRESOS EXTRAORDINARIOS (ÚLTIMOS 12 MESES) - 1 pregunta

- Monto recibido

\section{Sistema de Pensiones (2 preguntas)}

- Sistema de pensiones al que está afiliado

Ultimo mes y año que aportó

\section{Etnicidad (3 preguntas)}

- Por sus antepasados y de acuerdo a sus costumbres se considera

- Pertenencia a un pueblo indígena

- Pueblo indígena al que pertenece

\section{Gastos del hogar (67 preguntas y 324 ítems)}

- ALIMENTOS

a. Gastos en alimentos y bebidas consumidas dentro del hogar (últimos 15 días), 203 ítems.

- Relación de productos obtenidos, consumidos, comprados o regalados

- Formas de obtención de los productos

- Frecuencia de compra, cantidad y unidad de medida

- Lugar de compra

- Monto total de la compra

- Frecuencia obtenida, cantidad y unidad de medida

b. Alimentos para consumir dentro del hogar obtenidos de instituciones benéficas (últimos 15 días)

- Alimentos obtenidos, comprados o regalados de instituciones benéficas

- Número de veces por semana

- Número de raciones recibidas cada vez

- Número de miembros del hogar que se beneficiaron

- Pago o no por el alimento recibido

- Monto pagado cada vez por el alimento

- Pago mensual por otros conceptos

c. Alimentos consumidos fuera del hogar obtenidos de instituciones benéficas (Menores de 14 años)

- Alimentos obtenidos, comprados o regalados de instituciones benéficas

- Número de veces por semana

- Número de raciones recibidas cada vez

- Número de miembros del hogar que se beneficiaron

- Pago o no por el alimento recibido

- Monto pagado cada vez por el alimento Pago mensual por otros conceptos

d. Alimentos consumidos fuera del hogar obtenidos de restaurantes, ambulante, etc. (De 14 años y más edad)

- Alimento consumido la semana pasada

- Número de veces por semana

- Donde lo consumió

- Pago por el alimento

- Cuanto pago cada vez

- El consumo fue individual

- Numero de personas que consumieron

- otros gastos

a. Mantenimiento de la vivienda (mes anterior)

- Productos y/o servicios de mantenimiento de la vivienda, obtenidos, 
comprados y/o regalados

- Formas de obtención

- Lugar de compra

- Monto total de la compra

- Valor estimado de la adquisición

b. Gastos en transportes y comunicaciones (mes anterior)

- Productos y/o servicios obtenidos, comprados o regalados

- Formas de obtención de los productos y/o servicios

- Lugar de compra

- Monto total de la compra del producto o servicio

- Valor estimado de la adquisición del producto y/o servicio.

c. Gastos en transportes y comunicaciones (semana anterior)

d. Gastos en servicios a la vivienda (mes anterior)

- Uso de los servicios a la vivienda

- Formas de obtención de los servicios

- Monto pagado por el servicio

- Valor estimado de la adquisición del servicio.

e. Esparcimiento, diversión y servicios de cultura (mes anterior)

- Productos y/o servicios obtenidos, comprados y/o regalados

- Formas de obtención

- Lugar de compra

- Monto total de la compra del producto y/o servicio

- Valor estimado de la adquisición.

f. Bienes y servicios de cuidados personales (mes anterior).

- Productos y/o servicios obtenidos, comprados y/o regalados

- Formas de obtención

- Lugar de compra

- Monto total de la compra del producto y/o servicio

- Valor estimado de la adquisición.

g. Vestido y calzado (últimos 3 meses)

- Productos y/o servicios obtenidos, comprados y/o regalados.

- Formas de obtención

- Lugar de compra

- Monto total de la compra del producto y/o servicio

- Valor estimado de la adquisición.

h. Gastos de transferencia (últimos 3 meses)

- Gastos realizados por transferencias: alimentos, donaciones a instituciones, impuestos directos, remesas periódicas a otros miembros del hogar, etc.

- Monto total del gasto realizado

i. Muebles y enseres (últimos 12 meses)

- Productos y/o servicios obtenidos, comprados o regalados

- Formas de obtención

- Lugar de compra

- Monto total de la compra del producto y/o servicio

- Valor estimado de la adquisición. 
j. Otros bienes y servicios (últimos 12 meses)

- Productos y/o servicios obtenidos, comprados o regalados

- Formas de obtención

- Lugar de compra

- Monto total de la compra del producto y/o servicio

- Valor estimado de la adquisición.

k. Equipamiento del hogar

- Tenencia de artefactos y/o vehículos del hogar

- Número de artefactos y/o vehículos que tiene el hogar

- Tipo de uso

- Año de adquisición

- Mes de adquisición

- Costo del equipo

- Valor actual del mismo bien en las condiciones que lo adquirió

I. Venta de inmuebles, equipos

- Últimos 12 meses ¿el hogar ha vendido:

\section{Programas sociales de ayuda alimentaria (7 preguntas)}

- Programas sociales de ayuda alimentaría que recibió

Nombre de miembros del hogar que recibieron la ayuda alimentaría

- Tipo de programa de ayuda alimentaría recibida

- Lugar dónde recibió

- Frecuencia con que recibió

- Paga o retribución por la ayuda alimentaría

- Motivo por el que pago

10. Programas sociales no alimentarios (4 preguntas)

- Programas sociales no alimentarios que recibió

- Nombre de miembros del hogar que recibieron los programas no alimentarios

- Tipo de programa no alimentario recibido

- Período que fue beneficiario del programa

\section{Participación ciudadana (6 preguntas)}

- Participación o inscripción en algún grupo de organización, asociación y/o programa social

- Número de miembros del hogar que participan o están inscritas en algún grupo, organización, asociación y/o programa social

- Número de personas que participan o están inscritas por tipo de organización, asociación y/o programas sociales

- Cargo que ocupa en la organización, asociación, y/o programa social

- Forma como accedió a la organización, asociación, y/o programa social

- Motivo por la cual no ha participado en las elecciones de las organizaciones, asociaciones, y/o programas sociales

\section{MODULO DE OPINIÓN (37 preguntas)}

a. Gobernabilidad (Personas de 18 años y más de edad)

- Grado de confianza en las Instituciones o empresas públicas

- Principales problemas del país

- Opinión sobre gestión del gobierno central, regional y local 
b. Democracia (Personas de 18 años y más de edad)

- Conocimiento de democracia

- Características más importantes de la democracia

Utilidad de la democracia

Importancia de la democracia en el Perú

- Funcionamiento de la democracia

- Motivos por los cuales funciona mal la democracia

- Opiniones sobre tipos de gobierno

- Existencia de respeto o no en el país a la libertad de expresión, la igualdad frente a la ley, elecciones transparentes.

- A que grupo o comunidad se siente orgulloso de pertenecer

c. Transparencia y Corrupción (Personas de 18 años y más de edad)

- En los últimos 12 meses le solicitaron, dio propinas sobornos a funcionarios del Estado.

- Uso de los servicios públicos en los últimos 12 meses

- Código del servicio

- Le solicitaron o dio propinas sobornos, coimas, etc., a funcionarios del estado

- Monto gastado en propinas, sobornos, coimas

- Realizó denuncia a las autoridades

- Motivos de no denuncia

d. Percepción del hogar (Solo para el jefe del hogar y cónyuge)

- Evaluación sobre la actual situación económica de su hogar

- Evaluación del nivel de vida de su hogar y la comunidad

- Motivo por el cual mejoró el nivel de vida de su hogar

e. Percepción de los programas no alimentarios (Jefe del hogar y cónyuge)

- Evaluación sobre el grado de satisfacción por los programas

- Evaluación de la contribución en la mejora del nivel de vida en su hogar

f. Nivel de vida / Situaciones adversas (Solo para el jefe del hogar y cónyuge)

- Evaluación del bienestar del hogar en relación al ingreso

- Monto mínimo mensual que requiere el hogar para vivir (alimentos, vestido, etc.)

- Estabilidad o no de los ingresos del hogar

- Calificación del hogar

- Afección de problemas en los últimos 12 meses

- Implicancia de los problemas en el hogar

- Que solución se dio a estos problemas

- Solución de los problemas

- Tiempo en que se solucionaran

g. Educación de los padres del jefe del hogar

- Nivel de estudios alcanzado por sus padres

h. Discriminación (Solo para el jefe del hogar y cónyuge)

- Se ha sentido discriminado en los últimos 5 años

- Motivo de discriminación 


\section{DEFINICIONES BÁSICAS}

- Vivienda Particular.- Es todo local o recinto estructuralmente "separado e independiente" que ocupa un edificio o una parte de él, y está conformado por una habitación o conjunto de habitaciones, usada o destinada a ser habitada por una o más personas con o sin vínculos familiares, siempre que en el período de la entrevista no se utilice para otros fines. Una vivienda particular puede servir de alojamiento a un máximo de cinco hogares. Por excepción se consideran como tal a las pensiones familiares que albergan menos de 10 pensionistas.

Hogar.- Es el conjunto de personas, sean o no parientes (padres, hijos solteros, hijos casados, hermanos, tíos etc.), que ocupan en su totalidad o en parte una vivienda, comparten las comidas principales y atienden en común otras necesidades vitales.

Se incluye también en este grupo a las personas a quienes el Jefe considera que son miembros del hogar, por razones de afecto (ahijados, compadres, padrinos, etc.). Por excepción, se considera hogar al constituido por una sola persona.

- Actividad Económica.- Es la producción de bienes y servicios tal como han sido establecidos en el Sistema de Cuentas Nacionales (SCN) de las Naciones Unidas. Abarca toda la producción de mercado y algunos tipos de producción de nomercado, incluyendo la producción y elaboración de productos primarios para autoconsumo, la construcción por cuenta propia y otras producciones de activos fijos para uso propio. Excluye las actividades no remuneradas, como las tareas domésticas no retribuidas y los servicios voluntarios a la comunidad.

- Población en Edad de Trabajar (PET).- Es aquella población definida por las normas internacionales (OIT), como apta en cuanto a edad para ejercer funciones productivas (de 14 años y más de edad). Esta se subdivide en población económicamente activa (PEA) y población económicamente inactiva (PEI).

- Población Económicamente Activa (PEA).- Comprende a todas las personas de catorce (14) años y más de edad que en la semana de referencia se encontraban: i. Trabajando, ii. No trabajaron pero tenían trabajo, iii. Se encontraban buscando activamente un trabajo.

- Ocupado.- Para determinar que una persona se encuentra ocupada se utilizan cuatro criterios:

i. Ocupados son las personas de 14 años y más de edad que estuvieron participando en alguna actividad económica, en el período de referencia.

ii. Los trabajadores dependientes, que teniendo empleo fijo, no trabajaron, la semana anterior, por hallarse de vacaciones, huelga, licencia por enfermedad, licencia pre y post-natal, etc., todas ellas pagadas.

iii. Los trabajadores independientes, que estuvieron temporalmente ausentes del trabajo durante el período de referencia; pero, la empresa o negocio siguió funcionando.

iv. A las personas que no estuvieron en ninguna de las condiciones anteriores se les indaga si realizaron alguna actividad económica en el período de referencia, al menos una hora, por lo cual recibirá pago en dinero y/o especie. El objetivo es recuperar las actividades realizadas; pero, que no son consideradas como trabajo por las personas. 
Asimismo, en la definición de ocupados se incluye a las personas que trabajaron 15 horas o más como trabajador familiar no remunerado, a los practicantes con o sin remuneración y los oficiales y suboficiales de las Fuerzas Armadas y las Fuerzas Policiales.

- Desocupado.- Según la OIT (1983), los desocupados son todas aquellas personas, de uno u otro sexo, que durante el período de referencia cumplen en forma simultánea con los tres requisitos siguientes:

i. Sin empleo, es decir; que no tienen ningún empleo, como asalariado o como independiente.

ii. Corrientemente disponible para trabajar, es decir; con disponibilidad para trabajar en un empleo asalariado o independiente, durante el período de referencia.

iii. En busca de empleo, es decir; que habían tomado acciones concretas para buscar un empleo asalariado o independiente, en un período de referencia especificado.

Este concepto abarca tanto a las personas que buscaron trabajo pero que trabajaron antes (cesantes), como a los que buscaron trabajo por primera vez (aspirantes). Para fines de la encuesta se considera como desocupado a las personas de 14 años y más de edad, que en la semana de referencia buscaron trabajo, o hicieron gestiones para establecer un negocio por cuenta propia.

Para fines comparativos se considera como desocupados a aquellos trabajadores familiares no remunerados que trabajaron menos de 15 horas semanales.

- Tasa de Actividad (o de Participación).- Es la proporción de la PEA (población económicamente activa) respecto de la PET (población en edad de trabajar). La tasa de actividad es el indicador que mide el grado de participación de la población en edad de trabajar en la actividad económica.

- Tasa de Empleo.- Es la proporción de personas que se encuentran activamente empleadas sobre el total de la población económicamente activa.

- Tasa de Desempleo Abierto.- Es la proporción de personas desempleadas o desocupadas, que están buscando activamente un empleo, entre la PEA. Para determinar a los desempleados abiertos se consideran las condiciones siguientes: "Sin empleo", "Corrientemente disponible para trabajar" y en "Busca de empleo".

\section{CONSTRUCCIÓN DE LOS FACTORES DE EXPANSIÓN}

La metodología de estimación para procesar los datos de la Encuesta Nacional de Hogares, involucra el uso de un peso o factor de expansión para cada registro que será multiplicado por todos los datos que conforman el registro correspondiente.

El factor final para cada registro tiene dos componentes:

- El factor básico de expansión y

- Los factores de ajuste por la no entrevista

El factor básico de expansión para cada hogar muestral es determinado por el diseño de la muestra. Equivale al inverso de su probabilidad final de selección, el mismo que es el producto de las probabilidades de selección en cada etapa. 
El diseño de la muestra de la Encuesta Nacional de Hogares, involucra hasta tres etapas de muestreo donde las unidades son seleccionadas con probabilidades proporcionales al tamaño excepto la última etapa. En la última etapa se selecciona un número de viviendas para cada conglomerado teniendo en cuenta un intervalo de selección.

Por consiguiente, los factores de expansión básicos para la Encuesta Nacional de Hogares 2013 son ajustados teniendo en cuenta las proyecciones de población por grupos de edad y sexo para cada mes de encuesta y niveles de inferencia propuestos en el diseño de la muestra. Mayor detalle se encuentra en el documento anexo "Metodología del Cálculo del Factor de Expansión Anual".

Cabe mencionar que se podrán obtener estimaciones para otros niveles de desagregación y su precisión o confiabilidad estadística dependerá fundamentalmente del número de casos u observaciones contenidas en la base de datos.

\section{IMPUTACIÓN}

El proceso de imputación se realiza en dos etapas:

- Primera etapa corresponde a la asignación de las características cualitativas a los miembros del hogar que no informaron los módulos de educación (cap. 300), salud (cap. 400) y empleo (cap. 500) dejando como valor missing las variables cuantitativas. Para la imputación de las variables cualitativas se utiliza la técnica del Hot Deck.

- Segunda etapa se asignan valores a las variables cuantitativas que se registraron como valores missing (información no declarada por el informante). Para la imputación de las variables cuantitativas se utiliza la técnica de Matrices Medianas de esta forma se garantiza que el valor asignado no esté influenciado por los valores extremos.

\section{> IMPUTACIÓN HOT DECK (variables cualitativas)}

En esta primera etapa las imputaciones se realizan a los miembros del hogar que no informaron simultáneamente los tres módulos (300, 400 y 500), no se imputan a las personas que informaron solo alguno de estos módulos.

La imputación sobre las variables cualitativas faltantes se efectúa mediante el reemplazo de las características de información cualitativa de las personas que respondieron los módulos de educación (300), salud (400) y empleo (500) con características demográficas, educativas, espaciales, socioeconómicas y temporales similares, a estas personas se les denomina "donantes".

\section{Procedimiento}

La imputación a los miembros del hogar se realiza para tres grupos según el nivel de parentesco: jefes de hogar, cónyuge y resto de miembros.

- Los donantes para la imputación de los jefes del hogar se obtienen de la población de jefes de hogar mayores de 18 años.

- De igual manera para la imputación de los cónyuges (esposo o esposa), se obtienen donantes de la población de cónyuges (esposo o esposa), mayores de 12 años.

- La imputación del resto de miembros del hogar (hijo, yerno nuera, nietos, padres o 
suegros, otros parientes y otros no parientes), se efectúa a través de donantes de una población de hijos, yernos, nueras, nietos, padres o suegros, otros parientes y otros no parientes miembros del hogar.

\section{Características de selección de los donantes}

Para la selección de donantes para: jefes de hogar, esposas y los otros miembros del hogar y efectuar la imputación, se tiene en consideración las características y la jerarquía siguiente:

1. Dominio (departamento)

2. Estrato socioeconómico

3. Edad

4. Sexo

5. Número de miembros por hogar

6. Nivel educativo del jefe del hogar

7. Periodo (trimestre)

\section{Orden de Selección}

Para seleccionar un donante se ordena la base de datos de la siguiente manera:

- En el área urbana las variables de ordenamiento son: ubigeo, número de zona, número de manzana, vivienda, hogar y número de persona.

- En el área rural las variables de ordenamiento son: ubigeo, número de AER, número del conglomerado, número de vivienda, hogar, número de persona.

Nota:

Ubigeo : Departamento, provincia, distrito.

AER : Área de empadronamiento rural.

De no encontrar donantes de acuerdo con las características señaladas se amplia la selección al periodo anual, en segunda opción se apertura el estrato socioeconómico.

\section{IMPUTACIÓN MATRICES MEDIANAS (variables cuantitativas)}

En la segunda fase de imputación se emplea la "Imputación por Medianas", es decir, se construyen matrices de valores medianos en función a las variables con más alta correlación para la asignación de datos faltantes y posteriormente se emiten los listados que contengan las identificaciones del registro de hogares imputados, así como indicadores sobre el porcentaje imputado a nivel de cada pregunta.

Esta metodología considera como primer nivel de corrección al conglomerado, el segundo el distrito, el tercero la provincia, el cuarto el departamento y, por último, el nacional, estos niveles están diferenciados si se trata del área urbana o rural. Este procedimiento garantiza que en la mayoría de las veces la corrección se haga con información de hogares que pertenecen al mismo estrato socioeconómico.

En la corrección de datos de educación y salud se ha incluido como variable determinante el tipo de establecimiento; es decir, si pertenece al sector público o privado; y en la corrección de datos de consumo de alimentos fuera del hogar y servicios de transporte se ha considerado, además, como variable determinante del gasto, el lugar en que se efectúa el consumo y el tipo de servicio que se recibe. Así por ejemplo, se diferencia si se trata de alimentos consumidos en restaurantes, ambulantes, mercados u otros; en el caso del transporte público si éste proviene de microbús, taxi, colectivo u otro. 


\section{DEFLACTACIÓN}

Es el proceso de transformar valores monetarios nominales en valores monetarios reales (a precios constantes de un determinado período), mediante la aplicación de un índice de precios que elimine el efecto de los precios en el período de análisis.

\section{CÁLCULO DE ERRORES MUESTRALES}

Consiste en la elaboración y aplicación de un conjunto de indicadores que permitirá cuantificar los posibles errores que puedan obtenerse como consecuencia de la selección aleatoria de los hogares informantes.

\section{XVIII.RESULTADOS}

- Banco de datos, pagina web del INEI

- Indicadores de pobreza, según gasto de consumo e ingreso

- Perfil de la pobreza

- Informe técnico de estadísticas sobre condiciones de vida por trimestre

- Informe técnico de estadísticas sobre genero por trimestre

- Informe técnico de estadísticas sobre tecnología de la información por trimestre

- Informe técnico de estadísticas sobre la situación de la niñez y del adulto mayor por trimestre

- Indicadores de presupuesto por resultado

\section{COMISIÓN CONSULTIVA PARA ESTIMACIÓN DE LA POBREZA}

A inicios del año 2007, con el auspicio del Banco Mundial (BM), se convocó a un Comité Asesor especializado para participar en la medición de la pobreza, conformado por representantes de organismos internacionales de organismos gubernamentales nacionales, representantes de la comunidad académica y de centros de investigación. Este Comité Asesor ha estado participando regularmente cada año en la medición de la pobreza.

El 13 de abril del año 2010, mediante Resolución Suprema № 097-2010-PCM, publicado en el diario oficial El Peruano, el Comité Asesor de Pobreza se constituye en "Comisión Consultiva para Estimación de la Pobreza y otros indicadores relacionados en el pais"; cuyo objetivo es garantizar la calidad, transparencia y confianza de la información en el campo de la medición de la pobreza y otros indicadores relacionados.

Son funciones de la Comisión Consultiva:

- Asesorar en todos los procesos de medición de la pobreza y otros indicadores relacionados;

- Supervisar los procesos que se adopten;

- Evaluar y validar los resultados de las estimaciones que se efectúen periódicamente;

- Mantener reserva de los procesos de la información hasta antes de su publicación;

- Proponer modificaciones a las metodologías, cuando sea pertinente, a partir de la evaluación de su validez y la experiencia internacional, siempre que se asegure la comparabilidad en el tiempo de los indicadores. 


\section{ANEXO 2: Construcción de Variables}
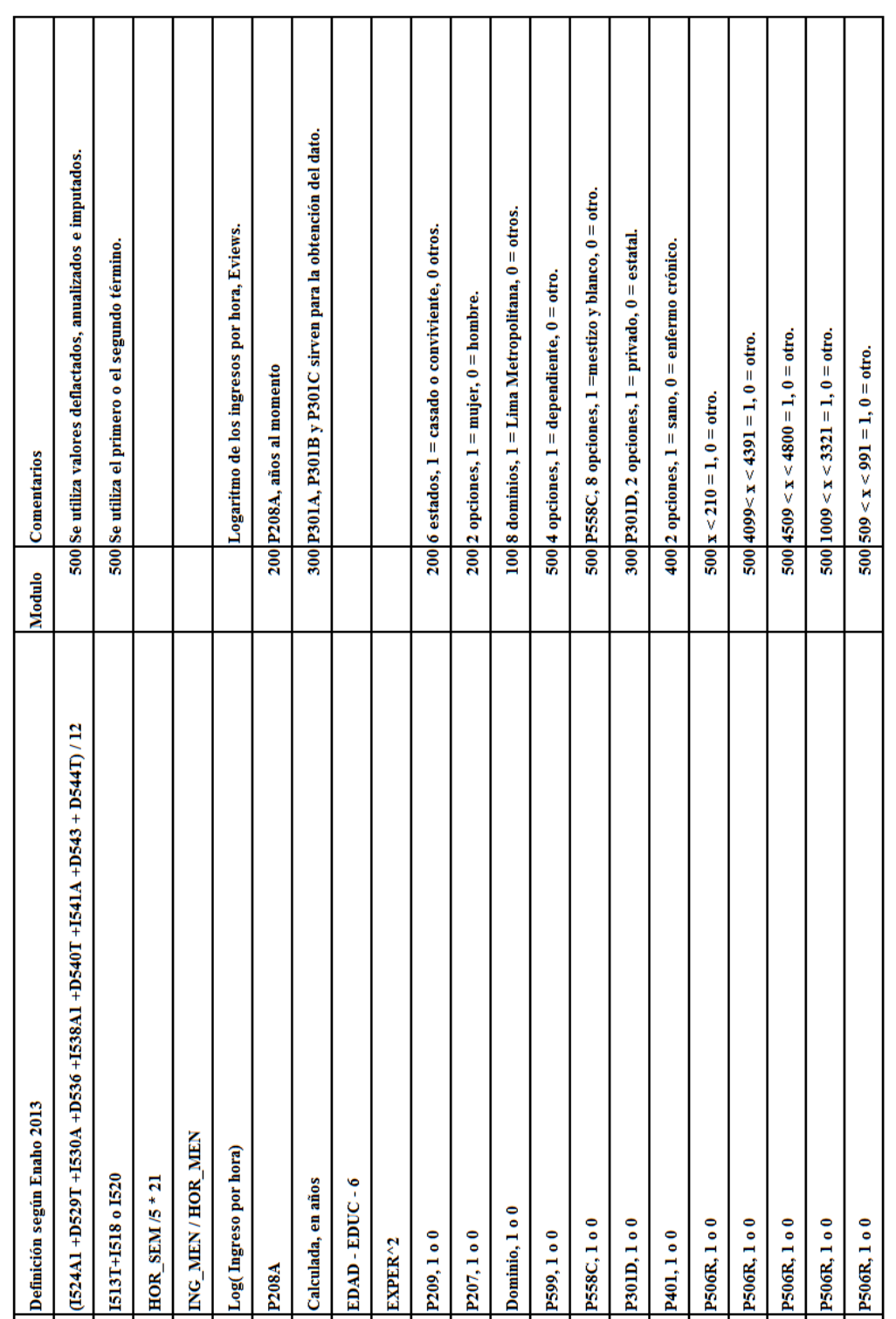


\section{ANEXO 3: Plan de Recodificaciones}

MTPE - DGPE - DISEL - ÁREA DE ESTADÍSTICA Y PROCESAMIENTO

DIRECCIÓN GENERAL DE PROMOCIÓN DEL EMPLEO

DIRECCIÓN DE INVESTIGACIÓN SOCIO ECONÓMICO LABORAL AREA DE ESTADÍSTICA Y PROCESAMIENTO

\section{PLAN DE RECODIFICACIONES}

ENCUESTA NACIONAL DE HOGARES

CONDICIONES DE VIDA Y POBREZA, 2013 
PLAN DE RECODIFICACIONES

ENCUESTA NACIONAL DE HOGARES CONDICIONES DE VIDA Y POBREZA, 2013

\begin{tabular}{|c|c|}
\hline v01Edad & a total) \\
\hline P208A & v01Edad \\
\hline Edad simple & Grupo de edad \\
\hline 14 & 1. 14 años \\
\hline $15-29$ & 2. De 15 a 29 años \\
\hline $30-44$ & 3. De 30 a 44 años \\
\hline $45-64$ & 4. De 45 a 64 años \\
\hline$>=65$ & 5. De 65 años y más \\
\hline
\end{tabular}

v02NivEdu
\begin{tabular}{|ll|}
\hline P301A & Nivel educativo alcanzado (población total) \\
Nivel educativo & v02NivEdu \\
& Nivel educativo alcanzado \\
1,2 & 1. Sin nivel \\
3,4 & 2. Primaria \\
5,6 & 3. Secundaria \\
7,8 & 4. Superior no universitaria \\
$9,10,11$ & 5. Superior universitaria \\
99 & 6. No especificado \\
\hline
\end{tabular}

\begin{tabular}{|c|c|c|c|c|c|c|c|c|c|}
\hline $\begin{array}{l}\text { P501, P502, } \\
\text { P503, P504 } \\
(1-11) \\
\text { ¿Trabaja? (*) } \\
\end{array}$ & $\begin{array}{c}\text { P507 } \\
\text { Ud. } \\
\text { Era }\end{array}$ & $\begin{array}{c}\text { I513T } \\
\text { Total } \\
\text { Horas }\end{array}$ & $\begin{array}{l}\text { P545 } \\
\text { ¿Hizo } \\
\text { algo? }\end{array}$ & $\begin{array}{l}\text { P546 } \\
\text { ¿Qué } \\
\text { hizo? }\end{array}$ & $\begin{array}{l}\text { P547 } \\
\text { ¿Quería } \\
\text { traba- } \\
\text { jar? }\end{array}$ & $\begin{array}{c}\text { P548 } \\
\text { ¿Estuvo } \\
\text { disponi- } \\
\text { ble? }\end{array}$ & $\begin{array}{c}\text { P549 } \\
\text { ¿Por } \\
\text { qué no } \\
\text { buscó? }\end{array}$ & $\begin{array}{l}\text { P550 } \\
\text { ¿Qué } \\
\text { Hizo? }\end{array}$ & $\begin{array}{l}\text { v03ConAct } \\
\text { Condición de } \\
\text { actividad }\end{array}$ \\
\hline 1 & $1-4,6$ & - & - & - & - & - & - & - & 1. Ocupado \\
\hline 1 & 5,7 & $>=15$ & - & - & - & - & - & - & 1. Ocupado \\
\hline $\mathbf{1}$ & 5,7 & $<15$ & 1 & - & - & - & - & $1-6$ & 2. Desocupado \\
\hline 1 & 5,7 & $<15$ & 2 & $1-2$ & - & - & - & - & 2. Desocupado \\
\hline 1 & 5,7 & $<15$ & 2 & $3-8$ & 1 & 1 & 10 & - & 2. Desocupado \\
\hline 1 & 5,7 & $<15$ & 2 & $3-8$ & 1 & 1 & 11 & $1-6$ & 2. Desocupado \\
\hline 2 & - & - & 1 & - & - & - & - & $1-6$ & 2. Desocupado \\
\hline 2 & - & - & 2 & $1-2$ & - & - & - & - & 2. Desocupado \\
\hline 2 & - & - & 2 & $3-8$ & 1 & 1 & 10 & - & 2. Desocupado \\
\hline 2 & - & - & 2 & $3-8$ & 1 & 1 & 11 & $1-6$ & 2. Desocupado \\
\hline 1 & 5,7 & $<15$ & 1 & - & - & - & - & 7 & 3. Inactivo \\
\hline 1 & 5,7 & $<15$ & 2 & $3-8$ & 1 & 1 & $1-9$ & - & 3. Inactivo \\
\hline 1 & 5,7 & $<15$ & 2 & $3-8$ & 1 & 2 & - & - & 3. Inactivo \\
\hline 1 & 5,7 & $<15$ & 2 & $3-8$ & 2 & - & - & - & 3. Inactivo \\
\hline 1 & 5,7 & $<15$ & 2 & $3-8$ & 1 & 1 & 11 & 7 & 3. Inactivo \\
\hline 2 & & & 1 & - & - & - & - & 7 & 3. Inactivo \\
\hline 2 & & & 2 & $3-8$ & 1 & 1 & $1-9$ & - & 3. Inactivo \\
\hline 2 & & & 2 & $3-8$ & 1 & 2 & - & - & 3. Inactivo \\
\hline 2 & & & 2 & $3-8$ & 2 & - & - & - & 3. Inactivo \\
\hline 2 & & & 2 & $3-8$ & 1 & 1 & 11 & 7 & 3. Inactivo \\
\hline
\end{tabular}

(*) $\mathbf{1}$ = Al menos una de las preguntas es igual a 1 ("Si"). $\mathbf{2}=$ Todas las preguntas son iguales a 2 ("No"). 
v04GruOcu Grupo ocupacional de la ocupación principal (v03ConAct =1)

\begin{tabular}{|c|c|c|}
\hline $\begin{array}{c}\text { Ocupación Principal } \\
\text { P505 (tres primeros dígitos) }\end{array}$ & $\begin{array}{c}\text { Para } \\
\text { quién trab } \\
\text { P507 }\end{array}$ & $\begin{array}{l}\text { v04GruOcu } \\
\text { Grupo ocupacional }\end{array}$ \\
\hline $\begin{array}{l}011-015,021-024,136,211-219,221-229,231-239 \\
241-247,251-259,261-269,271-274,281,282,284 \\
311-319,321-324,341-349,351-356,363-367,377 \\
383,391-393,395,396,531\end{array}$ & - & $\begin{array}{l}\text { 01. Profesional, técnico y } \\
\text { ocupación afín }\end{array}$ \\
\hline $111-116,121-129,131-135,137-139,141-148,283$ & - & $\begin{array}{l}\text { 02. Gerente, administrador y } \\
\text { funcionario }\end{array}$ \\
\hline $\begin{array}{l}334,381,382,411-419,421-423,431-436,441-444, \\
451,453-455,461,462,931\end{array}$ & - & 03. Empleado de oficina \\
\hline $\begin{array}{l}361,362,371-376,378,379,452,571-575,581-583, \\
911-919,921-927\end{array}$ & & 04. Vendedor \\
\hline $611-617,621-626,631-637,641,872,971-973$ & - & 05. Agricultor, ganadero y pescador \\
\hline $711,712,735,981$ & - & 06. Minero y cantero \\
\hline $\begin{array}{l}627,713-719,721-724,731-734,736,737,741-749, \\
751,752,761-769,771-779,781-785,791-799,811- \\
813,821,831-837,839,841-844,851,852,861- \\
867,871,873,874,882,984\end{array}$ & - & 07. Artesano y operario \\
\hline $868,961,982,983,987$ & - & 08. Obrero, jornalero \\
\hline $331-333,875-877,881,883-886,985,986$ & - & 09. Conductor \\
\hline $\begin{array}{l}335,394,456,511,512,521-523,541,551-553, \\
561-565,822,823,941-945,951-953\end{array}$ & - & 10. Trabajador de los servicios \\
\hline- & 6 & 11. Trabajador del hogar \\
\hline 999 & - & 12. No especificado \\
\hline
\end{tabular}

Nota: En la variable P505 el valor 999 indica los casos de no respuesta por omisión. 
MTPE - DGPE - DISEL - ÁREA DE ESTADÍSTICA Y PROCESAMIENTO

v05RamAct Rama de actividad económica de la ocupación principal (v03ConAct=1)

\begin{tabular}{|c|c|}
\hline P506 (¿A qué se dedica la empresa..?) & $\begin{array}{l}\text { v05RamAct (Rama de } \\
\text { actividad económica) }\end{array}$ \\
\hline 0111-0113,0121,0122,0130,0140,0150,0200,0500 & $\begin{array}{l}\text { 1. Agricult., ganadería, } \\
\text { silvicultura y pesca }\end{array}$ \\
\hline $1010,1020,1030,1110,1120,1200,1310,1320,1410,1421,1422,1429$ & 2. Minería \\
\hline $\begin{array}{l}\text { 1511-1515,1520,1531-1533,1541-1544,1549,1551-1554,1600,1711, } \\
1712,1721-1723,1729,1730,1810,1820,1920,2029,2109,2211,2212 \text {, } \\
2219,2221,2222,2520,3312,3313,3320,3330,3610,3691-3694,3699 .\end{array}$ & $\begin{array}{l}\text { 3. Industria de bienes de } \\
\text { consumo }\end{array}$ \\
\hline $\begin{array}{l}1911,1912,2010,2021,2022,2023,2101,2102,2213,2310,2320,2330, \\
2411-2413,2421-2424,2429,2430,2511,2519,2610,2691-2696,2699, \\
2710,2720,2731,2732,2811-2813,2891-2893,2899,2911-2915, \\
2919,2921-2927,2929,2930,2999,3000,3110,3120,3130,3140,3150, \\
3190,3210,3220,3230,3311,3410,3420,3430,3511,3512,3520,3530, \\
3591,3592,3599,3710,3720,7250\end{array}$ & $\begin{array}{l}\text { 4. Industria de bienes } \\
\text { intermedios y de capital }\end{array}$ \\
\hline $4510,4520,4530,4540,4550$ & 5. Construcción \\
\hline $\begin{array}{l}2230,5010,5030,5040,5050,5110,5121,5122,5131,5139, \\
5141-5143,5149,5150,5190,5211,5219,5220,5231-5234,5239,5240, \\
5251,5252,5259,5270,7130\end{array}$ & $\begin{array}{l}\text { 6. Comercio por mayor y } \\
\text { menor }\end{array}$ \\
\hline $\begin{array}{l}4010,4020,4030,4100,6010,6021-6023,6030,6110,6120,6210,6220, \\
6301-6304,6309,6411,6412,6420,6511,6519,6591,6592,6599, \\
6601-6603,6711,6712,6719,6720,7010,7020,7111-7113,7121-7123, \\
7129,7210,7220,7230,7240,7290,7310,7320,7411-7414,7421,7422, \\
7430,7491-7493,7495,7499,7511-7514,7521-7523,7530,8010,8021, \\
8022,8030,8090,8511,8512,8519,8520,8531,8532,9000,9111,9112, \\
9120,9191,9192,9199,9211-9214,9219,9220,9231-9233,9241,9249, \\
9900\end{array}$ & 7. Servicios no personales \\
\hline $5020,5260,5510,5520,7494,9301-9303,9309$ & 8. Servicios personales \\
\hline 9500 & 9. Hogares \\
\hline 9999 & 10. No especificado \\
\hline
\end{tabular}

Nota: En la variable P506 el valor 9999 indica los casos de no respuesta por omisión. 
v06Inglab Ingreso laboral mensual de las ocupaciones principal y secundarias (En nuevos soles). Solo para la PEA ocupada (v03ConAct $=1$ )

v06IngLab $=($ I524A1 +D529T +I530A +D536 +I538A1 +D540T +I541A +D543 + D544T) / 12

Donde:

I524A1 = Ingreso en la actividad principal por trabajo dependiente.

D529T $=$ Pago en especie en la actividad principal por trabajo dependiente.

$\mathrm{I530 \textrm {A }}=$ Ingreso en la actividad principal por trabajo independiente.

D536 = Autoconsumo de los trabajadores independientes.

I538A1 = Ingreso en la actividad secundaria por trabajo dependiente.

D540T $=$ Pago en especie en la actividad secundaria por trabajo dependiente.

I541A = Ingreso en la actividad secundaria por trabajo independiente.

D543 = Autoconsumo en la actividad secundaria por trabajo independiente.

D544T = Gratificación de navidad, Gratificación de fiestas patrias, Bonificación por últimas vacaciones, Bonificación por escolaridad, Participación de utilidades de la empresa, Bonificación por otro concepto relacionado con su trabajo, Compensación por tiempo de servicio (CTS), Otro ingreso por trabajo (reintegros, etc.).

Las variables de ingresos son indexadas y anualizadas por el INEI.

v07RanIng Rangos de ingreso laboral mensual de las ocupaciones principal y secundarias (En nuevos soles). Solo para la PEA ocupada (v03ConAct =1)

\begin{tabular}{|cl|}
\hline $\begin{array}{c}\text { v06IngLab } \\
\text { Ingreso laboral mensual }\end{array}$ & $\begin{array}{l}\text { v07RanIng } \\
\text { Rango de ingresos en nuevos soles }\end{array}$ \\
0.00 & 1. Sin ingresos \\
$0.01-499.99$ & 2. Menos de 500 soles \\
$500.00-999.99$ & 3. Entre 500 y 999.99 soles \\
$1000.00-1499.99$ & 4. Entre 1000 y 1499.99 soles \\
$>=1500$ & 5. De 1500 soles a más \\
\hline
\end{tabular}

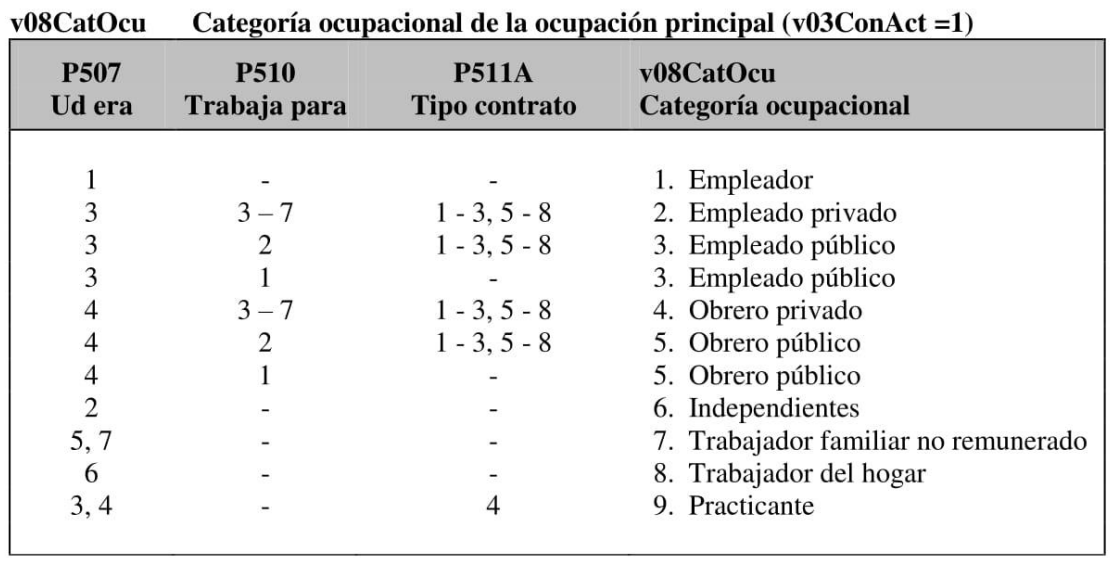


v09HorNor Horas normales de trabajo semanal de las ocupaciones principal y secundarias (v03ConAct $=1$ )

\begin{tabular}{|cc|}
\hline P519 & $\begin{array}{c}\text { v09HorNor } \\
\text { Normalmente trabaja esas horas }\end{array}$ \\
\hline 1 & Horas normales de trabajo \\
\hline 2 & I513T + I5 18 \\
& I520 \\
\hline
\end{tabular}

v10RanHor Rango de horas normales de trabajo semanal de las ocupaciones principal y secundarias $(\mathbf{v 0 3 C o n A c t ~}=\mathbf{1})$

\begin{tabular}{|cl|}
$\begin{array}{c}\text { v09HorNor } \\
\text { Horas normales de trabajo }\end{array}$ & $\begin{array}{l}\text { v10RanHor } \\
\text { Rango de horas normales de trabajo semanal }\end{array}$ \\
\hline$<15$ & 1. Menos de 15 horas \\
$15-34$ & 2. De 15 a 34 horas \\
$35-47$ & 3. De 35 a 47 horas \\
48 & 4. 48 horas \\
$49-59$ & 5. De 49 a 59 horas \\
$>=60$ & 6. De 60 a más \\
$\cdot$ & 7 No especificado \\
\hline
\end{tabular}

Nota: En la variable v09HorNor el punto indica los casos de no respuesta por omisión.

v11TamEmp Tamaño de empresa de la ocupación principal (v03ConAct $=1)$

\begin{tabular}{|cccl|}
\hline $\begin{array}{c}\text { P510 } \\
\text { Trabajó } \\
\text { para }\end{array}$ & $\begin{array}{c}\text { P512A } \\
\text { Rango de } \\
\text { trabajadores }\end{array}$ & $\begin{array}{c}\text { P512B } \\
\text { Número de } \\
\text { trabajadores }\end{array}$ & $\begin{array}{l}\text { v11TamEmp } \\
\text { Tamaño de empresa }\end{array}$ \\
- & - & 1 & 1. Una persona \\
- & - & $2-10$ & 2. De 2 a 10 personas \\
- & - & $11-100$ & 3. De 11 a 100 personas \\
- & 2,3 & - & 3. De 11 a 100 personas \\
- & - & $101-9998$ & 4. De 101 a más personas \\
- & 4,5 & - & 4. De 101 a más personas \\
1 & - & - & 4. De 101 a más personas \\
- & 1 & 9999 & 5. No especificado \\
- & 9 & 9999 & 5. No especificado \\
\hline
\end{tabular}

Nota: En las variables P512A y P512B el 9 y el 9999 respectivamente indican los casos de no respuesta por omisión. 
v12EstMer Estructura de mercado de la ocupación principal (v03ConAct =1)

$\begin{array}{|cccl|}\begin{array}{c}\text { v08CatOcu } \\ \text { Categoría } \\ \text { ocupacional }\end{array} & \begin{array}{c}\text { v11TamEmp } \\ \text { Tamaño de } \\ \text { empresa }\end{array} & \begin{array}{c}\text { v04GruOcu } \\ \text { Grupo } \\ \text { ocupacional }\end{array} & \begin{array}{l}\text { v12EstMer } \\ \text { Estructura de mercado }\end{array} \\ 3,5 & - & - & \text { 1. Sector público } \\ 1,2,4 & 2 & - & \text { 2. } 2 \text { a } 10 \text { trabajadores } \\ 1,2,4 & 3 & - & \text { 3. } 11 \text { a } 100 \text { trabajadores } \\ 1,2,4 & 4 & - & \text { 4. } 101 \text { a más trabajadores } \\ 1,2,4 & 5 & - & \text { 5. Sector privado no especificado } \\ 6 & - & 1 & \text { 6. Independiente profesional, técnico } \\ 6 & - & 1 & \text { 7. Independiente no profesional, no técnico } \\ 6 & - & - & \text { 8. Independiente no especificado } \\ 7 & - & - & \text { 9. Trabajador familiar no remunerado } \\ 8,9 & - & - & \text { 10. Trabajador del hogar, practicante } \\ 10 & - & & \end{array}$

v13Area Área geográfica (población total)

\begin{tabular}{|cl|}
\hline Estrato & v13Area \\
Estrato & Área Geográfica \\
$1-5$ & 1. Urbano \\
$6-8$ & 2. Rural \\
\hline
\end{tabular}

v14Dpto Departamento (población total)

\begin{tabular}{|c|c|}
\hline $\begin{array}{l}2 \text { primeros dígitos del Ubigeo } \\
\text { Ubicación geográfica }\end{array}$ & $\begin{array}{l}\text { v14Dpto } \\
\text { Departamento }\end{array}$ \\
\hline $\begin{array}{l}1 \\
2 \\
3 \\
4 \\
5 \\
6 \\
7 \\
8 \\
9 \\
10 \\
11 \\
12 \\
13 \\
14 \\
15 \\
16 \\
17 \\
18 \\
19 \\
20 \\
21 \\
22 \\
23 \\
24 \\
25\end{array}$ & $\begin{array}{l}\text { 1. Amazonas } \\
\text { 2. Áncash } \\
\text { 3. Apurímac } \\
\text { 4. Arequipa } \\
\text { 5. Ayacucho } \\
\text { 6. Cajamarca } \\
\text { 7. Prov. Const. del Callao } \\
\text { 8. Cusco } \\
\text { 9. Huancavelica } \\
\text { 10. Huánuco } \\
\text { 11. Ica } \\
\text { 12. Junín } \\
\text { 13. La Libertad } \\
\text { 14. Lambayeque } \\
\text { 15. Lima } \\
\text { 16. Loreto } \\
\text { 17. Madre de Dios } \\
\text { 18. Moquegua } \\
\text { 19. Pasco } \\
\text { 20. Piura } \\
\text { 21. Puno } \\
\text { 22. San Martín } \\
\text { 23. Tacna } \\
\text { 24. Tumbes } \\
\text { 25. Ucayali }\end{array}$ \\
\hline
\end{tabular}




\title{
ANEXO 4: Ecuación Mincer - Yamada 2004 (total urbano)
}

\author{
Mínimos \\ Cuadrados \\ Ordinarios \\ (MICO)
}
Number of obs $=$
$F(7,16721)$
Prob $>$ F
R-squared
Root MSE
16729
411.470
0.000
0.285
0.809

\begin{tabular}{lcccccc}
\hline Lsalth & Coef. & Std. Err. & $\mathbf{t}$ & $\mathbf{P}>\mathbf{t}$ & {$[\mathbf{9 5} \%$ Conf. } & Interval] \\
\hline Educ & 0.1025486 & 0.0026498 & 38.7 & 0 & 0.0973548 & 0.1077425 \\
Exp & 0.0370461 & 0.0022729 & 16.3 & 0 & 0.032591 & 0.0415011 \\
exp2 & -0.0004592 & 0.0000452 & -10.17 & 0 & -0.0005477 & -0.0003707 \\
Matrim & 0.0920392 & 0.0197215 & 4.67 & 0 & 0.053383 & 0.1306954 \\
Mujer & -0.2065296 & 0.0178084 & -11.6 & 0 & -0.2414359 & -0.1716234 \\
Lima & 0.2786497 & 0.0178421 & 15.62 & 0 & 0.2436773 & 0.3136221 \\
Depend & 0.3218011 & 0.0190294 & 16.91 & 0 & 0.2845016 & 0.3591007 \\
cons & -0.9230923 & 0.0402093 & -22.96 & 0 & -1.001907 & -0.8442778 \\
\hline
\end{tabular}

\section{Definiciones:}

Lsalth: Logaritmo neperiano del ingreso por hora (tanto dependiente como

independiente) de la actividad principal más secundaria.

Educ: $\quad$ Número de años de educación

Exp: $\quad$ Experiencia potencial (edad - años de educación - 6)

exp2: $\quad$ Experiencia potencial al cuadrado

Matrim: 1 si está casado o convive con alguien; 0 de otro modo

Mujer: $\quad 1$ si es mujer; 0 de otro modo

Lima: $\quad 1$ si el lugar de residencia es Lima Metropolitana; 0 de otro modo

Depend: $\quad 1$ si el trabajador es dependiente; 0 de otro modo

_cons: Constante 


\section{ANEXO 5: Modelo Mincer por MCO año 2013}

Dependent Variable: LSALHR

Method: Least Squares

Date: 05/25/15 Time: 10:35

Sample: 131735

Included observations: 31735

\begin{tabular}{lrlll}
\hline \hline \multicolumn{1}{c}{ Variable } & Coefficient & Std. Error & t-Statistic & Prob. \\
\hline \hline \multicolumn{1}{c}{ C } & 0.068899 & 0.020714 & 3.326264 & 0.0009 \\
EDUC & 0.104663 & 0.001398 & 74.85451 & 0.0000 \\
EXPER & 0.026862 & 0.001167 & 23.02727 & 0.0000 \\
EXPER2 & -0.000364 & $2.44 E-05$ & -14.95503 & 0.0000 \\
\hline \hline R-squared & 0.179852 & Mean dependent var & 1.579961 \\
Adjusted R-squared & 0.179774 & S.D. dependent var & 0.933909 \\
S.E. of regression & 0.845807 & Akaike info criterion & 2.503075 \\
Sum squared resid & 22700.02 & Schwarz criterion & 2.504129 \\
Log likelihood & -39713.54 & Hannan-Quinn criter. & 2.503412 \\
F-statistic & 2319.452 & Durbin-Watson stat & 1.801877 \\
Prob(F-statistic) & 0.000000 & & & \\
\hline \hline
\end{tabular}

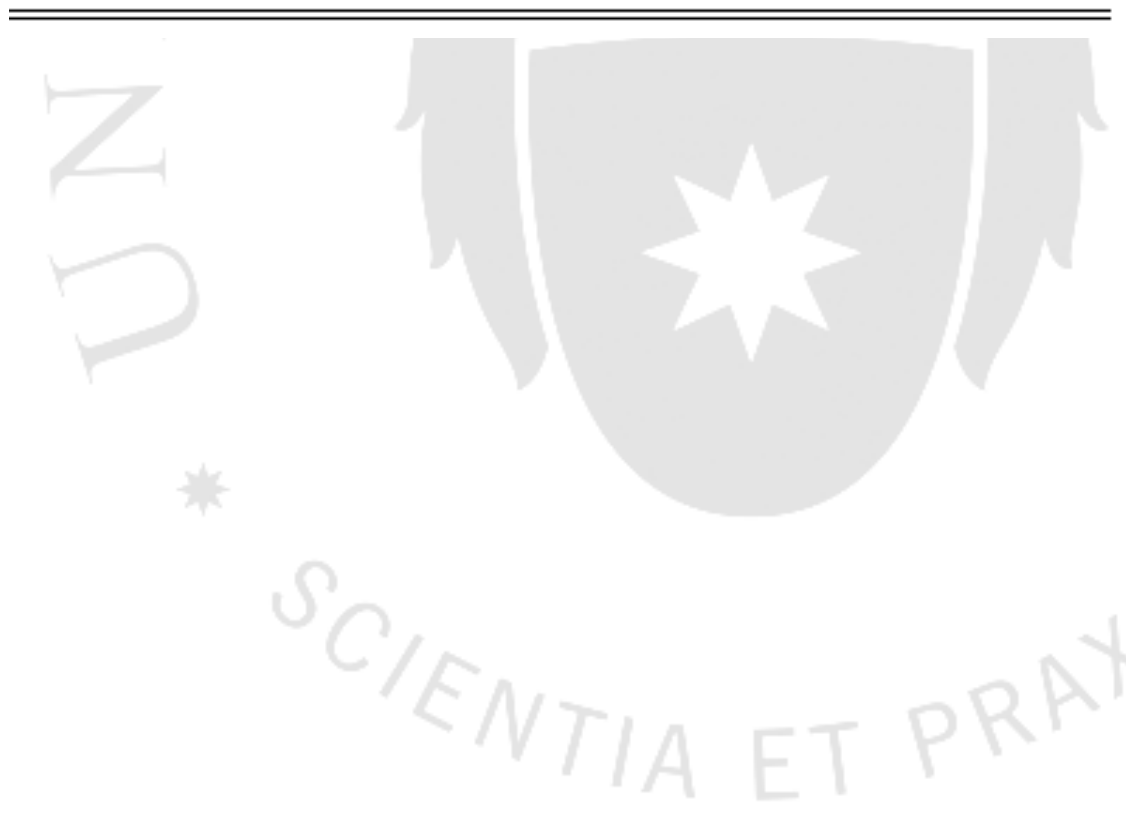

